University of Redlands

\title{
Analysis of Bobcats in Urban Areas of Orange County, CA
}

\author{
A Major Individual Project submitted in partial satisfaction of the requirements \\ for the degree of Master of Science in Geographic Information Systems \\ By \\ Ian Ice \\ Douglas Flewelling, Ph.D., Committee Chair \\ Russell Weaver, Ph.D.
}

November 2013 
Analysis of Bobcats in Urban Areas of Orange County, CA

Copyright (C) 2013

By

Ian Dennis Ice 
The report of lan Dennis Ice is approved.
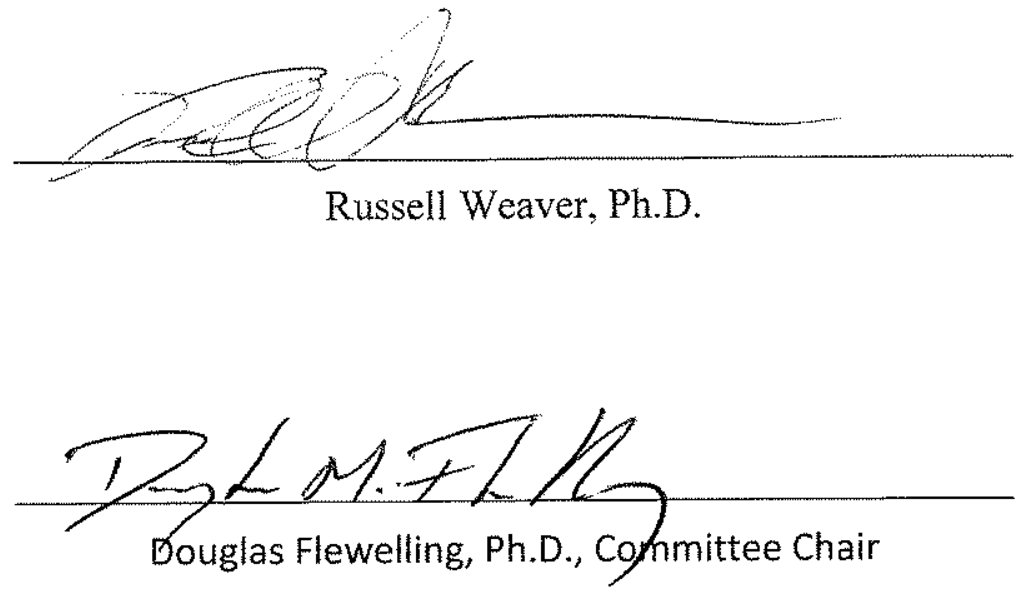

November 2013 



\section{Acknowledgements}

There was a particular student that extended great support for this project. Thanks goes out to Gakumin Kato for helping me debug some tool issues. In addition, there were a number of students that offered me useful advice and extended their motivation to complete the project. Particular thanks go out to Andrew Davis, Caitlyn Raines, and Violet Cullors for the time they took to help conceptualize solutions to problems. I would also like to thank Ren Fang and Ruijin Ma, staff members who extended their knowledge and support throughout the projects execution. Thanks go out to Mark Stewart for giving me advice on Hawth's Tools, which led me to the Geospatial Modelling Environment, a set of spatial ecology tools that generated urban edges for this project.

Thank you Dr. Erin Boydston, your need for free work in such financially limited times gave me the opportunity work on this project. Also, thanks for advising, informing, and supplying the vital data for this project. Although these people offered me great advice and support, I couldn't have completed the project without the guidance of my advisor, Douglas Flewelling; thanks for helping me approach the many complexities of wildlife analysis, with the use of limited resources. And I could never complete this section without thanking Debra Riley, her encouragement and tolerance helped pave my way to success. Finally, very special thanks goes out to all of cohort 22, who had to share the suffering of class work and problems with analyses, application development, and vehicle routing. Your suffering faces gave me courage to keep pressing on. 



\begin{abstract}
Analysis of Bobcats in Urban Areas of Orange County

By

Ian Dennis Ice California. Habitat fragmentation caused by human development has forced the bobcat to adapt to new urban influences. Although the bobcat is currently thriving in these urban areas, the continued reduction of critical habitat and the increase in bobcat interaction

The client for this project is a research ecologist with the USGS Western Ecological Research Center. Her bobcat research requires tracking bobcats with GPS radio-collars technologies to gain a better understanding of how bobcats are surviving in urban areas. She aimed to achieve this by the examination of bobcats' behavior with certain habitat variables and how they are characterized within defined study areas. Four tools were developed to measure the proximity and density of roads, hydrography (flow lines and
\end{abstract}

The bobcat, Lynx Rufus, has been increasingly observed in urban areas of Southern may ultimately lead to decline in future populations. and collecting sighting information from the public. Her goal was to utilize GIS water bodies), urban edges, and land cover. 



\section{Table of Contents}

Chapter 1 - Introduction ................................................................................................ 1

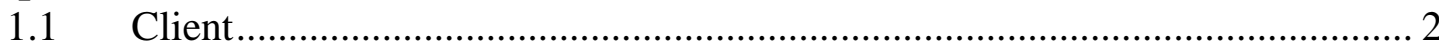

$1.2 \quad$ Problem Statement ........................................................................... 2

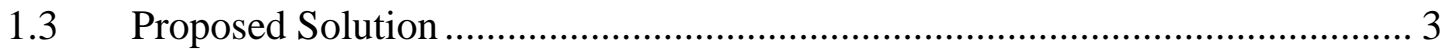

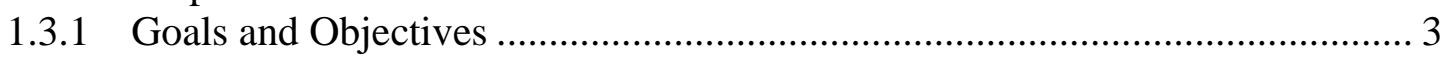

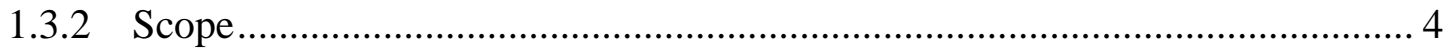

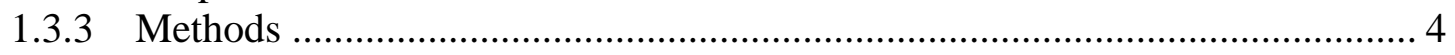

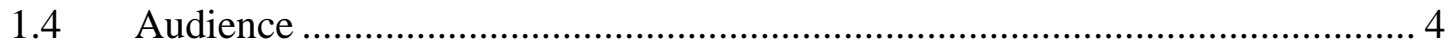

$1.5 \quad$ Overview of the Rest of this Report ........................................................ 5

Chapter 2 - Background and Literature Review ............................................................ 7

$2.1 \quad$ Similar Analyses and Approaches ……………....................................... 8

2.2 Relevance: Location, Scale, and Data.......................................................... 13

2.2.1 Study Area Definition and Generation …………….................................... 14

2.2.2 Location Considerations and Useful Analytic Approaches ............................ 14

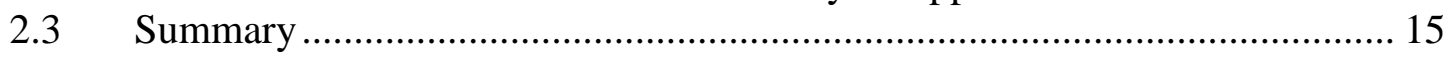

Chapter 3 - Systems Analysis and Design...................................................................... 17

$3.1 \quad$ Problem Statement ............................................................................ 17

3.2 Requirements Analysis ............................................................................ 17

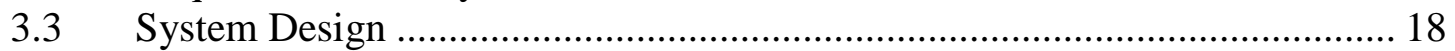

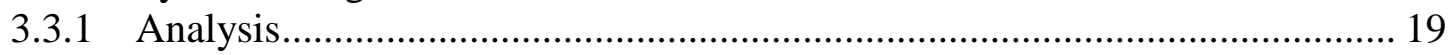

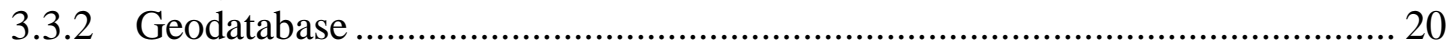

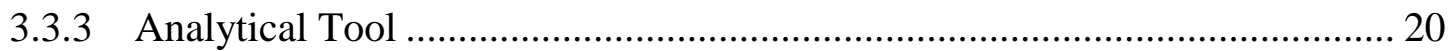

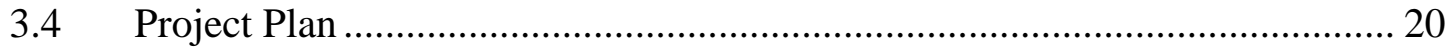

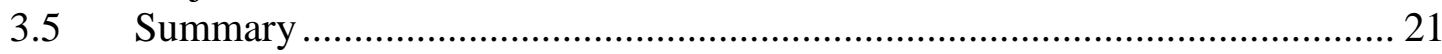

Chapter 4 - Database Design....................................................................... 23

4.1 Conceptual Data Model ...................................................................... 23

4.2 Logical Data Model ……………………….................................... 24

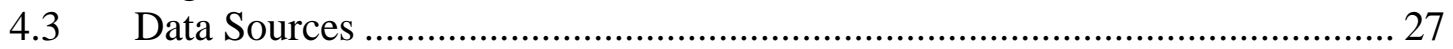

4.4 Data Scrubbing and Loading ……………………..................................... 27

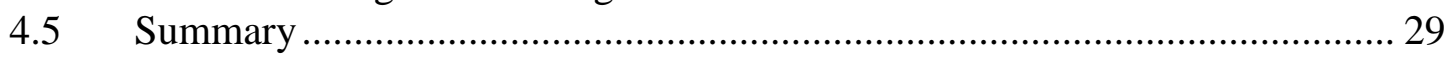

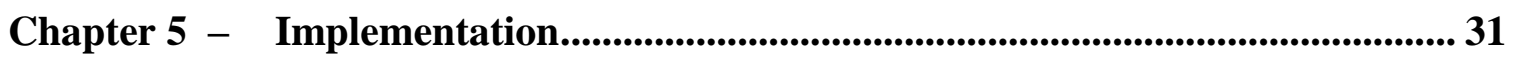

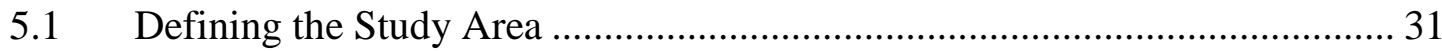

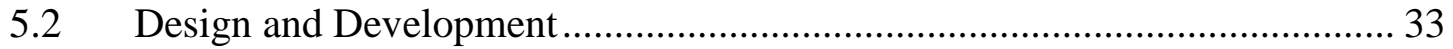

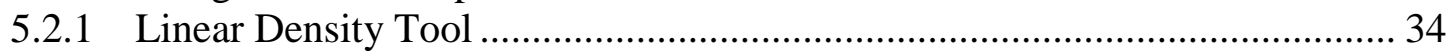

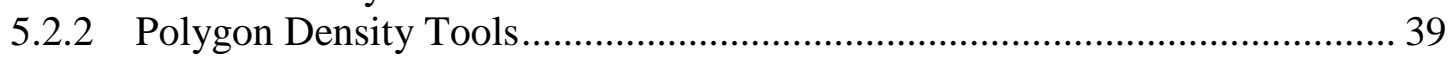

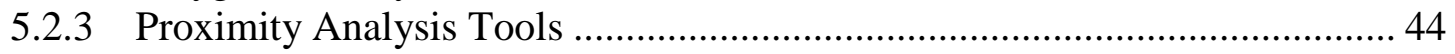

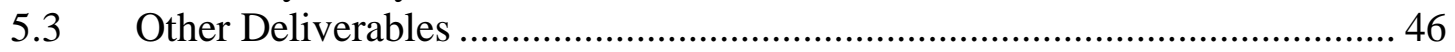

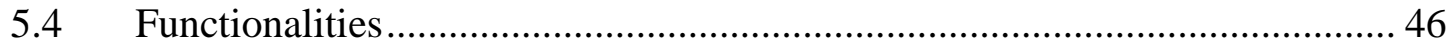

Chapter 6 - Results and Analysis............................................................................49

$6.1 \quad$ Radio-Collared Bobcat Results................................................................. 49

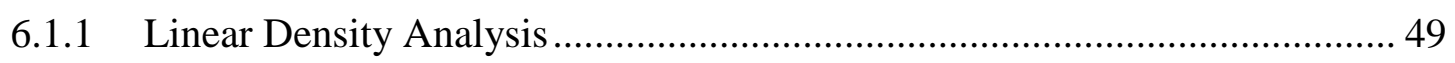




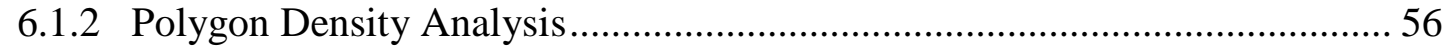

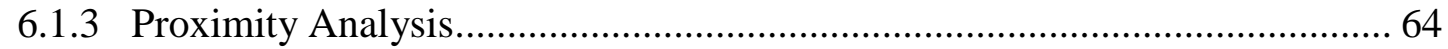

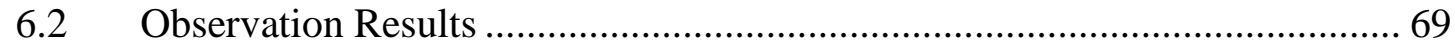

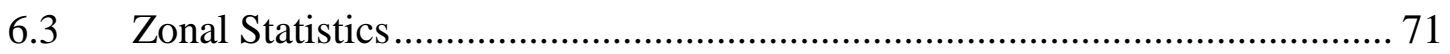

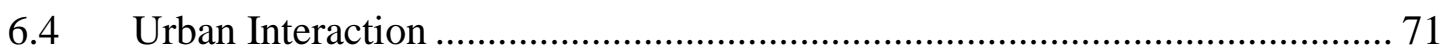

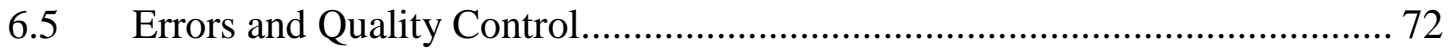

Chapter 7 - Conclusions and Future Work .................................................................. 75

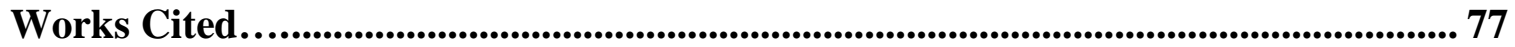

Appendix A: Attributes of the observed bobcat dataset. .............................................. 79

Appendix B: Attributes of the radio-collared bobcat dataset...................109 


\section{Table of Figures}

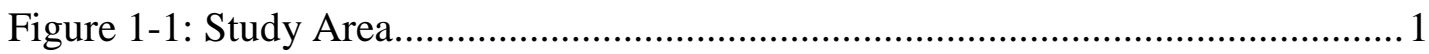

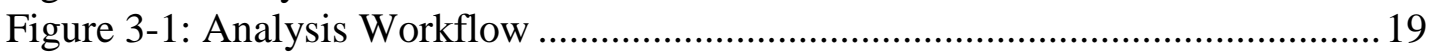

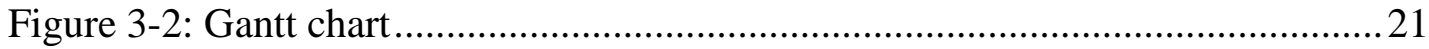

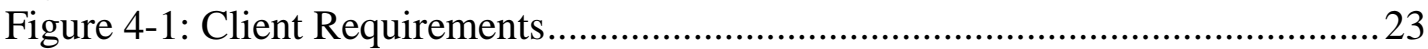

Figure 4-2: Conceptual Model .........................................................................2

Figure 4-3: Logical Data Model for Original Datasets and Analysis Components...25

Figure 4-4: Radio-Collared Logical Model. .........................................................2 26

Figure 4-5: Observed Logical Model.I.................................................................. 26

Figure 4-6: Open/Natural Land Cover Definition ………….....................................2 28

Figure 4-7: Urban edges within an area of Orange County.........................44

Figure 5-1: MCP for the Combined Home Ranges of Radio-collared Bobcats. ........31

Figure 5-2: MCP for an individual Radio Collared Bobcat [BAB].............................32

Figure 5-3: Minimum Bounding Geometry tool Group Option and Geometry

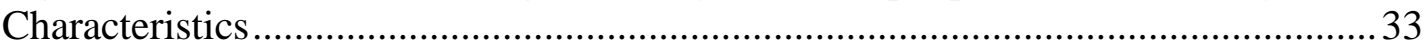

Figure 5-4: Workflow Describing the Major Tasks for Developing the Linear

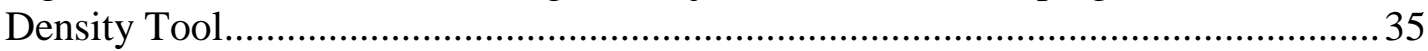

Figure 5-5: The Mean Center for the radio-collared bobcats. ...................................... 38

Figure 5-6: Linear Density (OC Roads) within the study area. This figure also illustrates coincident bobcat locations, which are summarized in a statistics table...38

Figure 5-7: Development Workflow for the Polygon Density Tool............................ 40

Figure 5-8: Point Density raster surface for all radio-collared bobcats...................... 43

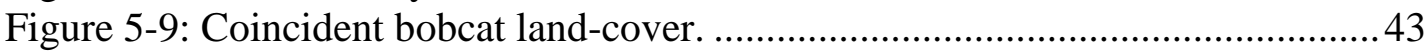

Figure 5-10: Development workflow for the Proximity Analysis Tool ...................... 44

Figure 6-1: Intersected linear feature output (Roads) ................................................50

Figure 6-2: Home range polygons (MCP's) generated for 17 individual radio-

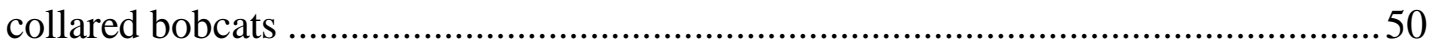

Figure 6-3: Home ranges for BAB (Top Left) and BUC (Bottom Right). BUC has a

$6.5 \%$ Home Range overlap with BAB..............................................................52

Figure 6-4: Home range for FAR with intersected roads and streams over a point

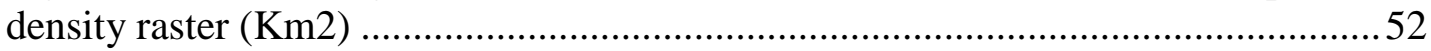

Figure 6-5: Home range for MRR with intersected roads and streams over a point

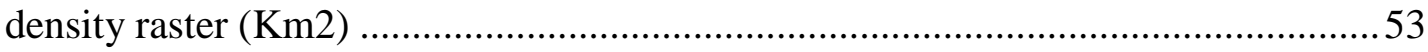

Figure 6-6: Road densities for individual home ranges calculated by the number of

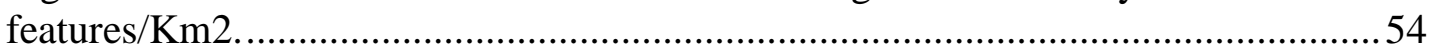

Figure 6-7: Flow line densities for individual home ranges calculated by the number

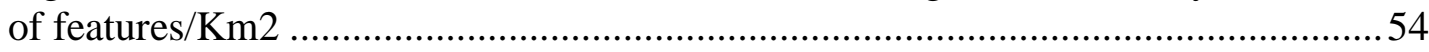

Figure 6-8: Urban edge densities for individual home ranges calculated by the

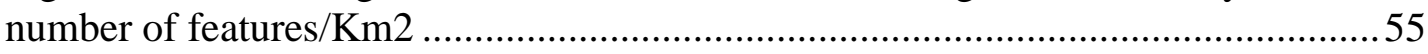

Figure 6-9: Linear densities, $\mathrm{Km} / \mathrm{Km} 2$, for flow lines, roads, and urban edges within

each individual's home range ...............................................................................5

Figure 6-10: Percent Land Cover for all radio-collared bobcats .................................57

Figure 6-11: Percent water body coverage for individual home ranges .....................57 
Figure 6-12: Land cover types and corresponding percentages for BAB's home range

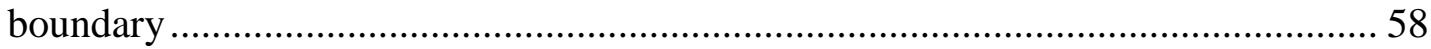

Figure 6-13: Land cover types and corresponding percentages for BUC's home range

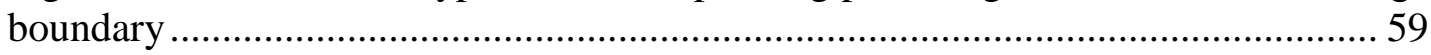

Figure 6-14: Land cover types and percentages for FAR's home range boundary... 59 Figure 6-15: Land cover types and percentages for MRR's home range boundary.. 60

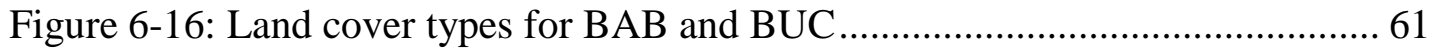

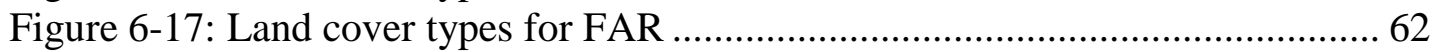

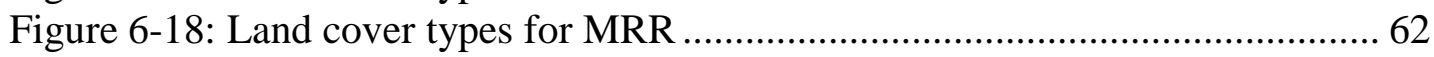
Figure 6-19: Number of observations within each land cover type for BAB, BUC,

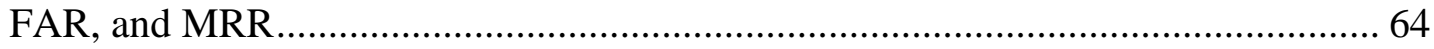

Figure 6-20: Bobcat proximity to urban edges summarized by mean and maximum distance values 66

Figure 6-21: Bobcat proximity to roads summarized by mean and maximum distance values 66

Figure 6-22: Bobcat proximity to flow lines summarized by mean and maximum distance values in meters

Figure 6-23: Bobcat proximity to water bodies summarized by mean, minimum, and maximum distance values 67 Figure 6-24: Bobcat proximity to "open/natural" land cover types summarized by the mean value. 68 Figure 6-25: Bobcat proximity to "open/natural" land cover types summarized by the maximum value 68 Figure 6-26: An urban Interaction surface for bobcats in Orange County, California. The raster was created from radio-collared bobcat proximity analysis results 72 


\section{List of Tables}

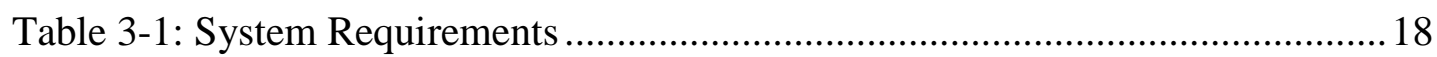

Table 5-1: Required and Optional Parameters for the linear density tool .................. 36

Table 5-2: Required and optional parameters for the polygon density models ..........41

Table 5-3: Development workflow for the Proximity Analysis Tool ........................ 45

Table 6-1: Linear density results for three habitat features ...................................51

Table 6-2: Polygon density results for two habitat variables..................................56

Table 6-3: Proximity results for all radio-collared bobcats considering five habitat variables and their proximity to observed bobcats. Distances are in meters .............65

Table 6-4: Linear density results for all observed bobcats, considering three habitat

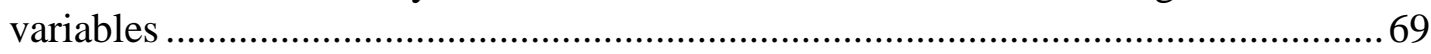

Table 6-5: Polygon density results for all observed bobcats considering two habitat

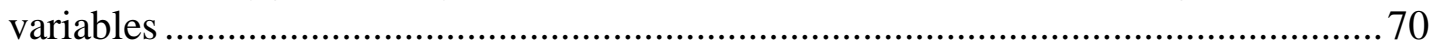

Table 6-6: Proximity results for all observed bobcats considering five habitat variables and their distance to radio-collared bobcats. 70

Table 6-7: Majority statistic results for radio-collared and observed bobcats. The top four most frequented values are reported 



\section{List of Acronyms and Definition}

$\begin{array}{ll}\text { CDF } & \text { Canonical Discriminant Function } \\ \text { CSI } & \text { Cover Suitability Index } \\ \text { DSI } & \text { Dens Suitability Index } \\ \text { FSI } & \text { Food Suitability Index } \\ \text { GIS } & \text { Geographic Information System } \\ \text { GPS } & \text { Global Positioning System } \\ \text { GME } & \text { Geospatial Modeling Environment } \\ \text { GRASS } & \text { Geographical Resources Analysis Support System } \\ \text { MCP } & \text { Minimum Convex Polygon } \\ \text { MBG } & \text { Minimum Bounding Geometry } \\ \text { MHSI } & \text { Modified Habitat Suitability Index } \\ \text { MSI } & \text { Modified Suitability Index } \\ \text { SLR } & \text { Stepwise Logistic Regression }\end{array}$





\section{Chapter 1 - Introduction}

The bobcat (Lynx rufus) is a wild cat that thrives throughout the United States and generally avoids human interaction. As the human population rises, the natural landscape becomes developed and fragmented, increasing urban-wildlife boundaries. In Southern California's Orange County, there has been a significant increase in human - bobcat encounters, particularly in urban and open altered areas such as parks and golf courses. Figure 1-1 illustrates the study area and surrounding counties in Southern California.

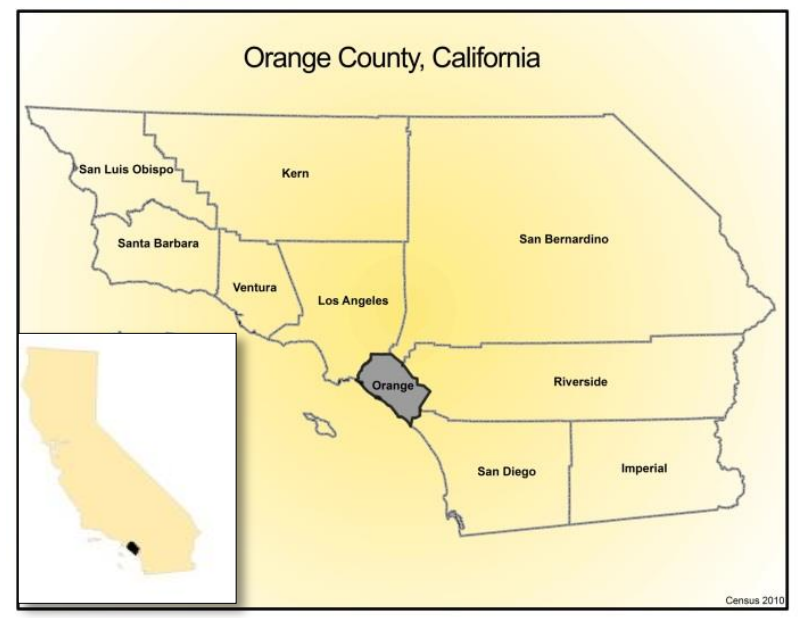

Figure 1-1: Study Area

As the bobcat's habitat becomes more limited and isolated, bobcat populations must adapt, forcing them to utilize and compete for resources close to or within the new environment. When the bobcat tries to adapt to these newly developed areas, numerous problems may arise. Interactions with roadways, toxicants, and domesticated animals are common threats to their survival in these areas. In extreme cases, female bobcats have located their dens within these altered areas to give birth and raise their kittens. Habitat modeling and spatial analysis of bobcats' responses to urbanization have been conducted in the past for various purposes. However, bobcat populations in the diverse landscapes of Southern California have been underrepresented in these studies. Behavioral traits such as gender differences in behavior, choice of den locations and temporal differences in behavior (daily and seasonally) are considered to be critical indicators of survival in the urban landscape. Critical habitat characteristics, such as the density of roads, hydrography, land cover, and urban edges often influence bobcat behaviors. Proximity to these features is also important in understanding bobcat interactions within the urban environment. 


\subsection{Client}

The client for this project is the U.S. Geological Survey Western Ecological Research Center, in particular, Dr. Erin Boydston. She is a research ecologist who specializes in bobcats. Her research uses GPS (Global Positioning System) tracking collars and traditional systematic field surveys. In addition, she collects opportunistic observations of bobcats from citizens, a non-traditional scientific dataset that may significantly contribute to the analysis of urbanized bobcats. Opportunistic observations have rarely been utilized in scientific bobcat research. Dr. Boydston intends to identify the urban landscape characteristics of bobcats to better understand their behavior and movement. A deeper understanding of how the urban bobcat is surviving in urban areas may also serve as supporting evidence for better management strategies in the future.

Better management strategies require the use of complex technological systems to achieve the most accurate and efficient analysis measures. Dr. Boydston would like to leverage a geographical information system (GIS) to help her in her analysis. A GIS contains software that provides complex analytical and cartographic capabilities and such technologies have been used for wildlife management in other analyses and study areas. GIS provides the necessary spatial and mathematical functions to help better understand how bobcats interact with the landscape in Orange County, and ultimately aid in better management solutions for the future. Data were available in the form bobcat sightings and tracks. Dr. Boydston provided the biological expertise and requirements for the project's execution.

\subsection{Problem Statement}

Urban development is the primary cause for habitat fragmentation. Fragmentation of critical contiguous habitat can put wildlife populations at risk for decline and even extinction. Unfortunately, bobcats have received minimal management considerations mainly attributed to low negative interactions with humans, and lower frequency of occurrence within urban environments in the past (Riley et al., 2010). In addition, there is a limited amount of research on urban bobcats, and it is scattered in different regions of the country. In Orange County, bobcat populations have been increasingly expanding in urban areas where they had not been previously, creating pressures on society for better management. However, an effective management plan is not complete without a comprehensive understanding of the main issue at hand, bobcats in the city. Although the client has access to current GIS software, her experience, time, and budget are limited. Implementing a GIS for analysis was necessary for a better understanding of urban bobcat behavior, which may lead to better management considerations.

Numerous problems arise when bobcats enter the urban environment. Transmission of diseases to the bobcat can occur, particularly from the domestic cat, although they are not reported to be significant threats to domesticated animals. Urban landscapes use chemicals for pest control, which poison bobcats when significant amounts are accumulated through the ingestion of contaminated rodents. In addition, roads can create interferences in bobcat habitat, making vehicle collisions a major threat to the well-being of both humans and bobcats. Inter-species competitions within the same territory may occur as well. Other urban carnivores, such as the coyote, not only compete with bobcats 
for food resources and space, but may kill bobcats, especially vulnerable kittens. These issues can be addressed by finding answers to critical questions.

What are the characteristics in the urban landscape that are associated with urban denning behaviors among female bobcats? Where are bobcats likely to occur in natural areas that have been fragmented by development? What degree of fragmentation is tolerable? Answers to these questions are critical to understand the differences and preferences among bobcats in their new urban environments. Mitigation is also crucial to ensure the survival of this animal, and to identify areas that need to be protected rather than developed. While individual bobcats have been observed for multiple years in these altered areas, increases in urban development and resource competition may ultimately lead to a sharp decline in future populations.

\subsection{Proposed Solution}

A geographic information system (GIS) is an extremely beneficial tool to help aid in the landscape analysis of bobcats. To accomplish the tasks of urban analysis, a set of analytical tools will be developed for the client's current and future research. These tools shall analyze bobcat data by habitat characteristics such as critical feature density and proximity to these features. Critical features include: roads, hydrography, urban edges, land cover, elevation, and slope. Density analysis will include linear feature densities within the study area. Polygon features will be summarized for their percent coverage within the study area polygon. Density analysis will analyze the entire data set combined and for group attributes of interest, season, sex, bobcat individuals. Proximity analysis will be conducted by measuring all the distances between bobcat locations and habitat features of interest. This information will be used to predict other locations in Orange County where bobcats may be present. Tools will provide useful descriptive statistics and measures, and will allow for the storage of derived data for later use. Storage will be in a file geodatabase for the management of complex datasets and to allow for future growth. GIS's and the underlying science have been used in the past to solve numerous environmental issues, applied across many different fields, and provide a richer source of information. ModelBuilder in ArcGIS version 10.1 and the Geospatial Modeling Environment (GME) will be the primary software used for this analysis.

\subsubsection{Goals and Objectives}

The goal of the project is to develop a system to enable a research ecologist to assess how bobcats are surviving in developed areas in Orange County. An in-depth analysis was conducted on the urban landscape characteristics that the bobcats are opportunistically using for survival. The analytical tools shall allow the user to analyze bobcat data with respect to specific attributes (groups) of interest. Using the results from the landscape analysis, a set of tools would be developed using Model Builder: a platform in ArcGIS where a multitude of toolsets can be organized. A database will also be developed for the client. This will allow for easier storage, access, and manipulation. 


\subsubsection{Scope}

There were several considerations when developing the project's scope. The timeframe for this project was eleven months, with an emphasis on being completed by August, 2013. First, the project required the conversion of opportunistic observations into spatially referenced features in a GIS. A landscape analysis of both the radio-collared and observed bobcat locations was then conducted for the client. Spatial considerations for sex, dens, kittens and time (day/night/twilight) was further broken down for analysis. The two datasets were analyzed according to proximity and density to critical habitat variables. Elevation and slope was also be used for the analysis. As analysis methods and results were reported to the client, she provided feedback on the utility of the particular analysis. This assessment aided in creating a useful analytical toolset for the client.

The proximity analysis included distance to roads, water sources, and natural/open areas. The density analysis included roads, vegetation, residential parcels, and parks/open areas. Elevation will be considered for topography, looking at slope and aspect. Elevation will also be used on the radio collared bobcat dataset to better track their individual movements, where distances between two points can be significantly altered by topography. Approved methodologies were implemented into an analytical toolset, with a friendly user interface and interaction environment. The geodatabase was embedded with a user friendly interface and environment, in order to maintain logical relationships and a hard coded editing environment.

\subsubsection{Methods}

Using ModelBuilder 10.1, four tools were developed for density and proximity analysis. Density analysis was conducted by intersecting habitat features with a defined study area, and then calculating the number of features within the intersection. Using the Calculate Areas script tool along with the Add/Calculate tools, fields were created to store area units. The Intersect tool was then used to intersect the two datasets while maintaining all attributes. Linear feature density was calculated by measuring the total length of a linear feature by the total study area. For polygon features, percent coverage was calculated by taking the ratio of total feature area coverage by the total study area coverage and multiplying by 100. Land cover features were converted to polygon features for better processing times and easier storage. This was accomplished by using the Raster to Polygon conversion tool. Proximity analysis was used to calculate all distances between bobcat locations and features of interest. The Near tool was used to accomplish this task, while allowing the user to apply an optional search radius. Tools also provided derived feature outputs for later geovisualization and mapping purposes. All results were to be stored in a table that also contains descriptive statistics about the particular feature. The Summary Statistics tool was used to accomplish this task. The GME program was used to create urban edges from the land cover data by drawing polylines between two different raster values, i.e. land-cover values.

\subsection{Audience}

This project and all derived information products will be primarily for spatial ecologists at the U.S. Geological Survey, Western Ecological Research Center. Other researchers 
from federal and state agencies may also use information used in this project for constructing management strategies.

\subsection{Overview of the Rest of this Report}

The rest of this report begins with a literature review in Chapter Two. Chapter Two compares previous studies, methodologies, and results. Chapter Three details the clients' problem and the proposed solutions and designs. Chapter Four discusses the implemented design choices and why they were made and how they adequately meet the needs of the clients' problem. Chapter Five describes the projects implementation, and how the analytical tools were developed. Chapter 6 details the analysis results and their usefulness to the client. This chapter also discusses what went right and what went wrong throughout the projects life cycle. Chapter 7 summarizes the project's conclusions and discusses possible avenues for future work. 



\section{Chapter 2 - Background and Literature Review}

Bobcats are widespread across the Western Hemisphere, living in diverse ecosystems such as mountains, deserts, forests, swamplands, plains, and shrub lands (Riley, Boydston, Crooks, \& Lyren, 2010). When the bobcats' preferred habitat becomes discontinued or fragmented primarily from development, they must try to adapt to the new urban settlements. Habitat fragmentation is a landscape phenomenon that can lead to multiple patches of land. Habitat fragmentation can also create urban-wildlife edges around natural habitats. Species interactions and complex ecological systems may be disturbed at these edges (Ewers \& Raphael K, 2006). Fragmentation of natural habitat caused by human development has effects at all scales, from local to global, and is a major threat to biodiversity across the globe. When human development occurs over a natural area, there are numerous ways in which the landscape can be altered. These landscape alterations may include:

1. A decrease in the total area of a contiguous habitat.

2. Isolation or a loss of habitat connectivity

3. Further breakup of habitat fragments into smaller patches; and

4. A decrease in area of individual patches.

Habitat loss caused by human disturbance makes the bobcat more susceptible to population loss, primarily due to low population densities, home range dynamics, and slow growth rates (Ordenana, et al., 2010). Ordenana, and others (2010) further explain that due to a top-trophic level, carnivores are great indicators of the overall fate of an ecosystem. This analysis will focus on urban associated bobcats (Lynx rufus) in areas of Orange County, California. Orange County is located in Coastal Southern California and is characterized by a Mediterranean type climate and dominated by Chaparral type vegetation. The climate has cool, wet winters and dry, warm summers yielding very few days below freezing. In addition, Orange County has very diverse topography, from sea level to nearly 6,000 feet at Mt. Santiago. As elevation increases, the scrub type Chaparral vegetation gives way to oak and pine tree mosaics. The landscape of Orange County is home to a broad range of ecosystems, all being potential habitats for the bobcat.

Analyses of bobcats have been conducted in the past, using many different techniques and applied across a wide range of habitat types. However, there are few analyses that consider how bobcats respond to changes in their natural habitat, particularly regarding urban disturbances. Considering the nature of the analysis, location is a crucial aspect to consider, especially when dealing with the complexities of wildlife and the habitats they comprise. Locational characteristics are particularly important for the bobcat, whose territory expands across the entire United States and is therefore home to some very diverse landscapes.

From county level to an entire state or region, bobcat analyses have been conducted across many different scales. Furthermore, it is also important to explore the types of methods previous studies have used for analysis because different locations, habitats, and scales may have provoked the use of different analytical techniques. These types of analyses not only lead to a better understanding of the bobcat species in general, but can help focus preservation efforts and management concerns for the urban associated bobcat. 
The remainder of this chapter will focus on how a Geographical Information System (GIS) and other techniques have been implemented in wildlife management and analyses, particularly for the bobcat. Section 2.1 covers analytical approaches within relevant literature. Section 2.2 covers relevant locations, scale, and data. Section 2.2.1 covers how study areas have been defined throughout the literature review. Finally, 2.2.2 examines which analytical techniques would be most useful for my analysis. A broad range of analytical techniques were used to examine bobcats in urban and natural habitats. An extensive coverage of relevant literature regarding previous wildlife analyses, particularly the bobcat, is necessary for sufficient guidance in analyzing wildlife populations.

\subsection{Similar Analyses and Approaches}

A study conducted by Ordenana and others (2010), focused on carnivores including bobcats, in the south coast ecoregion. It is one of the most populated ecoregions in California, home to over 19 million people. Native habitats from Riverside, San Bernardino, Orange, San Diego, and Los Angeles were included in the study. These native habitats are mainly composed of chaparral scrub, oak woodland, California sage scrub, and annual grasses. A meta-analysis was conducted on 9 mammalian carnivores in the south coast eco region. Analysis measures included camera-traps, GIS, and statistics. The camera-trap study represented 217 camera traps yielding 36,152 sampling nights. Species, time, date, GPS location, and number of individuals were recorded. Because of the redundancy in recording the same individuals, the study represented occurrence and not abundance. The camera-trap study also analyzed two measures of urbanization, proximity of cameras to urban edges and the total area of urbanization surrounding the cameras. Species were given scores for their status as being either native or non-native, as well as the total species richness. GIS analyses were performed using ESRI's Resource Assessment Program (2002) for Southern California, in ArcGIS 9.2.

This program identified native vegetation habitats within a 150-meter radius, which was set to identify habitats that are naturally limited in size. Urban classifications required that 100 percent of human altered land cover types were within the 150 meter radius. This was done to avoid patches of native vegetation that are critical resources for survival. If the human altered landscape was less than 100 percent, the dominant vegetation type was used for classification. Finally, for the statistical analyses, chi-square test was used to assess habitat selection. This tested the significant differences between expected and observed species within a habitat. In addition, bivariate logistic regression models were used to examine relationships between occurrence probability and the urbanization variables. The relationship between the probability of occurrence and the two urbanization variables was examined by bivariate regression models. Relationships between species richness (native, non-native, and total) and the two urbanization variables were examined by Spearman's rank correlation (rs). Although these analyses have spatial overlap and an ideal scale to compare to the clients study area, they lack sufficient GIS techniques in their analysis. Other studies that take a better GIS approach for wildlife analysis have been done in different parts of the county and at different scales (Ordenana, et al., 2010).

In a study conducted by (Gibbs-Kieninger and others (2002), bobcats were analyzed for the entire State of Illinois and at the county level. Bobcat presence was associated with habitats such as: major waterways, riparian woodland areas, and flood plain 
vegetation. The study used bobcat sightings and remotely sensed habitat data and a variety of techniques to model bobcat habitat presence, absence and abundance. SAS and ARCINFO/ARCVIEW were used for all statistical and GIS analyses respectively. To quantify the habitat relationships among bobcats, two modeling techniques were used. Analysis using the Canonical Discriminant Function (CDF) was applied at the county scale to model presence, absence, and relative abundance. This function attempts to use linear combinations of variables of interest to characterize differences among variable groups. Analysis using the stepwise logistic regression (SLR) was applied at the home range scale of bobcats to analyze habitat suitability. Pinpointed sighting locations were buffered to match the size of the average minimum convex polygon (MCP) home ranges of 11 radio collared bobcats.

For the CDF analysis, 145 potential habitat variables were derived from densities of the human population, roads, and streams. In addition, slope and land cover datasets were also used in the CDF analysis. All variables were tested for normality and a smaller group of uncorrelated variables to be used in the analysis were established between pairs of variables, and used to calculate Pearson's correlation coefficients. One of the highly correlated variables was removed, depending on the number of correlations with other variables. In the case of ties, the variable that was suspected to have greater importance to the bobcat was given priority. For the SLR analysis, 78 potential habitat variables were derived from densities of human population, streams, roads, and land ownership. Slope and land cover data sets were also used in the SLR analysis.

FRAGSTATS was used for the evaluation of the landscape and to perform class metrics and was used to derive landcover classifications from sighting and non-sighting locations. Modeling techniques were used to generate a smaller dataset created by transforming all variables into their normal equivalents. The non-parametric Wilcoxon ranked sum test was used for variables that could not be transformed. For normally distributed transformed variables, a t-test was used for comparing sighting and nonsighting areas. If significant differences were present between these areas, the variables were retained. This method coupled with Pearson correlation coefficients reduced the potential predictor variables to 17 .

Finally, multivariate statistical analysis was utilized in the study. A two class CDF model was created for identifying bobcat presence and absence for all counties. A three class CDF model was used to identify bobcat abundance in individual counties. For each model, variables were ranked according to their contribution. A SLR model was used to differentiate between sightings and non-sightings for each county. A moving window approach was applied to the SLR equation and was used to determine significant variables. From the equation, probability was assigned to every grid cell in Illinois. Plotted sighting locations were overlaid to the probability grid for further assessment (Gibbs-Kieninger, Nielsen, Weber, \& Woolf, 2002).

At a larger scale, bobcat habitat was modeled for northern New Jersey (Fowles, 2006). The study analyzed bobcats primarily in the Skylands region of northern New Jersey. Elevation, aspect, slope, agriculture, urban, residential, wetlands, forest, urbanwildlife edges, soil, and road density were variables considered for habitat suitability analysis. 85 bobcat occurrences including; sightings, accidental trappings, and road kill data were used to develop a predictive model. The Animal Movement Extension in ArcView 3.2 was used to create a minimum convex polygon (MCP) around the bobcat 
occurrences, and was used to define the study areas. The study area included seven counties in Northern New Jersey. The Animal Movement Extension was also used to generate 85 randomly distributed points across the study area, and was at least 1000 meters away from the nearest bobcat location. Buffers of $2.82 \mathrm{~km}$ were generated for all points, occurrence and random. Both datasets were analyzed against road density, vegetation, soil composition, edge, and topography. This data was acquired respectively from Census 2000 Tiger Roads, 1995/97 Landuse/Landcover, SURGO soil layers, and USGS 7.5 minute Digital Elevation Models (DEM).

Vegetation and soil categories were converted into $30 \mathrm{~m}^{2}$ raster datasets, mainly for faster processing. Edges were created by identifying where forest pixels were adjacent to developed, open, and a mix of both, producing three different grids. Topography was categorized from slope and aspect. Habitat attributes were generated from extracting the landscape information that was within the buffered points using a GIS. For the model development, the relationships of the habitat variables were examined, eliminating any parameters that were multicollinear or invariant. To assess whether the habitat variables were associated with bobcat locations or the random locations, point biserial correlations were made. Using SPSS 10.0, logistic regression models were created with the binary response variable of presence or absence, addressing every variable combination. Finally, ArcGIS was used for cartographic display (Fowles, 2006). The analyses mentioned so far were of various kinds and scales but lacked certain analytical aspects such as time and animal movement. An analysis of bobcats at the landscape level was approached on an urbanizing barrier island in South Carolina.

According to Roberts, Jordan, Bettinger, \& Warren (2010), "These prior assessments of bobcat suitability primarily considered habitat requirements of bobcats inhabiting natural landscapes (i.e., not urban-suburban) and were not conducted at appropriate scales to assess suitability of individual land parcels (e.g., residential building lots)." An analysis conducted on an urbanizing Barrier Island located $25 \mathrm{~km}$ south of Charleston South Carolina was performed to assess bobcat populations' responses to urbanization. A majority of Kiawah Island is home to salt marsh habitat with smaller mosaics of maritime forests of oak and pine species, shrub thickets, yaupon, wax myrtle, brackish and fresh water ponds, golf courses, residential and resort development, and sand. Local regulations required open habitat corridors around development, creating mosaics of urban-wildlife patches. To assist the local land trust organization for habitat preservation assessment, an effective tool was created and used for habitat suitability.

To accomplish this, the authors used an existing bobcat habitat suitability index created by Boyle and Fendley (1987) that took only one factor into account, food. The suitability index was modified to include coverage and den sites, two additional and equally important factors for a better assessment of habitat suitability in a human altered environment. Using ArcGIS 9.1 and field biology methods, the Modified Habitat Suitability Index (MHSI) was used to assess habitat suitability on undeveloped land parcels, to help focus preservation efforts of natural landscapes. Nine land cover types were manually digitized from digital orthophotography at a 1meter resolution, a georeferenced plat map, and municipal building permit data. Canopy cover prevented accurate delineation over some land cover types, primarily roads and urban landscapes. To more accurately represent these land cover types, rights of way were used to represent roads and platted property boundaries were used for urban delineation. Any parcel that 
was issued a building permit was included in the analysis, whether it was developed or not.

Before modification, the habitat suitability index described suitable bobcat habitat as being greater than or equal to 90 percent grass, forb, or shrub ground cover, and between 50-70 percent of the vegetation being forbs or grasses (Roberts, Jordan, Bettinger, \& Warren, 2010). This habitat mosaic is optimal for the bobcats' primary diet in the southeastern U.S., including cotton rats and eastern cottontail rabbits. One thousand points were randomly generated to assess Food Suitability Index (FSI) for each land cover type. This was done using Hawth's tools, a set of landscape analysis tools used primarily for ecological assessment. The original Habitat Suitability Index was used to generate FSI for 107 randomly generated points. Randomly selected developed parcels (107) were visually examined for vegetation type from a distance, due to private property barriers. Canopy cover on aerial photography also prevented accurate and easy vegetation identification. Area and composition metrics were used on visible parcels, and were used along with the parcels total area to calculate FSI for the entire parcel. FSI was also calculated for road rights of way by using ArcGIS measurement tools to measure vegetation that partially covered the linear feature. For urban areas, a Cover Suitability Index (CSI) was generated mainly along natural area corridors, providing food and shade relief during the day for the bobcat. FSI was estimated within these habitat patches and corridors.

An aspect not apparent in a majority of previous studies was including bobcat dens in their analyses. "Although published literature is lacking, it is intuitive that a scarcity of adequate den habitat could negatively affect kitten survival by placing kittens closer to anthropogenic disturbances (e.g., roads) or in areas with suboptimal cover (i.e., increased vulnerability to predation) "Riley et al. (2003)." A Den Suitability Index (DSI) was included in MHSI using forest and shrub land covers. A moving window approach was used to average the DSI values within a two-ha area. Water was not used in the analysis because it was assumed to be plentiful and easily available to bobcats on the island. To estimate mean MHSI, land cover types were rasterized and merged to a raster grid. This grid was reclassified into mean component index values, outputting FSI, CSI, and DSI raster grids. Microsoft Visual Basic was used to generate a MHSI raster grid and ArcGIS Zonal Statistics tool was used to calculate mean MHSI within parcels.

The validity of the MHSI was assessed by using 16 radio collared bobcats, eight male and eight female (used in a different study). Telemetry locations, provided by radio collard tracks, were recorded two to five times a week from April 1, 2004 to March 30, 2005. Monitoring sessions were progressively shifted in two hour increments for collecting data during the diel period. Consecutive locations were placed 12 hours apart for observation independence. Frequencies of bobcat locations within the MHSI output grid was used for final assessment. In addition, DSI was tested for validity by one of the tracked females, known for rearing kittens in den locations. Furthermore, the point intersect tool in Hawth's analysis toolset and sunset data were used to record FSI values 30 minutes before and after sunset at nocturnal telemetry locations. CSI values were calculated at all other times. Finally, G statistics and degrees of freedom were applied for all bobcats to estimate use versus availability (Roberts, Jordan, Bettinger, \& Warren, 2010). 
Modeling habitat selection in a temporal setting was also accomplished by Quinn (1997), where coyote habitat selection from routine movements was analyzed in urban areas of western Washington. Quinn states "Habitat preference is often determined by examining temporally independent animal location data with little attention paid to movement behavior." Coyotes were analyzed in a portion of King County, Washington in the Western Hemlock Zone. The study area was at a relatively low elevation, less than $100 \mathrm{~m}$, where most of the dominating forests have been cleared for urban development, creating a myriad of habitat patches consisting primarily of Douglas-fir, western hemlock, red alder, big leaf maple, and vine maple. Techniques using radio telemetry, geographical analysis telemetry locations, compositional analysis, and step-wise regression of movement data were used for the analysis.

Six radio collared coyotes were used, three male and three female, who's home ranges extended to parts of Seattle. Coyotes were tracked during 12, six hour sessions over all four seasons. Breeding season occurs through January 1 to March 15, gestation season occurs through March 16 to April 13, pup-rearing season occurs between May first to July thirty first, and dispersal season occurs through August 1 to December 31 . Three tracking sessions per time period beginning at $6 \mathrm{am}, 12 \mathrm{pm}, 6 \mathrm{pm}$, and 12 am were observed, where consecutive tracks for individuals were separated by 24 hours or greater. A one hour interval tracking session yielded six locations and five movements all connected by straight lines. Seasonal tracks and time considerations led to day and night movement designations.

For the breeding seasonal period, daytime movements were designated from occurrences over a ten hour tracking session, from seven am to five pm. For the gestation seasonal period, daytime movements were designated from occurrences over a twelve hour tracking session, from seven am to seven pm. For the pup-rearing seasonal period, daytime movements were designated from occurrences over a fifteen hour tracking session, from six am to nine pm. And finally, for the dispersal season period, daytime movements were designated from occurrences over a twelve hour tracking session, from seven am to seven pm. Movements throughout any other time periods were designated as nighttime. This time breakdown approach was taken to allow animal movement across multiple pixels within the study area, so used and available habitat identification could be made. "I had little guidance on appropriate time intervals from published literature since no one to my knowledge had looked at coyote movements as a function of habitat preference in this way and there were no studies of coyote movements in urban habitats to guide me" according to Quinn. For an easier hypothesis testing design, spatial patterns were weighted for compositional analysis rather than radio locations. A p - value of 0.05 was chosen for the statistical analysis. Once the data was acquired, GIS technologies were utilized for analytical procedures.

Geographical Resources Analysis Support System (GRASS) was used for location plotting, projection transformations, overlays, and database storage. LANDSAT imagery from a 1985 database was acquired for pixel classification into five different habitat types. Each individual pixel was 28.5 meters on each side. Habitat classification methods for this study considered many landscape habitats and dynamics, such as density and vegetation height. Habitats were classified as forest, shrub, densely mixed vegetation, moderately mixed vegetation, and sparsely mixed vegetation. Densely mixed vegetation areas were associated with high income housing. Moderately mixed vegetation areas 
were associated with the most residential development in King county. Sparsely mixed vegetation areas were associated with the most industrial development and also contained metropolitan areas, with very low residential density.

Compositional analysis was performed at two different scales for habitat selection comparison. Habitat selection within coyote home ranges and movement data were considered for the comparison. Compositional analysis used coyote movement data to consider the individual coyote rather than a single telemetry location. Randomized statistical analysis using Wilks's lambda (L) and t test were performed to determine significance levels. Home range estimates were made for each individual coyote using $100 \%$ adaptive kernel estimates. Equal sampling, required for compositional analysis, was accomplished by weighting each animal's habitat composition by their radio locations. Since Sequential telemetry locations were distributed in a relatively uniform manner, they fit into the equal sampling analysis design. Animal movements were assessed for habitat use by looking at habitat availability and habitat used. Habitat availability was defined by a circular polygon. The center of the polygon was a radio location at time $t$, where the radius represented a movement distance, from $t$ to $t+1$. Habitat actually used by the coyote was defined as the intersecting habitat along a straight line movement. Habitat composition for an individual's movements was calculated by summing the number of pixels across all generated movements. Tracked animal numbers were insufficient to account for seasonal effects. Using results from the compositional analysis, habitat type was ranked from one to five.

Habitat quality was examined along animal movements, from initial habitat to end habitat, using stepwise multiple regression analysis. This relationship was also examined for habitat gradient determination, the difference between initial and end movements, and also considered illumination conditions, day versus night. This analysis was constructed to provide information into how far coyotes move when they are in favorable versus non favorable conditions. The calculation of habitat quality was considered for the individual pixel on which the coyote was located, the total values for nine surrounding pixels, and the mode of the nine pixel group. A stepwise multiple regression analysis was performed again to examine habitat quality and movement distance for all coyotes, achieving analysis results within the authors defined study area. To enter and remove predictors from the regression equations, an alpha $=0.15$ (F-test) was used within the stepwise model fitting program. Eleven outliers were removed by natural log-transforming the dependent variable (movement distance +1 ) and skewed the distribution of residuals Quinn (1997).

\subsection{Relevance: Location, Scale, and Data}

Riley, Boydston, Crooks, \& Lyren (2010) reviewed bobcats from other studies in three areas of California, all at county or city scales. Although the scale and habitat types in this area were appropriate for my study, their lack of analytical techniques eliminates its usefulness in my analysis. Fowles (2006), conducted bobcat analysis at a slightly larger scale than my study area, but examined the landscape characteristics, an important characteristic for this analysis. Furthermore, the data used for analysis included bobcat sightings, relevant for this study, but did not use temporal telemetry locations from radio tracked bobcats. Gibbs-Kieninger, Nielsen, Weber, \& Woolf (2002) used telemetry 
locations in their bobcat analysis. Bobcat sighting datum was also included, but they analysis only had very few analytical aspects that could be applied for my purposes.

Their analysis was performed at the home range scale, although the results were compiled for the entire state of Illinois. Landscape analysis was performed at a larger scale than my study area, but some aspects important for my study. Telemetry locations considering temporal aspects was accomplished in Roberts, Jordan, Bettinger, \& Warren, (2010), but were not used to study animal movement over specific landscape characteristics. Furthermore, the study heavily focused on urbanization effects on bobcats within urban parcels. In contrast to the previous studies of bobcats, (Quinn, 1997), analyzed radio collared coyotes at a sub county scale and considered the impacts of urbanization. In addition to having a similar study area size, his analysis used telemetry locations and considered temporal aspects of male and female coyotes. Location and topography were of different nature however.

\subsubsection{Study Area Definition and Generation}

Minimum Convex Polygon's (MCP's) are created by enclosing all outer points of a dataset by connecting them with lines to create a polygon. If the polygon contains all line segments for its points, then it is considered to be convex (Mohr, 1947). MCP's are typically used in wildlife analysis to define study areas and home range boundaries. In Fowles (2006), MCPs were used to define the study area using the Animal Movement Extension in ArcView 3.2. Two urban bobcat analysis reviews by Riley, Boydston, Crooks, \& Lyren (2010), including Ventura and Orange Counties, used 95\% MCPs. In contrast to these methods of home range identification, home range estimates were made for each individual coyote using 100\% adaptive kernel estimates in (Quinn, 1997).

\subsubsection{Location Considerations and Useful Analytic Approaches}

The analysis for this requires the identification of landscape characteristics and habitat usage of bobcats in urban areas of Orange County. In Fowles (2006), an urban variable was included for analyzing bobcats against road and vegetation densities, urban/wildlife edges, and topography. Quinn (1997) used a Geographical Resources Analysis Support System (GRASS) for location plotting, projection transformations, overlays, and database storage. LANDSAT imagery from a 1985 database was acquired for pixel classification into 5 different habitat types, considering vegetation height and density. Gibbs-Kieninger, Nielsen, Weber, \& Woolf (2002), analyzed bobcats against road and stream density, slope, and land cover. Ordenana and others (2010) used ESRI's Resource Assessment Program (2002) for . Operating in ArcGIS 9.2, the program was used for the identification of native habitats. They also used a small search radius to take into account habitats small in area, important in urban analysis. Roberts, Jordan, Bettinger, \& Warren (2010), Created suitability raster grids and performed reclassification methods. More importantly, the study included temporal aspects of where sunset data was used 30 minutes before and after sunset, at nocturnal telemetry locations. This temporal aspect was taken a step further in Quinn (1997), who analyzed coyote telemetry data for illumination conditions for day and night.

Useful statistics were applied across all reviewed literature. Ordenana and others (2010) used habitat selection methods with a Chi Square testing approach. They 
examined difference between observed and expected selection. The relationships between occurrence and urbanization variables were examined through bivariate regression models, in addition to Spearman's rank correlation (r) for species richness relationships. Gibbs-Kieninger, Nielsen, Weber, \& Woolf (2002) used FRAGSTATS for the evaluation of the landscape and to perform class metrics in addition to deriving landcover classifications from sighting and non-sighting locations. Stepwise Logistic Regression (SLR) approach was used for habitat suitability analysis. Further usefulness with tstatistics was used for sighting versus non sighting comparisons and moving window approaches were added to the SLR equation for habitat variable significance testing.

SPSS 10.0 was used for regression analysis in Fowles (2006) to assess whether the habitat variables were associated with bobcat locations or the random locations. Roberts, Jordan, Bettinger, \& Warren (2010), used a random selection of parcels for statistical testing. Random generation and point intersect operations were accomplished in Hawth's tools. G statistics and degrees of freedom were applied for all bobcats to estimate use versus availability. Movements over preferred habitat and its respective quality was examined in (Quinn, 1997), using stepwise multiple regression analysis methods.

\subsection{Summary}

A broad range of analytical techniques have been used for wildlife analysis in the past, particularly with the consideration of urban influences. In addition, numerous programs and complex software were used to perform a multitude of analytical functions over a variety of locations, habitats, and scales. Although these analytical techniques could benefit my particular project, not all of them will be used in the analysis, primarily due to the scope and timeframe of the project and lack of experience with some approaches. Some of the programs and software used in previous studies are now outdated and incompatible with newer GIS. However, advances including the same functionalities and interoperability's are inherent in newer programs and software, some offering great improvements. 



\section{Chapter 3 - Systems Analysis and Design}

Before a project can be successfully implemented, there are numerous details to be worked out with the client. Problems need to be identified so that their respective solutions can be integrated into the system design. This chapter will review the initial problem(s) faced by the client and details the requirements needed for the project's completion. Based on what the client needs, the development of the system design will be discussed and how the particular tasks will be accomplished. The chapter will continue with a discussion of the project plan, the projected time frame assumed to complete the required tasks, and will wrap up with a brief summary.

\subsection{Problem Statement}

The client collects large volumes of bobcat data in the form of opportunistic observations and GPS radio tracking collars. Approaching an analysis is a complex and time consuming task, especially where literature on previous analyses is lacking and not fully applicable to Southern California. Bobcats are more reclusive and less notorious than other urban associated carnivores like the coyote and mountain lion, giving them low attention for management considerations. Recently, bobcat sightings and GPS tracks have grown in urban areas, especially within the clients study area. Understanding this recent interaction with urban and natural features is critical to mitigate the many problems that are associated. Some of these problems include: deaths from vehicular collisions, toxin accumulations, disease transmissions, and competition for resources.

\subsection{Requirements Analysis}

For any project to be successful, an examination of the functional and non-functional requirements is a necessary component. Functional requirements refer to what the deliverable(s) shall do and how they should perform. The client wants to know the urban landscape characteristics on which bobcats are surviving upon so the analytical tool is required to perform many analytical tasks. From analytical outputs, the tool shall provide useful maps and graphs for geovisualization purposes and shall generate descriptive reports to better convey the information displayed. The tool shall allow the user to analyze bobcat data in its entirety, in addition to choose certain attributes such as gender and season. The tool shall delineate the study area for these datasets for analytical purposes. The tool shall analyze bobcats in regard to densities of urban features such as roads, water sources, and open/altered areas. The tool shall analyze bobcats in regard to proximities to the urban features mentioned above, in addition to urban edges. The tool shall allow the user to calculate results in desired units of measurement. The tool shall allow the use of many different datasets such as den locations and road kill.

In contrast, non-functional requirements describe what the system shall be. Most importantly, the tool shall be user friendly, where GIS dialect is transformed into understandable terms and where the client or other users can input data, click a few buttons, and get the desired results. These results, derived datasets, analytical results, and maps shall be loaded into a geodatabase. The geodatabase shall be capable of handling 
large volumes and sizes of future bobcat data. The geodatabase shall be well organized, so the myriad of future data and results can be easily imported. These functional and nonfunctional requirements are listed in table 3.1 below.

Table 3-1: $\quad$ System Requirements

\begin{tabular}{|c|l|c|}
\hline Requirement & \multicolumn{1}{|c|}{ Description } & Type \\
\hline Tool Considerations & $\begin{array}{l}\text { Shall analyze bobcats in terms of density, } \\
\text { proximity, and predicted interaction. }\end{array}$ & Functional \\
\hline Analysis Components & $\begin{array}{l}\text { Shall consider important elements such as } \\
\text { roads, water features, land cover and urban } \\
\text { edges. Shall allow the user to analyze data } \\
\text { by grouping or case attributes. }\end{array}$ & Functional \\
\hline Results & $\begin{array}{l}\text { System shall delineate the study area for } \\
\text { analytical purposes. }\end{array}$ & Functional \\
\hline Platform & $\begin{array}{l}\text { Shall provide results in tables and graphs, } \\
\text { and analysis maps, including urban } \\
\text { interaction maps. }\end{array}$ & Functional \\
\hline Geodatabase & System shall function in Arc GIS 10.1 & Non-Functional \\
\hline Geodatabase & $\begin{array}{l}\text { All results shall be stored in a file } \\
\text { geodatabase. }\end{array}$ & Non-Functional \\
\hline $\begin{array}{l}\text { Geodatabase shall be well organized and } \\
\text { shall have a large storage capacity. }\end{array}$ & Non-Functional \\
\hline
\end{tabular}

\subsection{System Design}

The system was designed according to the needs stated by the client in the beginning stages of the project. The client needed analytical results to help her better understand how bobcats are interacting with the urban environment within Orange County, California. In addition, she needed an analytical tool to provide results on the urban landscape characteristics for her future research. The main components included were the analysis, geodatabase, and analytical tool. These components are detailed respectively in the sections below. The analysis should characterize urban bobcat habitat and measure their interactions with certain habitat variables, or elements. Furthermore, the analysis should take bobcat interactions into account to predict interactions for all of Orange County. The analytical tool should not only re-create analysis results originally delivered 
to the client, but should also be used to generate results for different datasets and selected datum attributes. The geodatabase should be capable of storing large and complex datasets, in a well-structured fashion.

\subsubsection{Analysis}

Understanding the urban landscape characteristics frequented by bobcats will require defining the study area and characterizing it in terms of important habitat elements. These elements were defined as being features such as roads, hydrography, land cover types, and urban edges. The features should be characterized by measuring their densities within the study area. In addition, urban bobcat interactions should be measured by their proximity to the features mentioned above, with the addition of urban edges. The analysis should be conducted on different groupings or attributes of radio-collared and observation bobcat datasets. These attributes include sex, season, animal id (radiocollared individuals), and dens/possible dens (observations). Figure 3.1 below outlines the nature of the analysis.

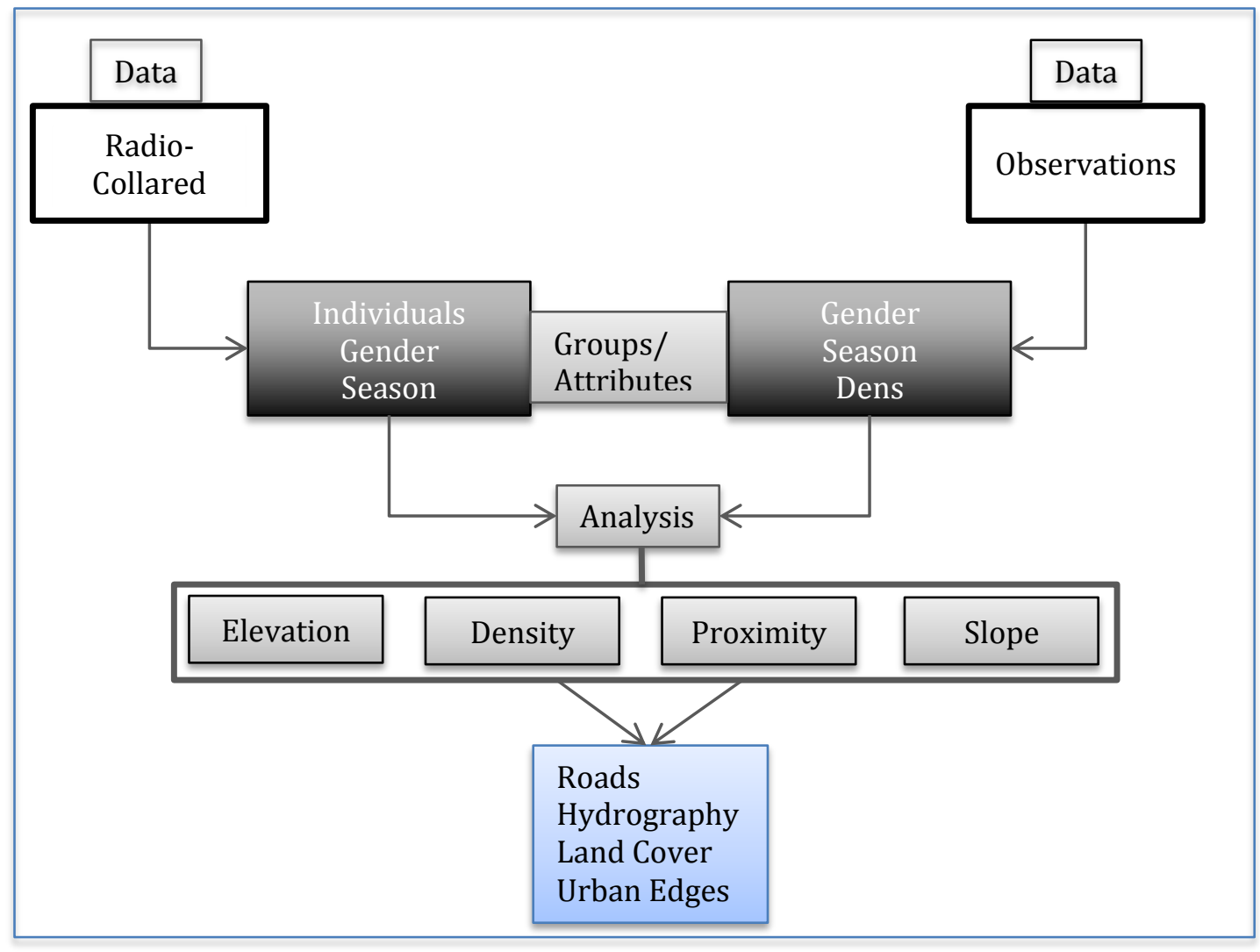

Figure 3-1: Analysis Workflow 
Polygon feature densities and proximities are to be summarized in a table as total percent coverage within the study area. Land cover and water bodies should be considered for polygon habitat elements. In addition, open/natural areas should be defined and summarized by total percent coverage within the study area. Further summarization should be considered to report the frequency of bobcat observations within all land cover types. Linear features should be summarized for total density and linear density within the study area. Roads and streams should be considered for linear urban elements. For the proximity analysis, summary tables should report bobcat distances to important urban elements. All urban elements mentioned above should be used for the proximity analysis, with the addition of urban edges. Furthermore, bobcat urban interaction was to be extended outside of the immediate study area, and applied to all of Orange County, yielding a predicted urban interaction.

\subsubsection{Geodatabase}

A file geodatabase shall be used to store all initial data, results, and any other derived information. This type of database was considered to enable future additions of bobcat data, and also shall serve in projecting all components to a common coordinate system. Added components shall be categorized into multiple feature datasets. Radio-collared bobcats will store individuals, sex, and seasons. Bobcat observations, or sightings, made up another feature dataset, containing the feature datasets mentioned above, with the addition of bobcat dens and possible den sites. Within both of the datasets and their different groupings or categorical breakdowns, further categories were contained within, for the type of analysis result: density and proximity. Another feature dataset called miscellaneous was created to hold analytical features such as roads, hydrography, land cover, and the Orange County boundary.

\subsubsection{Analytical Tools}

Multiple analytical tools were to be created in Arc GIS 10.1, using ModelBuilder. A tool for polygon features and linear features was to be created. Polygon features included land cover and water bodies, linear features included roads and streams. Analyzing bobcat habitat elements in terms of densities and their proximities to these elements, four analytical tools were required. The tools shall be designed to handle study area delineations considering different categorical groupings of bobcat data features. This task was accomplished by using the MBG tool. Although the common way to define the study area for wildlife is the convex hull geometry type, particularly for an individual's home range, the user is given the option to define the study area by other geometry types. These other types include: rectangle by area, rectangle by width, circle, or envelope. Additional functionality of these tools should allow the user to analyze urban characteristics of the radio-collared bobcats by specific attribute information. Bobcat sex, season, and animal id (each individual) are the primary attributes analyzed in this project.

\subsection{Project Plan}

The timeframe for the project completion was set for 11 months, from September 2012 to August 2013. When the project was first initiated, the first major task was to acquire the 
datasets from the client and integrate it into ArcGIS. This task was allotted four months due to changing project components and data considerations. Once the data were prepared for analysis, it was necessary to define concrete requirements. During the same timeframe, a more thorough understanding of the data and analysis setup was to be accomplished. Furthermore, the geodatabase design and setup was planned to be concurrent with the previous tasks, as data and any results were collected. This task was allotted 5 months for completion as analysis requirements were considered for feasibility. By April, 2013, one month was allotted for spatial analysis and for the collection of all results. Also, at the same time the development phase of the analytical tool. The analytical tool was projected to be completed in June 2013, in addition to working out any bugs along the way. And finally, all bugs in the analytical tool were to be solved and the geodatabase was to be populated with the requested data and results. The details of these tasks and mile stones are outlined in figure 3.2 below.

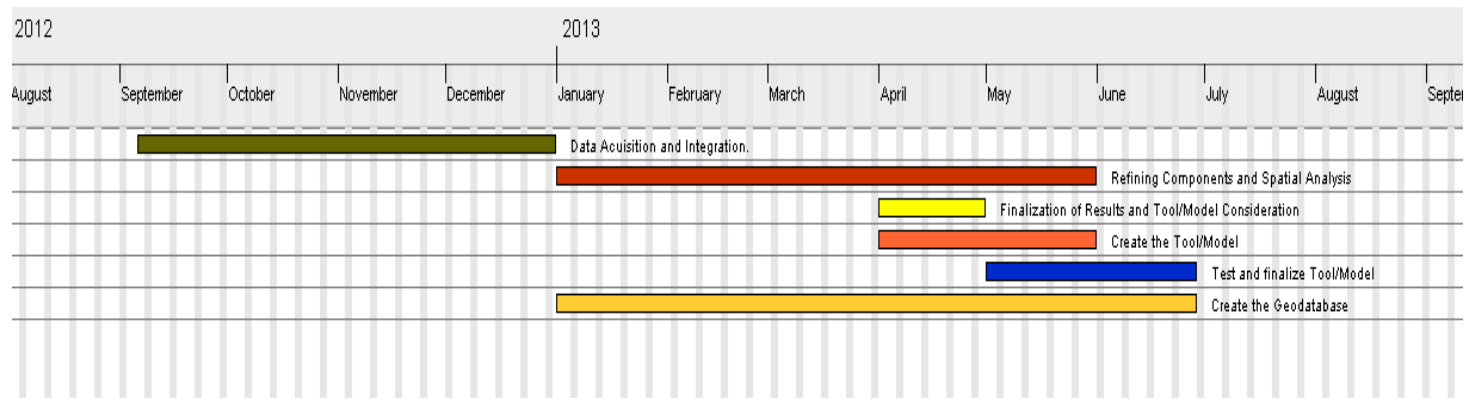

Figure 3-2: Gantt chart

Although the first tasks were allocated sufficient time for completion, communications with the client and the lack of concrete analysis requirements put this task behind by one month. The complete datasets were not acquired until February, 2013. Also, with communications being once every two weeks, and a heavy overload of information from my client via phone conversations, whom is a research ecologist, made the definition of a concrete analysis workflow a difficult and time consuming task. This slow progress continued and every other expected milestone was altered. After multiple meetings with the MS GIS faculty in a GIS 695 Project Execution course, the analysis and tool development were finalized and approved by the client. The final tools were completed by mid-July.

\subsection{Summary}

To gain a better understanding of urban bobcat behavior in Southern California, the client wanted an analytical tool to help her characterize the urban landscape and measure interactions on which the bobcat is tracked and observed, and for future considerations as 
her data grows through time. To meet the needs of the client, three main project components should be considered. These components included an analysis to produce results, a geodatabase to store all results and data, and an analytical tool to work with other bobcat data. The complexities of the acquired data created the need for numerous requirements and functionality for the analytical tool. These complexities were not only attributed to the amount of data acquired, but more to the large nature of information recorded about each bobcat, mainly their temporal attributes. 


\section{Chapter 4 - Database Design}

A detailed data model reflects a logical representation of the objects involved in a database. Modeling these objects requires a profound understanding of their specific attributes for retrieval and analysis purposes. Before the logical model can be constructed, a conceptual design must first be considered to reflect, in plain English, what is needed. Section 4.1 explains this basic understanding of the project, or conceptual data model. Section 4.2 gives an explanation of the logical data model, a more technical understanding of the project. Section 4.3 details the various data that was used for this project. Section 4.4 explains the scrubbing of the data, or how it was manipulated to be used for analysis. Section 4.5 gives a brief summary of the chapter.

\subsection{Conceptual Data Model}

The conceptual model gives a basic explanation of the client's requirements. The client is a research ecologist who collects bobcat data in the form of GPS radio-collars and opportunistic observations from citizens. The initial purpose was to gain a better understanding of bobcat behavior in urban areas of Southern California. Knowing how bobcats interact with habitat variables was critical to the analysis. Habitat variables were defined as: roads, hydrography, land cover, urban edges, elevation, and slope. How close bobcats are to these features was important to and yielded a better understanding of urban bobcat interaction. How many urban elements are present in an area, particularly roads, hydrography, and land cover also lead to a better understanding of the level of urbanization and particular habitat preference. The overall project concepts and requirements are illustrated in Figure 4.1 below.

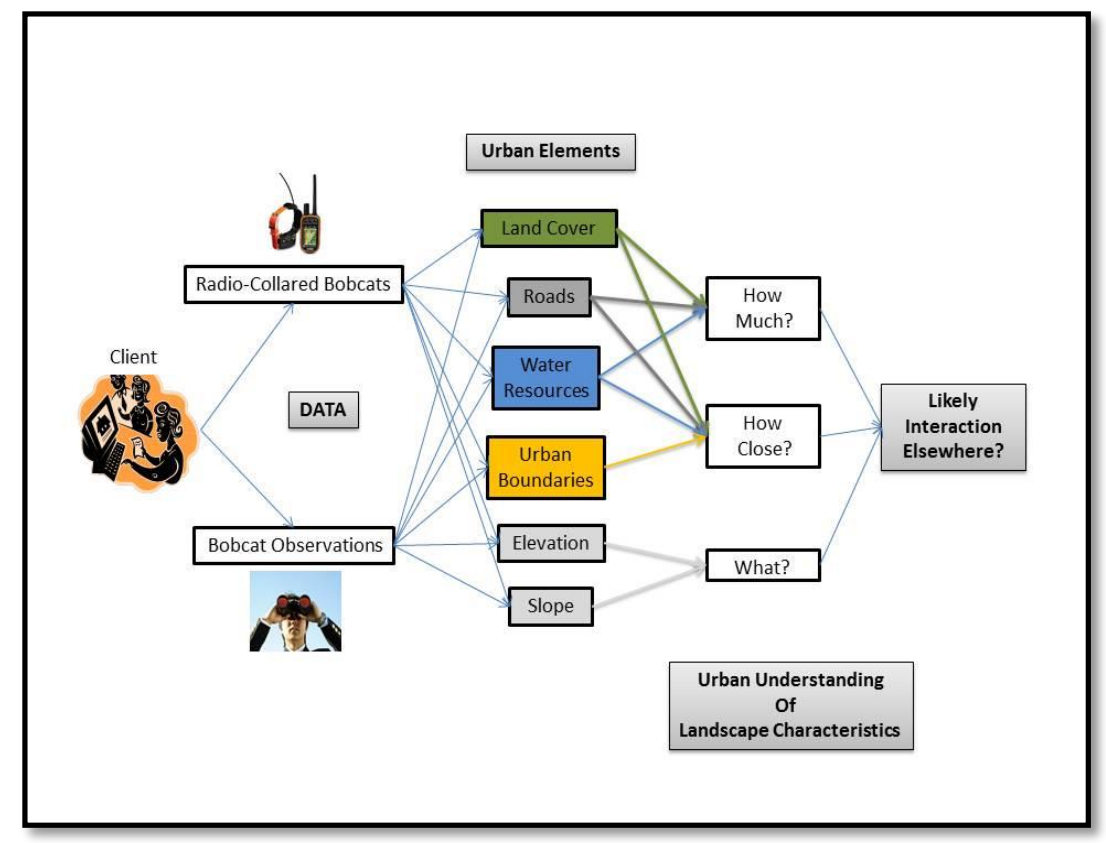

Figure 4-1: Client Requirements. 
The analysis is centered on bobcats in urban and natural environments. We know the bobcats move around by an individual's track, or a sighting, yielding single point locations. The bobcat needs resources such as food and water for survival, but obtaining a better understanding of the landscape characteristics of bobcats in between the known locations is the primary goal of this project. There are many tracks for one tracked bobcat. There are one-to-many observers sighting one to many bobcats, where a sighting is a component between the observer and sighting. The client intends to find out the how bobcats are interacting with the natural and urban environment using the knowledge she already knows, that bobcats are crossing roads and need certain resources to survive. One of the main project goals was to analyze how bobcats interact with urban features and how they are characterized. These relationships are illustrated in the conceptual model in Figure 4-2.

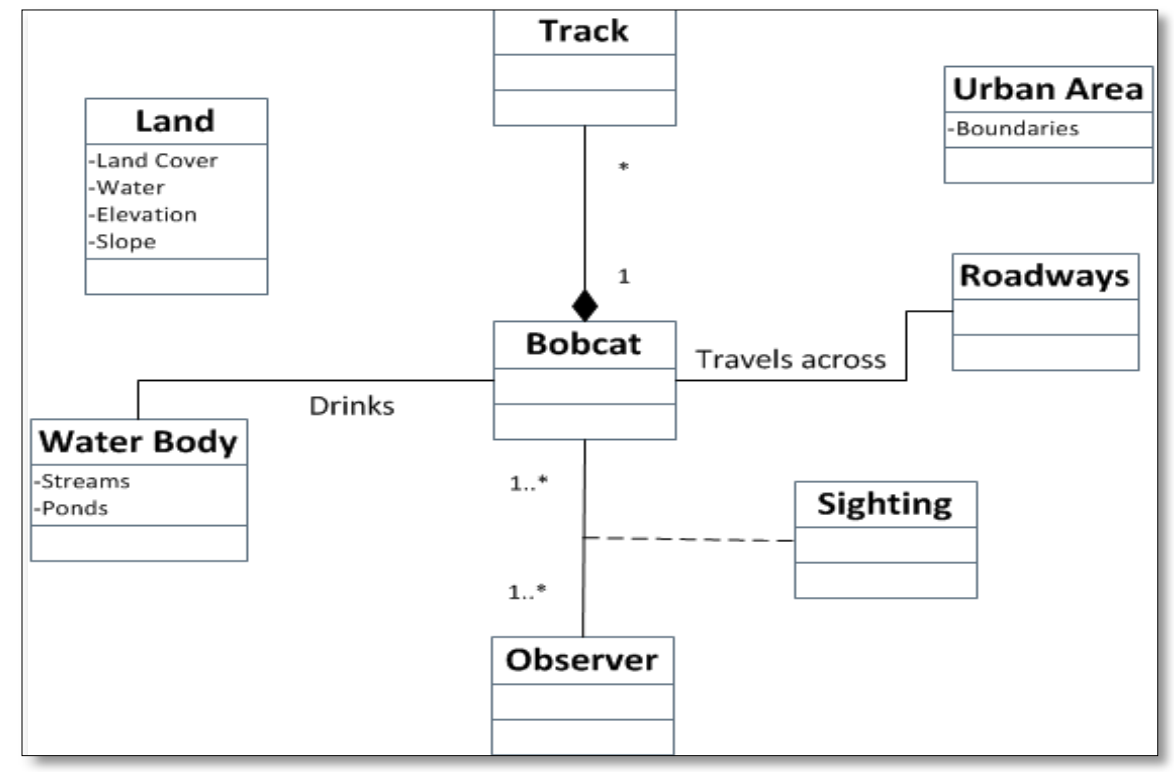

Figure 4-2: Conceptual Model.

\subsection{Logical Data Model}

An object-relational data model was used for this project. Two file geodatabases were created in ArcGIS 10.1 for the storage of data, maps, and results. One geodatabase was created for the storage of the original datasets acquired from the client. This geodatabase contains three separate feature datasets; observations, radio-collared bobcats, and miscellaneous data. Within the two "bobcat" feature datasets, there are feature classes for the complete shapefiles. Because the observation dataset was originally acquired in an excel spreadsheet form, that original file was stored only in the geodatabase. This had to be done because feature datasets are designed to maintain topological rules for features that have geometries, so tabular results could not embedded within. The miscellaneous feature dataset contains feature classes for Orange County, including items such as: 
roads, hydrography (flow lines and water bodies), urban edges, land cover, and the county boundary. Figure 4.3 illustrates the layout of this geodatabase.

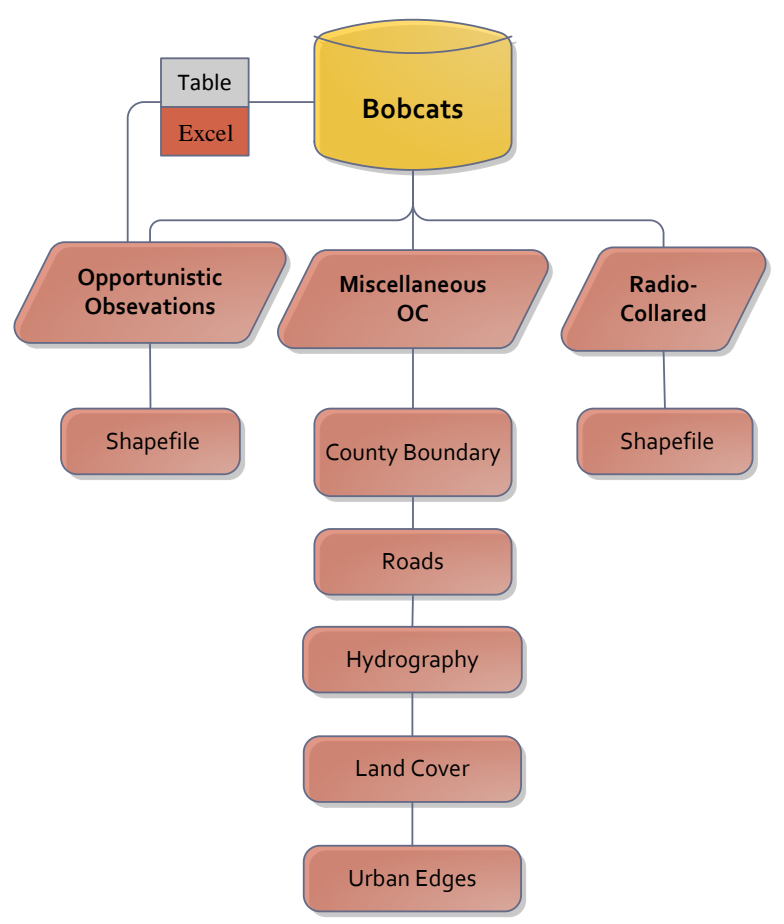

Figure 4-3: Logical Data Model for Original Datasets and Analysis Components.

Another geodatabase was created to store the analysis results and derivatives, or intermediate data for both datasets. The radio-collared feature dataset contains feature classes for all cats combined, and important attributes such as individuals, gender, and seasonal considerations. The complete attribute list for radio-collared bobcats can be found in Appendix B. Each of these datasets contains data and map derivatives from density and proximity analyses. All result tables were stored outside of feature datasets, but within the geodatabase. These results were derived from the summary statistics tables generated from the analysis and zonal statistics tables for elevation and slope evaluation. The same organization and logic applies to the observation dataset, except there are a few attribute differences for analysis consideration. There are no feature classes for individuals or gender. These attributes were not inherent within the original dataset due to the nature in which it was collected. Instead, a feature dataset for bobcat dens, possible dens, and time comments were used. The client added the den and possible den categories under one attribute field labeled "notes_eb." Figures 4-4 and 4-5 illustrate the storage of these analytical considerations within the database. The complete list of attributes for the observation dataset can be found in Appendix A. 


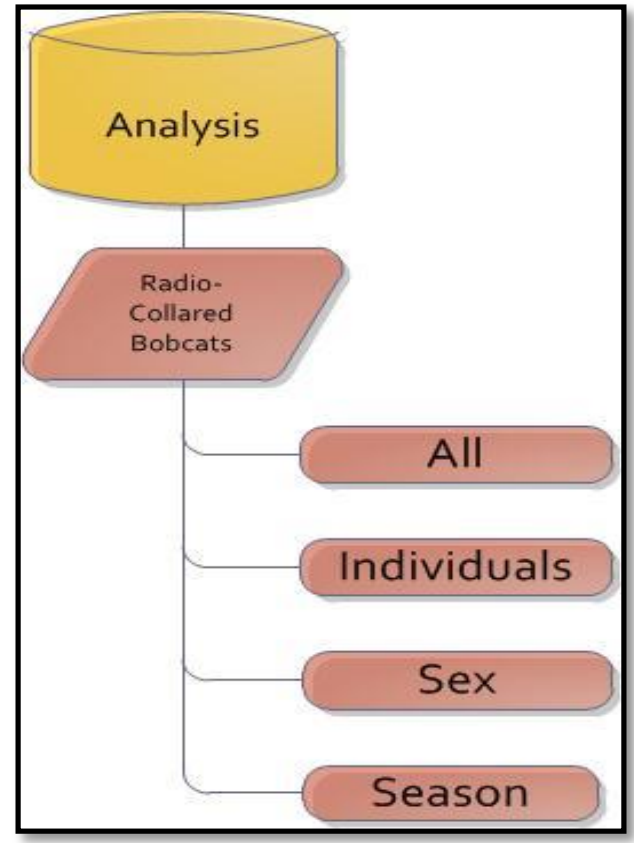

Figure 4-4: Radio-Collared Logical Model.

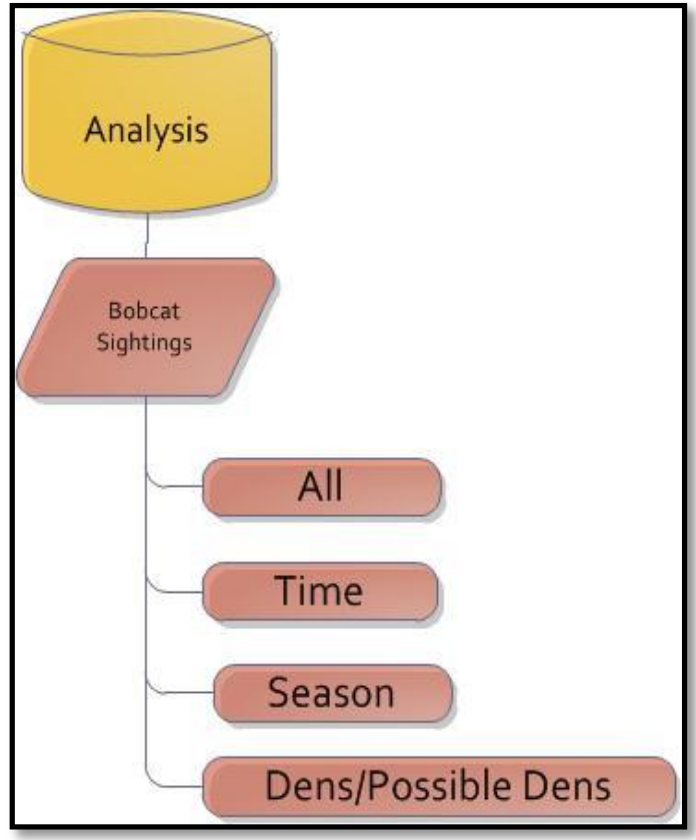

Figure 4-5: Observed Logical Model. 
The observer of the bobcat was not included in the logical model because he or she was not required to be identified in the reporting structure. It was assumed that for a bobcat sighting to occur there had to have been an observer to report it. These datasets were recorded and delivered in a single excel spreadsheet. The radio-collared dataset contains 17 bobcat individuals and was also delivered in a non-normalized fashion, all combined in one shapefile. Multiple assessments of an animal's unique identifier, or the animal id, were checked for accuracy and consistency. Gender for a particular animal id was checked for consistency throughout the individual's tracks. The individual's name was also checked for consistency throughout. The combined dataset was not broken up by individual bobcats for ease of analysis processes and better containment. The client delivered the dataset in one shapefile, so it made sense to analyze it and return it in that condition. In addition, it is not easy to re-join all of the bobcat individuals and their newly created fields back into one complete shapefile.

\subsection{Data Sources}

The two primary datasets, bobcat observations and radio-collared bobcats, were acquired directly from the client. She uses traditional field and trapping methods to collar bobcat individuals. She also collects opportunistic observations from the public. Characterizing the urban environment and how bobcats interact with critical variables will require an assessment of density and proximity to urban features including: roads, hydrography, land cover, and urban edges were used. Roads were acquired from the Census Bureau using 2010 tiger lines. Hydrography was acquired from the USGS using their National Hydrography Dataset (NHD). The land cover dataset was acquired from the Multi Resolution Land Characteristics Consortium using their National Land Cover Database, 2006.

\subsection{Data Scrubbing and Loading}

The radio-collared bobcat dataset came in the form of a shapefile ready to be loaded into a geodatabase. However, the observation bobcat dataset came in the form of a Microsoft Excel spreadsheet that needed some preparation to be integrated with ArcGIS.

Fortunately, latitude and longitude coordinates were already stored as separate fields within; otherwise geo-referencing observations from geocoding provided addresses would have been required. To analyze bobcats in terms of season and other temporal aspects, date and time fields had to be queried and the proper fields labeled. For radiocollared bobcats, date and time were in Julian decimal format. For convenience, the dataset was exported to Microsoft Excel, where the decimal form was converted to month/day/year hours/minutes/seconds AM/PM.

Once prepared, that particular field was rejoined back into the original shapefile because creating a new $\mathrm{x}$ and y event layer did not lead to a successful geo-reference, the datum was consistently plotted in the Pacific Ocean, despite double checking projection information and importing the file into the coordinate defined geo database, This new text field was converted to a string type to enable wildcard inquiries. These queries were run to break the datum up into seasonal attributes: spring, summer, and winter. Further temporal classification was done for AM, PM, and solar illumination. Although these temporal aspects were not part of the original analysis, they were agreed to be prepared 
for the client, who could perform analysis with them in the future. To analyze bobcats against open/natural land cover types, the 16 land cover types in the land cover database needed to be redefined. This definition is illustrated in figure 4-6.

\begin{tabular}{|l|}
\hline NLCD Land Cover Classification Legend \\
11 Open Water \\
12 Perennial Ice/ Snow \\
\hline 21 Developed, Open Space \\
\hline 22 Developed, Low Intensity \\
23 Developed, Medium Intensity \\
24 Developed, High Intensity \\
\hline 31 Barren Land (Rock/Sand/Clay) \\
41 Deciduous Forest \\
42 Evergreen Forest \\
43 Mixed Forest \\
51 Dwarf Scrub* \\
52 Shrub/Scrub \\
71 Grassland/Herbaceous \\
72 Sedge/Herbaceous \\
73 Lichens* \\
74 Moss** \\
81 Pasture/Hay \\
82 Cultivated Crops \\
90 Woody Wetlands \\
95 Emergent Herbaceous Wetlands \\
\hline Alaska only \\
\hline
\end{tabular}

Figure 4-6: Open/Natural Land Cover Definition.

Open water is not considered part of the open/natural classification because bobcats are not aquatic animals, and their proximity to this resource was covered with the water bodies in the National Hydrography Dataset. Furthermore, items marked with an asterisk in Figure 4.6 were not included because they refer to vegetation that only exists in Alaska. The time comments field is an optional parameter for the bobcat reporting structure, reflecting only a portion of the records. The analysis results from this attribute are categorized under the feature class labeled time. One hundred sixty five records were designated as: early morning, morning, daytime, afternoon, midafternoon, late afternoon, and evening. These were reduced into day and night attributes. Urban edges were generated from a landscape analysis program called the Geospatial Modeling Environment (GME), compatible with GIS features. This program consumed the land cover data to produce these urban edges by drawing lines between two pixels that have very different values using the "extractedge" tool. Unfortunately, this extracted the edges between all land cover types so further data extraction was required to achieve just urban/natural land cover edges. This was attainable because the output edge file from GME contained attributes for edge 1, edge 2, and edge (Both values combined; edge1_edge2). For example, urban edges for this project required "EDGE" values of $21 \_31$ or 24_52 rather than 21_22 or 52_42. Refer to Figure 4-6 above for land cover references. Figure 4-7 illustrates the output of this process. 


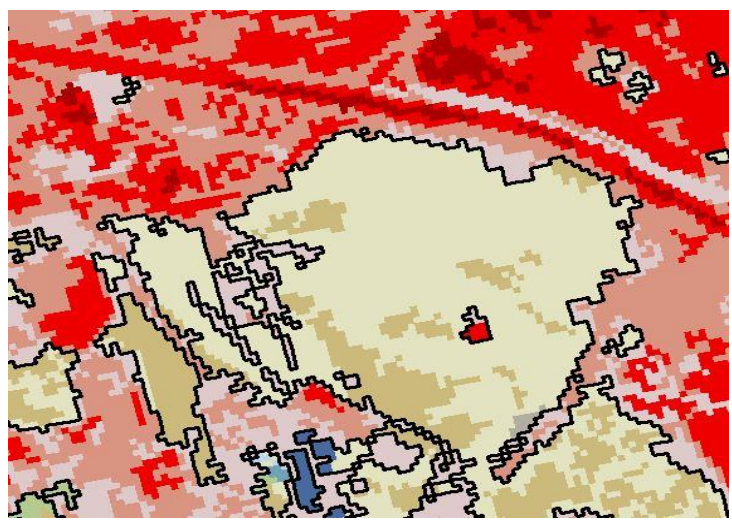

Figure 4-7: Urban edges within an area of Orange County. Note that developed areas (shades of red) are not separated by edge lines because they are not urban to natural transitions; this is also the case for natural areas.

\subsection{Summary}

A logical representation of the database is important to understand how the objects stored within are related and represented. To create this model, a simpler understanding of the needs and requirements of the system should be established. This is reflected in the conceptual model, where ideas are stated and illustrated in their most basic form. The data used for this project came from many different sources and required considerable manipulation for analysis preparation. Among these manipulations, temporal aspects were the most difficult to derive from the original dataset. This task was especially difficult for the radio-collared bobcats, where there were 12,543 records to consider. 



\section{Chapter 5 - Implementation}

Four analytical tools were developed for the client to help in her current and future bobcat research. These tools were designed to provide analytical measures of habitat characterization and bobcat interactions with critical habitat features. Bobcat habitat was characterized in terms of the density of habitat features within a defined study area. These habitat features included: roads, hydrography (flow lines and water bodies), land cover, and urban edges. Bobcat interactions were measured in terms of proximity to these habitat features. Elevation and derived slope were added to the analysis, but were added externally to the analytical tools. The design of he tools was to not only allow the client to analyze her bobcat data in its entirety, but to also provide analytical measures for specific bobcat attributes, or groups.

\subsection{Defining the Study Area}

A common approach for defining the study area for wildlife analysis is the Minimum Convex Polygon (MCP). MCPs are created by enclosing all outer points of a dataset by connecting them with lines to create a minimum bounding polygon. If the polygon contains all line segments for its points, then it is considered to be convex (Mohr, 1947). MCPs are also used to define home ranges for tracked individuals. Figure 5-1 shows the MCP study area for all radio-collared individuals and Figure 5-2 shows the MCP, or home range for an individual radio-collared bobcat.

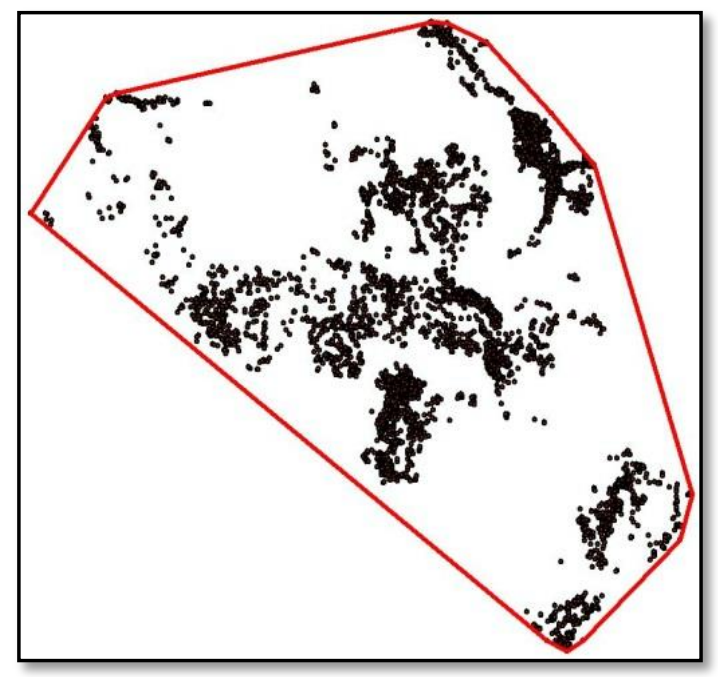

Figure 5-1: MCP for the Combined Home Ranges of Radio-collared Bobcats. 


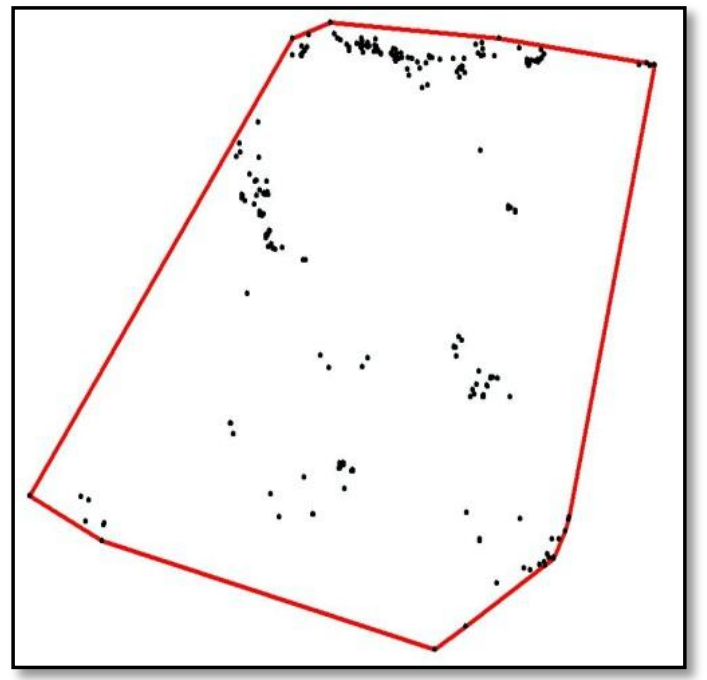

Figure 5-2: MCP for an individual Radio Collared Bobcat [BAB].

This task was accomplished by using the Minimum Bounding Geometry (MBG) tool in the ArcGIS data management toolbox, and was embedded within the delivered analytical tools. This tool takes input features with point, line, and polygon dimensions and offers more than one option for defining the study area. An optional Geometry Type field contains the main geometry of interest, the Convex Hull type, with the addition of four others. These include: Rectangle by Area, Rectangle by Width, Circle, and Envelope geometry types. The tool also has an optional Group Option field for creating polygons around features that have a specific attribute of interest. These attributes can be selected from a list under the parameter Group Field's. And finally, the tool has an option to check a box that adds geometries as attributes to the output. Figure 5-3 on the next page illustrates the overall interface of the tool and its optional parameters. 


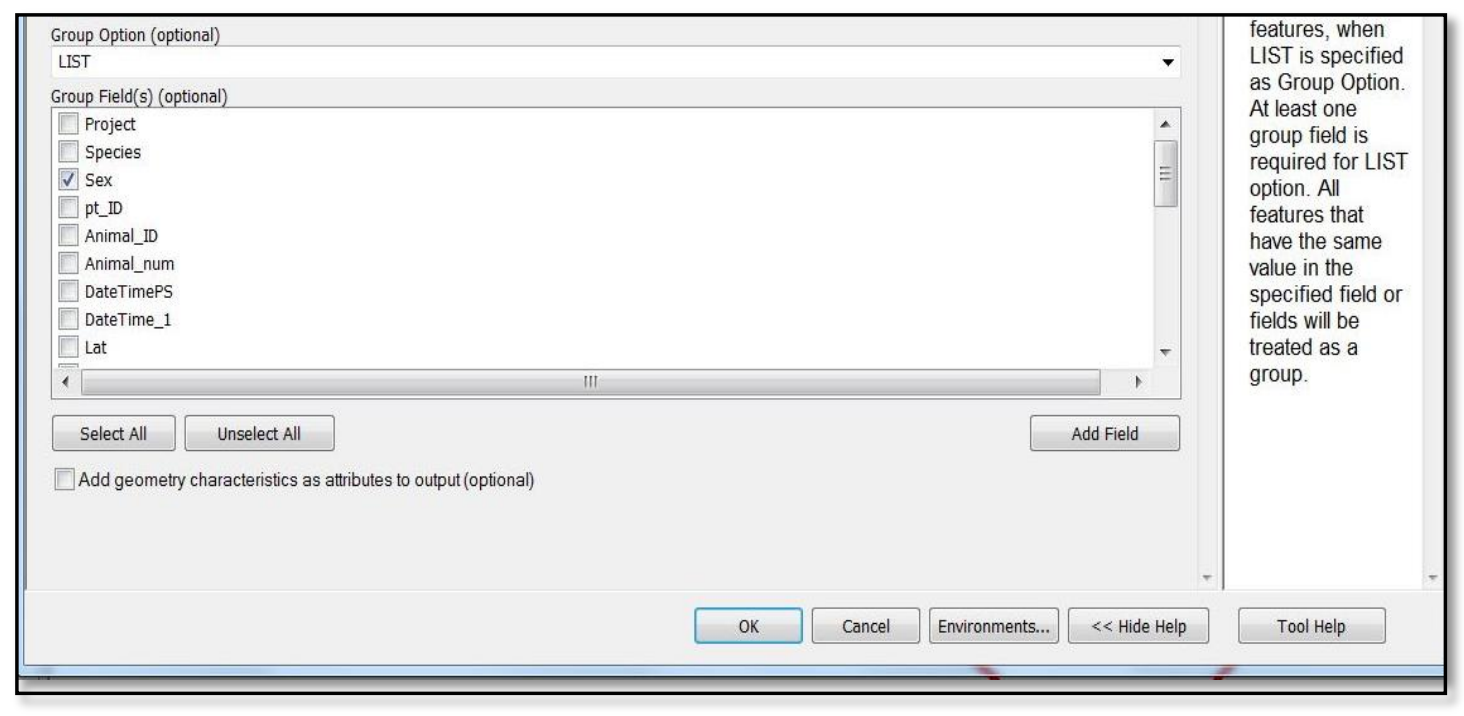

Figure 5-3: Minimum Bounding Geometry tool Group Option and Geometry Characteristics

\subsection{Design and Development}

ModelBuilder 10.1 was the platform used to develop the analytical tools for the client. The tools were designed according to the initial datasets acquired by the client, observed and radio-collared bobcats. The purpose was to create a set of analytical tools that could be used for the current and future accumulation of bobcat data. These tools were also designed to handle the analysis of different attributes contained in the bobcat datasets. Furthermore, tools were designed to handle different habitat feature datasets, all in effort to increase functionality and efficiency. In addition, this multi-functionality reduced the number of tools needed to produce the desired results and to avoid overwhelming a nonGIS expert. This section details the development of linear density tools in section 5.2.1, the development of the polygon density tools in section 5.2.2, the development of the proximity tool in section 5.2.3, and wraps up with the discussion of the bobcat interaction tool in section 5.2.4.

Three models were developed to analyze linear features in terms of their densities within the study area. Analyzing features such as roads, flow lines, and urban edges were combined in a single tool. The purpose of this model was to provide derived data from the analysis and tables from descriptive statistics. Also, these linear features were measured for their density and length densities within the study area. Density is measured by the total number of features divided by the study area and linear density is measured by the total length of the feature in the study area divided by the study area. Linear density indices' provide important information on the level of urbanization, and can provide an understanding of what is urban versus natural.

Another function of this tool provided a point density analysis with a raster output and a mean center point for input features. Polygon features such as land cover were 
developed as separate tools due to the definition of open/natural land cover types. This required the manipulation of the input polygon features by an attribute selection process, an attribute not inherent within the water body's dataset. Water bodies do not contain a land cover classification type so this was developed as a third tool. These tools also provided derived data from the analysis and tabular descriptive statistics. Also, these polygons were reported by their percent coverage in the study area. Within this tool was an embedded functionality to report bobcat locations coincident with a particular land cover.

\subsubsection{Linear Density Tool}

To accomplish the main goals of the linear density tool, the linear features had to intersect the defined minimum bounding polygon, or study area. To successfully achieve the density results of the linear input, the study boundary required a field to hold an area unit attribute. The Calculate Areas script in ArcGIS was used to create this field. The default area units were populated in square map units, so further tools were used to create and populate another field to hold the attribute in a different unit. The Add Field and Calculate Field in the Data Management toolbox were used to accomplish this task. A formula was used in the appropriate dialogue box for the conversion of previously added area units. An expression used in the Calculate Field tool was used to achieve the linear density analyses. A Python expression was used for converting the linear features length. The first area statistic for the MCP area field was used in the density calculations because it maintains the same value in all tuples. The study area was calculated in $\mathrm{Km}^{2}$.

At this point in the model, the updated study area polygon is now prepared for the intersection with the input linear features.

An intersection was used to maintain all of the attributes of the features involved in the model. In addition, part of the design was to produce a linear density raster surface, accomplished using the Line Density tool in the Spatial Analyst toolbox. A 30 meter cell size was used to stay consistent with the 30 meter land cover data. Square map units were set as a default and were not designed as an adjustable parameter. This raster surface was produced for geovisualization and analysis purposes. Although the linear features that were intersected to the study area inherently contained shape length, they needed to be converted to the proper units for density analysis.

This was accomplished using the same methods as the study area unit conversions, except that a Python expression was used for the conversion in the proper dialogue box within the Calculate Field tool. At this point in the model the two features, polygons and linear features, were ready for descriptive statistics and density analyses in tabular form. To achieve the density measures, descriptive statistics, including the sum of the shape length and the count of roads in the study area, were needed for calculations. Count of the OBJECTID divided by the area MCP was used to calculate the number of features within the study area. The sum of the shape length divided by the area MCP was used for calculating linear density. Other descriptive statistics included the Min, Max, and the Mean of shape length. The Add Field tool was used to create a field in the table to hold the linear density attributes and an expression was used within the Calculate Field tool to populate these attributes. This table was further updated using the methods previously mentioned to populate the length density attributes. Formulas 5-1 and 5-2 illustrate the 
field names and the formulas used for unit conversion. Figures 5.5 and 5.6 illustrate the formulas used to calculate the density index values.

$$
\begin{aligned}
& \text { Area_MCP }=\frac{\text { F_AREA } \mathrm{m} 2 * \mathrm{Km} 2}{1,000,000 \mathrm{~m} 2} \\
& \text { Line_Leng }=! \text { shape. length@kilometers! } \\
& \text { Line_Dens }=\frac{\text { COUNT of Features }}{\text { Study Area }} \\
& \text { Leng_Dens }=\frac{\text { Total Length of Features }}{\text { MAX_Area_MCP }}
\end{aligned}
$$

The complete workflow for the linear density tool is illustrated below in figure 5-4. Table 5-1 on the next page outlines the required and optional parameters in the user interface and states their description and data types.

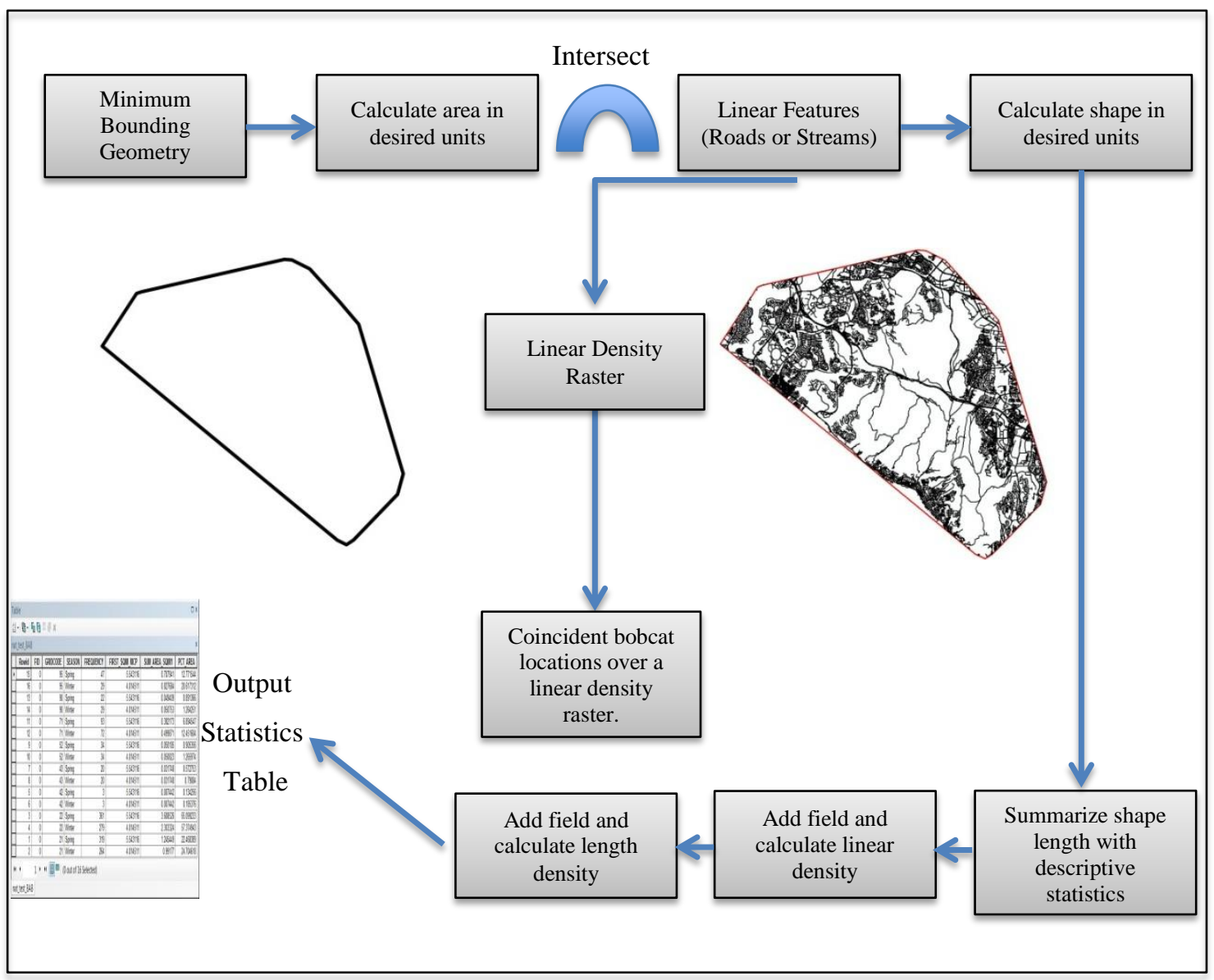

Figure 5-4: Workflow Describing the Major Tasks for Developing the Linear Density Tool. 
Table 5-1: $\quad$ Required and Optional Parameters for the linear density tool.

\begin{tabular}{|c|c|c|c|}
\hline Parameter/Tool & Description & Data Type & Type \\
\hline $\begin{array}{l}\text { Input Bobcat Feature } \\
\text { Layer }\end{array}$ & $\begin{array}{l}\text { Allows the user to input point data } \\
\text { of interest. }\end{array}$ & $\begin{array}{l}\text { Feature } \\
\text { Layer }\end{array}$ & Required \\
\hline Input Linear Features & $\begin{array}{l}\text { Allows the user to input polyline } \\
\text { features of interest. }\end{array}$ & $\begin{array}{l}\text { Feature } \\
\text { Layer }\end{array}$ & Required \\
\hline $\begin{array}{c}\text { Geometry Type } \\
\text { (Minimum Bounding } \\
\text { Geometry) }\end{array}$ & $\begin{array}{l}\text { Allows the user to select the } \\
\text { geometry type for the minimum } \\
\text { bounding polygon. Defaulted to } \\
\text { Convex Hull type. }\end{array}$ & String & Optional \\
\hline $\begin{array}{c}\text { Group Option } \\
\text { (Minimum Bounding } \\
\text { Geometry) }\end{array}$ & $\begin{array}{l}\text { Allows the user to define how the } \\
\text { input points will be grouped and } \\
\text { bound. If there is an attribute of } \\
\text { interest, it can be selected as a } \\
\text { group. Each group will be } \\
\text { enclosed by a bounding polygon. }\end{array}$ & String & Optional \\
\hline $\begin{array}{l}\text { Group Field(s) } \\
\text { (Minimum Bounding } \\
\text { Geometry) }\end{array}$ & $\begin{array}{l}\text { Allows the user to select from a } \\
\text { list of fields or attributes of } \\
\text { interest. }\end{array}$ & $\begin{array}{l}\text { Multiple } \\
\text { Value }\end{array}$ & Optional \\
\hline $\begin{array}{c}\text { Add geometry } \\
\text { characteristics as } \\
\text { attributes to output. } \\
\text { (Minimum Bounding } \\
\text { Geometry) }\end{array}$ & $\begin{array}{l}\text { Allows the user add geometry } \\
\text { fields to the output polygon } \\
\text { feature. These dimensions include } \\
\text { width, length, and orientation. }\end{array}$ & Boolean & Optional \\
\hline $\begin{array}{l}\text { Calculate Area for } \\
\text { MCP Polygon. } \\
\text { (Calculate Field(s)) }\end{array}$ & $\begin{array}{l}\text { Allows user to change the } \\
\text { conversion expression to obtain } \\
\text { the unit of interest. Defaulted to } \\
\text { square miles. }\end{array}$ & $\begin{array}{c}\text { SQL } \\
\text { Expression }\end{array}$ & Optional \\
\hline $\begin{array}{l}\text { Calculate Length for } \\
\text { Polyline Feature. } \\
\text { (Calculate Field(s)) }\end{array}$ & $\begin{array}{l}\text { Allows user to change the } \\
\text { conversion expression to obtain } \\
\text { the unit of interest. Defaulted to } \\
\text { miles. }\end{array}$ & $\begin{array}{c}\text { SQL } \\
\text { Expression }\end{array}$ & Optional \\
\hline
\end{tabular}




\begin{tabular}{|c|c|c|c|}
\hline $\begin{array}{l}\text { Statistics } \\
\text { Field(s) } \\
\text { (Summary } \\
\text { Statistics) }\end{array}$ & $\begin{array}{l}\text { Allows the user to select field(s) and } \\
\text { choose descriptive statistic types } \\
\text { including: } \\
\text { SUM: Adds all field values } \\
\text { MIN: Minimum field value } \\
\text { MAX: Maximum field value } \\
\text { MEAN: Calculates the values average } \\
\text { STD: Calculates the values standard } \\
\text { deviation } \\
\text { RANGE: Calculates the difference of } \\
\text { the minimum and maximum values } \\
\text { COUNT: Reports a count of the } \\
\text { number of values } \\
\text { FIRST: Reports the first record in the } \\
\text { given field table } \\
\text { LAST: Reports the last record in the } \\
\text { given field table }\end{array}$ & Value Table & Required \\
\hline $\begin{array}{l}\text { Case Field } \\
\text { (Summary } \\
\text { Statistics) }\end{array}$ & $\begin{array}{l}\text { Gives the user the option to select } \\
\text { attribute(s) of interest in the input table } \\
\text { of the field selected above. Provides } \\
\text { separate calculated statistics for each } \\
\text { attribute selected. }\end{array}$ & Multiple Value & Optional \\
\hline $\begin{array}{l}\text { Feature } \\
\text { Outputs }\end{array}$ & $\begin{array}{l}\text { Mean Center for the input feature layer. } \\
\text { MCP with added area unit field. } \\
\text { Linear intersect output with added area } \\
\text { field. } \\
\text { Linear statistics table. }\end{array}$ & $\begin{array}{l}\text { Feature Class } \\
\text { Feature Class } \\
\text { Feature Class } \\
\text { Table }\end{array}$ & Required \\
\hline
\end{tabular}

Further functionality within this tool provides mean center points for input point features and study area polygons. This was accomplished using the Mean Center tool under Spatial Statistics toolbox. An example of this output, along with the linear density is illustrated in Figures 5-5 and 5-6 on the next page. 


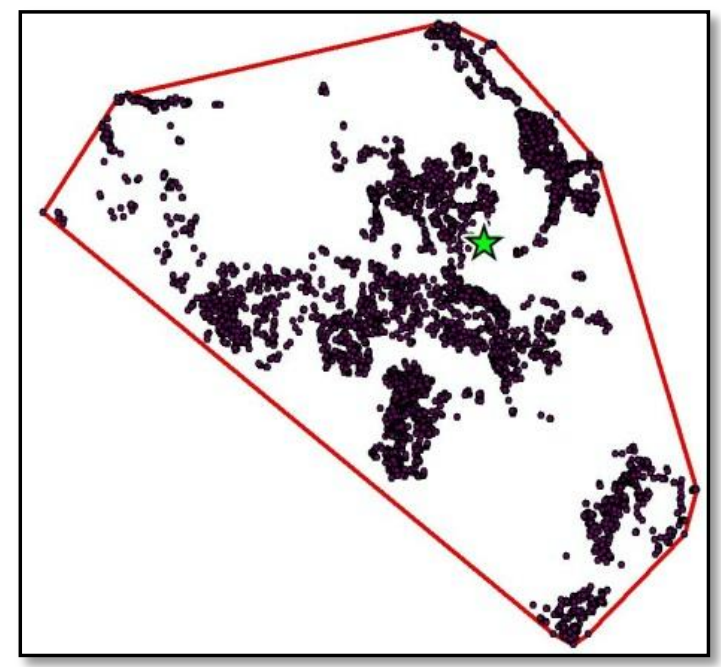

Figure 5-5: The Mean Center for the radio-collared bobcats.

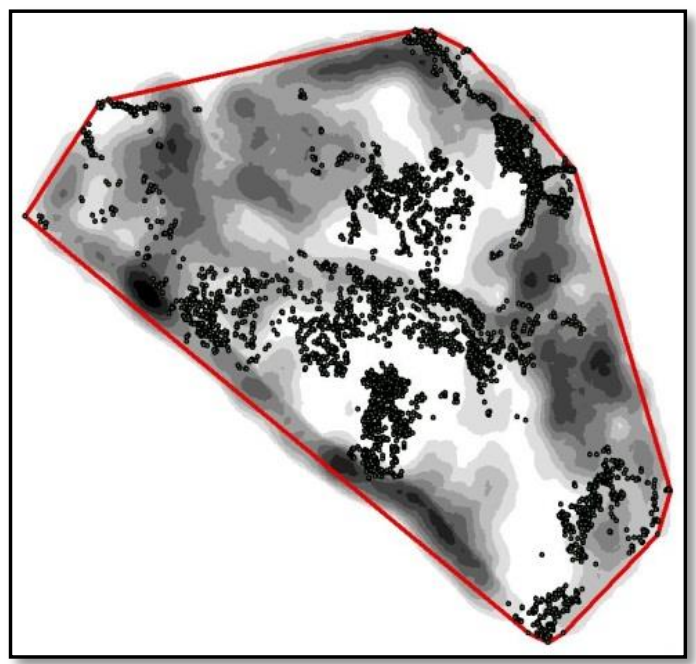

Figure 5-6: Linear Density (OC Roads) within the study area. This figure also illustrates coincident bobcat locations, which are summarized in a statistics table. 


\subsubsection{Polygon Density Tools}

Two tools were developed to handle polygon density analyses, one designed for land cover classifications and one for other polygon features, water bodies for this project. In developing the polygon density tools, the polygon features had to be intersected with the defined study area, as in the linear density model. The study area polygon was prepared as described earlier, with the MBG tool and using the Calculate Areas script tool to maintain area geometry after intersection. Once prepared with the area units, an intersection with polygon features was the next task. Two models were developed to handle polygon features. The first polygon density tool was designed to consume land cover polygon features. Because the converted land cover polygon features used for this tool do not contain a shape area field, the Calculate Areas script had to be applied to populate this field. The model was designed to provide density measures for open/natural land cover polygons, with the option to change the definition of what is open/natural. The Select tool was used to create an output following this definition. At this point, the model was designed for desired area unit conversion using Add and Calculate Field tools.

The Summary Statistics tool was then used to provide the same (tabular) descriptive statistics as in the linear density tool but with different fields. Square kilometers were used for area units. The most important field in the output table is the percent coverage of each land cover type, a value representing the proportion of the total study area covered by a particular land cover, generated for each land cover class (Formula 5-5). The database units are in meters therefore it was necessary to convert database areal units to square kilometers for the study area (Formula 5-6) and each feature (Formula 5-7).

$$
\begin{aligned}
& \text { PCT_Area }=\frac{\sum \text { Polygon Area }}{\text { Study Area }} * 100 \\
& \text { Area_MCP }=\frac{\text { F_AREA } 2 * \mathrm{~km} 2}{1,000,000 \mathrm{~m} 2} \\
& \text { Unit_Area }=\frac{\text { F_AREA } 2 * \mathrm{~km} 2}{1,000,000 \mathrm{~m} 2}
\end{aligned}
$$

This same process was applied to the branch of the model providing results for all land cover types with the exception of the selection process. In addition, this method was also used for the water body density tool, excluding the selection branch, as water bodies do not have land cover attributes and no need for considering attribute selection. Figure 5-7 illustrates the workflow of these models. 


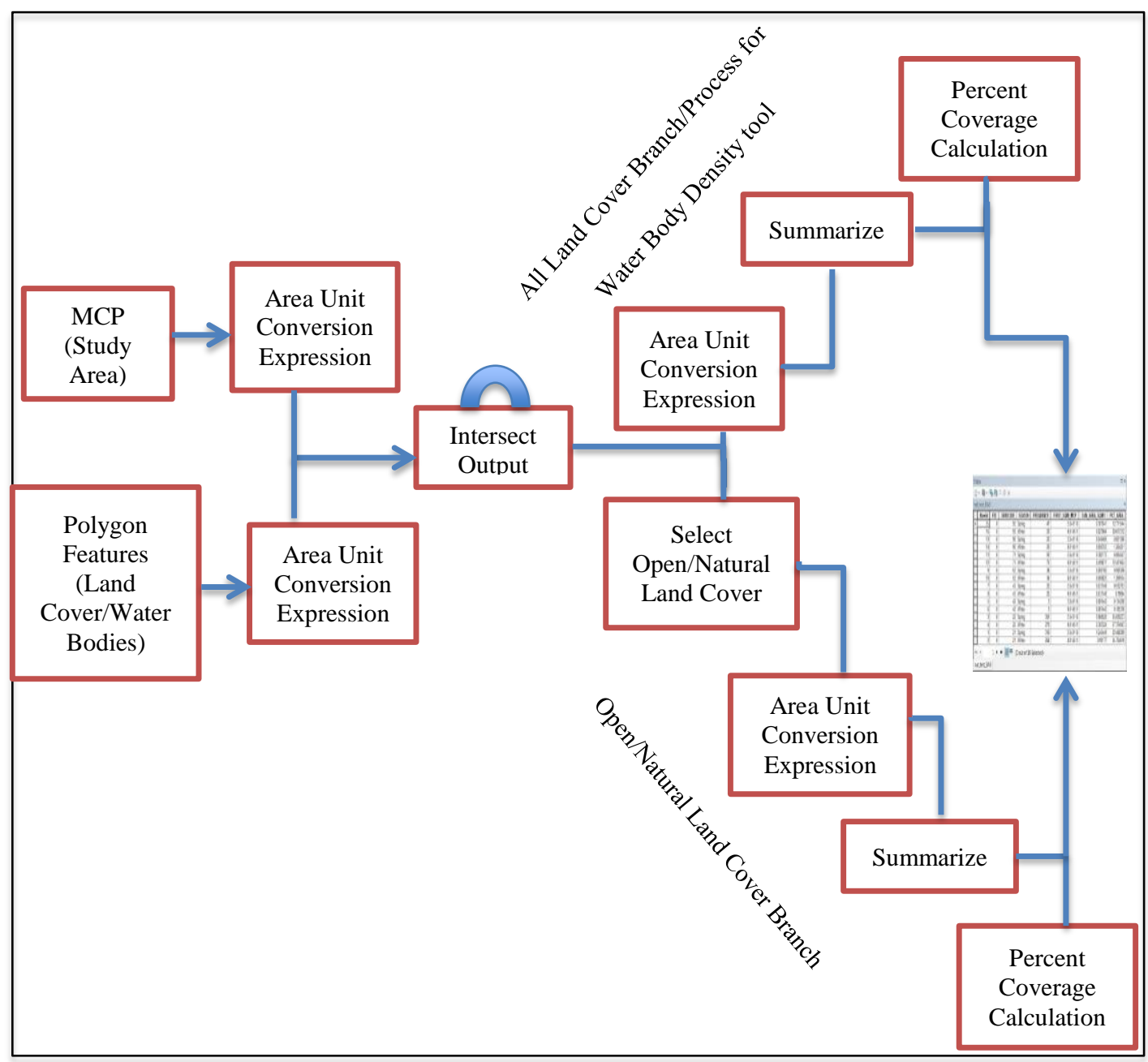

Figure 5-7: Development Workflow for the Polygon Density Tool.

Table 5-2 on the next few pages outlines the required and optional parameters and provides a brief description and the data types used in the model. It is important to note here that this user interface applies to the other polygon density model, omitting the parameters that refer to the open/natural definition. 
Table 5-2: $\quad$ Required and optional parameters for the polygon density models. Applies to the water body density model as well, omit open/natural land cover parameters.

\begin{tabular}{|c|c|c|c|}
\hline Parameter/Tool & Description & Data Type & Type \\
\hline $\begin{array}{l}\text { Input Land } \\
\text { Cover Features }\end{array}$ & $\begin{array}{l}\text { Allows the user to input the landcover data of } \\
\text { interest. }\end{array}$ & $\begin{array}{l}\text { Feature } \\
\text { Layer }\end{array}$ & Required \\
\hline $\begin{array}{l}\text { Input Bobcat } \\
\text { Data Features }\end{array}$ & $\begin{array}{l}\text { Allows the user to input bobcat data of } \\
\text { interest. }\end{array}$ & $\begin{array}{l}\text { Feature } \\
\text { Layer }\end{array}$ & Required \\
\hline $\begin{array}{l}\text { Study Area } \\
\text { Geometry Type } \\
\text { (Minimum } \\
\text { Bounding } \\
\text { Geometry) }\end{array}$ & $\begin{array}{l}\text { Allows the user to select the geometry type } \\
\text { for the minimum bounding polygon. Defaulted } \\
\text { to Convex Hull type. }\end{array}$ & String & Optional \\
\hline $\begin{array}{l}\text { Group Option } \\
\text { (Minimum } \\
\text { Bounding } \\
\text { Geometry) }\end{array}$ & $\begin{array}{l}\text { Allows the user to define how the input points } \\
\text { will be grouped and bound. If there is an } \\
\text { attribute of interest, it can be selected as a } \\
\text { group. Each group will be enclosed by a } \\
\text { bounding polygon. Defaulted to ALL values. }\end{array}$ & String & Optional \\
\hline $\begin{array}{l}\text { Group Field(s) } \\
\text { (Minimum } \\
\text { Bounding } \\
\text { Geometry) }\end{array}$ & $\begin{array}{l}\text { Allows the user to select from a list of fields or } \\
\text { attributes of interest from input bobcat data. }\end{array}$ & $\begin{array}{l}\text { Multiple } \\
\text { Value }\end{array}$ & Optional \\
\hline $\begin{array}{c}\text { Add geometry } \\
\text { characteristics } \\
\text { as attributes to } \\
\text { output. } \\
\text { (Minimum } \\
\text { Bounding } \\
\text { Geometry) }\end{array}$ & $\begin{array}{l}\text { Allows the user add geometry fields to the } \\
\text { output polygon feature. These dimensions } \\
\text { include width, length, and orientation. }\end{array}$ & Boolean & Optional \\
\hline $\begin{array}{l}\text { Calculate Area } \\
\text { of MCP } \\
\text { (Calculate Field) }\end{array}$ & $\begin{array}{l}\text { Allows user to change the conversion } \\
\text { expression to obtain the unit of interest. } \\
\text { Defaulted to square miles. }\end{array}$ & $\begin{array}{c}\text { SQL } \\
\text { Expression }\end{array}$ & Optional \\
\hline $\begin{array}{l}\text { Calculate Area } \\
\text { of All Land } \\
\text { Cover Features. } \\
\text { (Calculate Field) }\end{array}$ & $\begin{array}{c}\text { Allows user to change the conversion } \\
\text { expression to obtain the unit of interest. } \\
\text { Defaulted to miles. }\end{array}$ & $\begin{array}{c}\text { SQL } \\
\text { Expression }\end{array}$ & Optional \\
\hline
\end{tabular}




\begin{tabular}{|c|c|c|c|}
\hline $\begin{array}{l}\text { Select Land Cover } \\
\text { (Select) }\end{array}$ & $\begin{array}{l}\text { Allows the user to change the expression } \\
\text { to select different land cover types. }\end{array}$ & $\begin{array}{c}\text { SQL } \\
\text { Expression }\end{array}$ & Optional \\
\hline $\begin{array}{l}\text { Calculate Area } \\
\text { (Natural Landcover } \\
\text { Features) (Calculate } \\
\text { Field) }\end{array}$ & $\begin{array}{l}\text { Allows user to change the conversion } \\
\text { expression to obtain the unit of interest. } \\
\text { Defaulted to miles. }\end{array}$ & $\begin{array}{c}\text { SQL } \\
\text { Expression }\end{array}$ & Optional \\
\hline $\begin{array}{l}\text { Statistics Field(s) for } \\
\text { Open/Natural Land } \\
\text { Cover and All Land } \\
\text { cover types } \\
\text { (Summary Statistics) }\end{array}$ & $\begin{array}{l}\text { Allows the user to select field(s) and } \\
\text { choose descriptive statistic types } \\
\text { including: } \\
\text { SUM: Adds all field values } \\
\text { MIN: Minimum field value } \\
\text { MAX: Maximum field value } \\
\text { MEAN: Calculates the values average } \\
\text { STD: Calculates the values standard } \\
\text { deviation } \\
\text { RANGE: Calculates the difference of the } \\
\text { minimum and maximum values } \\
\text { COUNT: Reports a count of the number of } \\
\text { values } \\
\text { FIRST: Reports the first record in the } \\
\text { given field table } \\
\text { LAST: Reports the last record in the given } \\
\text { field table }\end{array}$ & Value Table & Required \\
\hline $\begin{array}{l}\text { Case Field (Summary } \\
\text { Statistics) }\end{array}$ & $\begin{array}{l}\text { Gives the user the option to select an } \\
\text { attribute of interest in the input table of } \\
\text { the field selected above. Provides } \\
\text { separate calculated statistics for each } \\
\text { attribute selected. }\end{array}$ & $\begin{array}{l}\text { Multiple } \\
\text { Value }\end{array}$ & Optional \\
\hline $\begin{array}{l}\text { Output Table for } \\
\text { Open/Natural Land } \\
\text { Cover }\end{array}$ & $\begin{array}{l}\text { Descriptive statistics and percent land } \\
\text { cover within study area polygons. }\end{array}$ & Table & Required \\
\hline $\begin{array}{l}\text { Output Table for All } \\
\text { Land Cover }\end{array}$ & $\begin{array}{l}\text { Descriptive statistics and percent land } \\
\text { cover within study area polygons. }\end{array}$ & Table & Required \\
\hline Outputs & $\begin{array}{c}\text { All Land Cover Intersect. } \\
\text { Open/Natural Intersect. } \\
\text { Bobcat locations/land cover intersect. }\end{array}$ & $\begin{array}{l}\text { Feature Class } \\
\text { Feature Class } \\
\text { Feature Class }\end{array}$ & Required \\
\hline
\end{tabular}


Further functionalities included the generation of a point density raster surface using the Point Density tool in the Spatial Analyst toolbox. This tool was embedded within the land cover density model. The raster is designed to be created at a 30 meter resolution for consistency with the land cover data and is illustrated in Figure 5-8. Another added functionality was summarizing coincident bobcat locations with the land cover type using the intersect tool. This is illustrated in Figure 5-9.

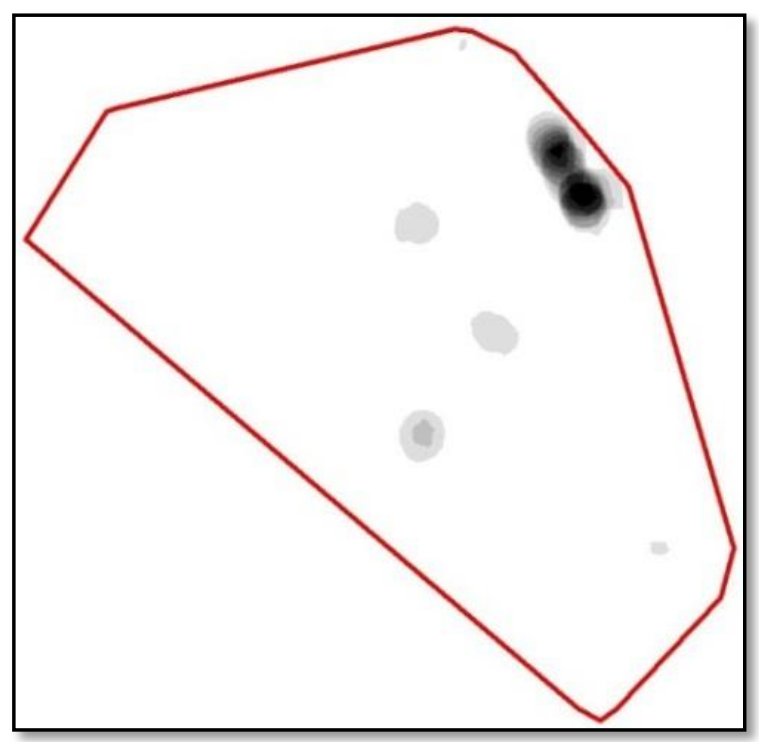

Figure 5-8: Point Density raster surface for all radio-collared bobcats.

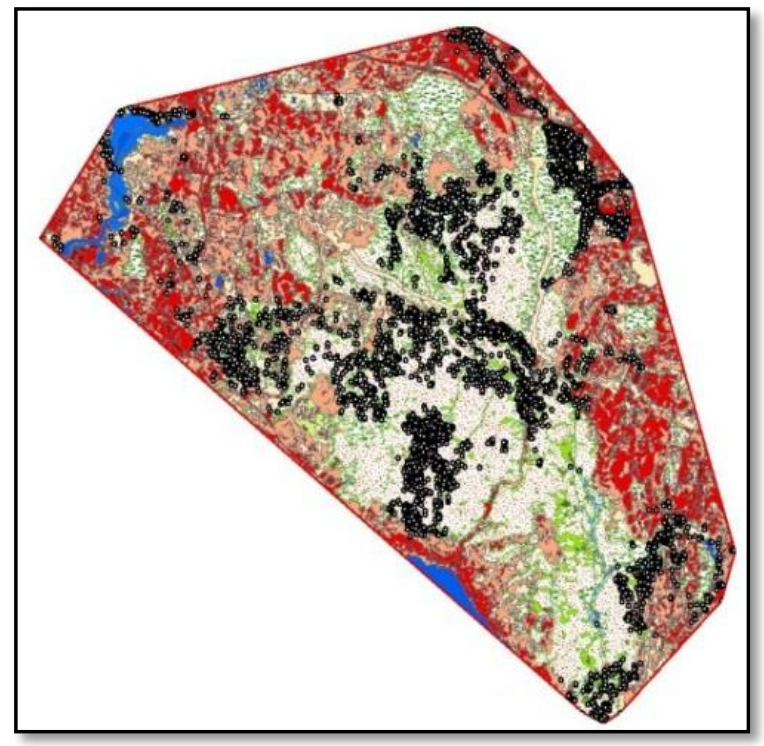

Figure 5-9: Coincident bobcat land-cover. 


\subsubsection{Proximity Analysis Tools}

The proximity analysis tool was designed to analyze how bobcats interact with critical urban features. As mentioned earlier, urban features include: roads, hydrography (streams and water bodies), landcover, and urban edges. These interactions are measured by how close bobcats are to these features, or more precisely their proximity to them. The Near Features tool located in the ArcGIS Analysis toolbox was used to measure proximity to all urban variables. This tool calculates the distance of the input features to the defined features of interest and generates field in the input features table to store the values. All features can be point, line, or polygon. Although the Generate Near Table tool could have been used for an output result, this generated table does not contain valuable descriptive statistics. Instead, the Summary Statistics tool was used for a better description of the near values. The Min, Max, Mean, and Range statistics were used as parameter defaults for analysis results.

Only one tool was created for all proximity analyses because there were no particular calculations that needed to be considered for linear or polygon features, just distances to them. However, for the desired fields to be populated for statistical analysis, the Near Features Tool needed to be saved as a separate model and embedded within another model using the Summary Statistics tool. Once the inputs and single output of the near features model were set as parameters, the precondition of the near model needed to be set, and the desired NEAR_DIST fields were recognized in the statistics field(s) parameter of the tool. Otherwise, the fields were not recognized, even if if the "Output Near Features" was set as a precondition within the Near Analysis Tool. The work flow for this tool is illustrated in Figure 5-10 below and the user interface design and parameters are outlined in Table 5-3 on the next page.

\section{Proximity Statistics Tool}

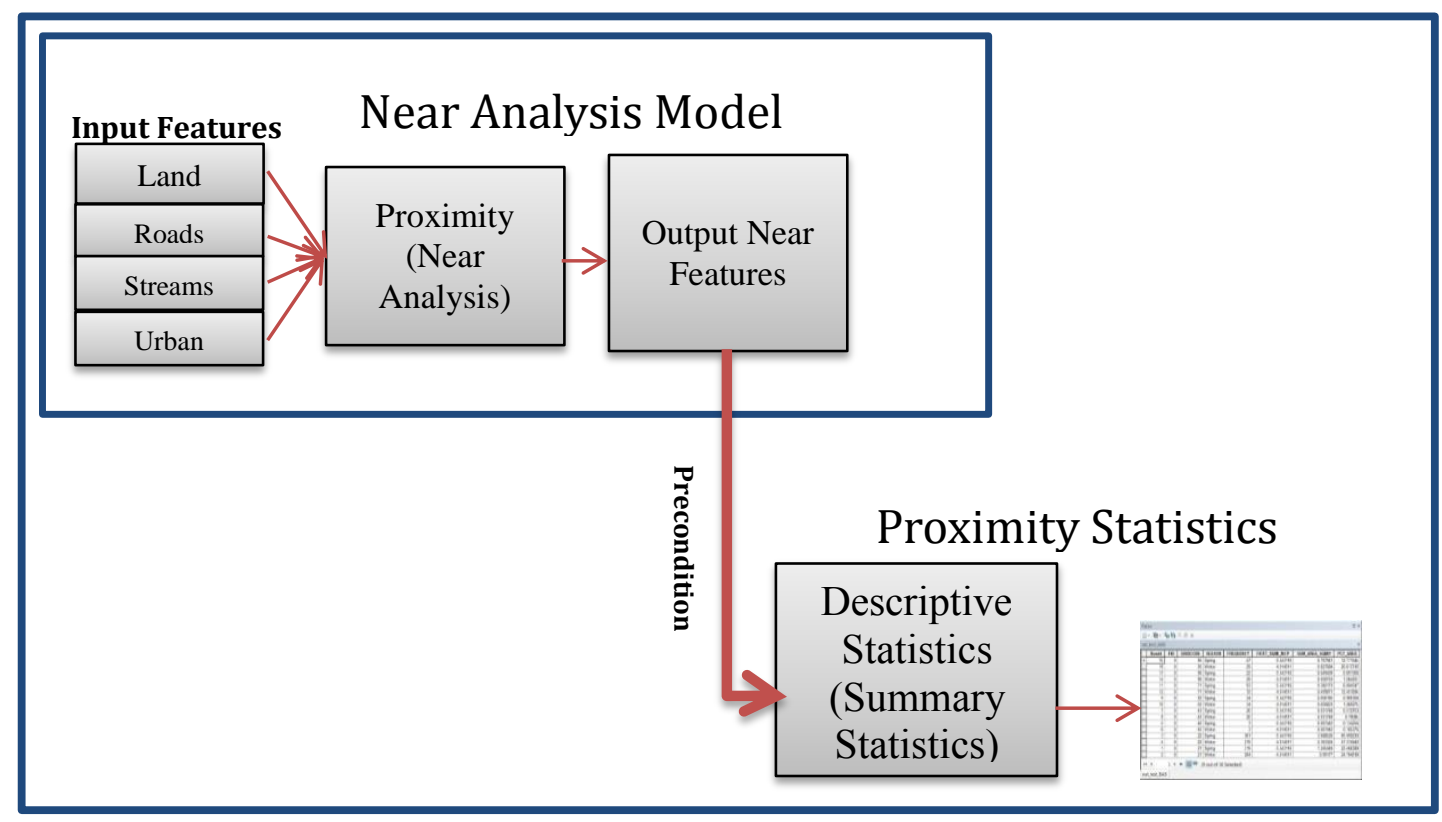

Figure 5-10: Development workflow for the Proximity Analysis Tool. 
Table 5-3: Development workflow for the Proximity Analysis Tool.

\begin{tabular}{|c|c|c|c|}
\hline Parameter/Tool & Description & Data Type & Type \\
\hline $\begin{array}{l}\text { Input Bobcat } \\
\text { Features }\end{array}$ & $\begin{array}{c}\text { Allows the user to input bobcat data of } \\
\text { interest. }\end{array}$ & $\begin{array}{l}\text { Feature } \\
\text { Class }\end{array}$ & Required \\
\hline $\begin{array}{l}\text { Input Near } \\
\text { Features }\end{array}$ & $\begin{array}{l}\text { Allows the user to enter the near features } \\
\text { of interest. }\end{array}$ & $\begin{array}{l}\text { Feature } \\
\text { Class }\end{array}$ & Optional \\
\hline $\begin{array}{l}\text { Search Radius } \\
\text { (Near) }\end{array}$ & $\begin{array}{l}\text { Allows the user to specify a search radius } \\
\text { to find candidate near features }\end{array}$ & Linear Unit & Optional \\
\hline $\begin{array}{c}\text { Statistics } \\
\text { Field(s) for } \\
\text { Proximity } \\
\text { Results } \\
\text { (Summary } \\
\text { Statistics - FID) }\end{array}$ & $\begin{array}{l}\text { Allows the user to select field(s) and } \\
\text { choose descriptive statistic types } \\
\text { including: } \\
\text { SUM: Adds all field values } \\
\text { MIN: Minimum field value } \\
\text { MAX: Maximum field value } \\
\text { MEAN: Calculates the values average } \\
\text { STD: Calculates the values standard } \\
\text { deviation } \\
\text { RANGE: Calculates the difference of the } \\
\text { minimum and maximum values } \\
\text { COUNT: Reports a count of the number } \\
\text { of values } \\
\text { FIRST: Reports the first record in the } \\
\text { given field table } \\
\text { LAST: Reports the last record in the } \\
\text { given field table }\end{array}$ & Value Table & Required \\
\hline $\begin{array}{l}\text { Case Field } \\
\text { (Summary } \\
\text { Statistics- } \\
\text { EDGE) }\end{array}$ & $\begin{array}{l}\text { Gives the user the option to select an } \\
\text { attribute of interest in the input table of } \\
\text { the field selected above. Provides separate } \\
\text { calculated statistics for each attribute } \\
\text { selected. }\end{array}$ & $\begin{array}{l}\text { Multiple } \\
\text { Value }\end{array}$ & Optional \\
\hline Outputs & $\begin{array}{l}\text { Proximity Statistics } \\
\text { Feature w/ Near Table }\end{array}$ & $\begin{array}{c}\text { Table } \\
\text { Feature } \\
\text { Class }\end{array}$ & Required \\
\hline
\end{tabular}




\subsection{Other Deliverables}

Some deliverables used tools not packaged within the main toolset. Statistics described for raster datasets and a predicted bobcat urban interaction raster were the other deliverables provided to the client. The raster datasets used were elevation, slope, and land cover. Descriptive statistics including the mean, majority, maximum, median, minimum, minority, range, standard deviation, sum, variety were reported. The Zonal Statistics as Table tool in the Spatial Analyst toolbox was used to generate these statistics. This tool summarizes raster values within defined zones of another feature or raster dataset, and reports them to a table. Using a unique identifier for an input zone ID, all values upon coincident with the value raster will be reported with these statistics, to be compared with the intersect product of the tool. In addition, these statistics were calculated for individuals, sex, and season. Dens/possible dens and time comments were reported for the observation dataset. If zone inputs are not raster datasets, an internal vector to raster conversion will be applied to it. A point to raster conversion was not created and used as a zone field because the dataset contains only a value attribute, thus eliminating the use of other important zone considerations, or attributes. Bobcat point features were used for the input zone field.

A predicted urban interaction raster was generated considering the proximity results to the five habitat variables. The datasets for these variables were intersected to the Orange County boundary and were used in Euclidean Distance raster generations. Each cell in this output raster contains the distance value to the input feature. The Reclassify tool was used to define value ranges and to create new class values. These new class values were reclassified as a rank of favorable bobcat proximity, with a value of one being the most favorable. Rankings were defined by creating a histogram of near distances in Microsoft Excel, and examining frequencies of observations. All reclassified variables were then combined together, to produce a raster that displays the intersection of the defined values. This was done with the Raster Calculator tool in the Spatial Analyst toolbox which allows you to make and execute map algebraic expressions using raster datasets.

\subsection{Functionalities}

The Group Option and Case Field parameters offer the capabilities of analyzing input data based on attributes of interest, rather than just in their entirety. These parameters offer a quick and easy way to do such an analysis. Otherwise, input data would have to be selected and exported manually prior to adding them as inputs in the tools. The Group Option, a parameter of the MBG tool, allows the user to select multiple group fields around which to draw bounding polygons. For example, the radio-collared bobcat dataset contains an animal ID field corresponding to a unique identifier for each individually tracked bobcat. There were 17 collared bobcats so selecting the LIST option from the Group Option parameter and choosing the animal ID attribute from the Group Field(s) parameter should yield 17 different bounding polygons, or home range boundaries. Furthermore, multiple attributes can be selected for drawing the bounding polygons. If animal ID and sex are selected from the Group Field(s) parameter, the resulting polygon's output table will be updated with the sex of each 17 animals. If an attribute is 
selected that does not correspond to a one to one relationship, the output polygons will multiply by the number of relationships the attribute has with another attribute.

The Case Field, a parameter of the Summary Statistics tool also allows the user to select from a list of attributes. In addition to the capability of being able to select multiple fields and statistical types under the Statistics Field(s) parameter, these statistical types can be calculated separately for each unique attribute selected under the Case Field. For example, if the shape area of a bounding polygon and shape length of the streams intersected with the polygon are selected as statistical fields, along with their statistical types, and animal ID is selected as the Case Field attribute, the resulting table will contain the specified statistics regarding shape area and length for each individual collared bobcat's home range. Additional fields of interest for the radio-collared bobcat dataset include: year, season, illumination (day or night), am/pm, and fix type (number of satellites available for tracking). Additional fields of interest for the citizen observation bobcat dataset include: notes_eb (dens or possible dens), year, season, time comments (day or night), and am/pm. Roads can also be summarized by road type and the number of lanes. Streams can be summarized by f type (perennial, intermittent), and water bodies by depth, area, or f type. 



\section{Chapter 6 - Results and Analysis}

The purpose of this project was to provide a set of analytical tools to a research ecologist. These tools were developed to aid in the analysis of bobcats for the client's current and future research. The tools were developed to analyze bobcats in the context of urban and natural features. Roads, hydrography (water bodies and streams), land cover, and urban edges were considered to be critical habitat features for analysis. Density and proximity to these features were considered by habitat characterization and interaction respectively. For this chapter, results from executing the tools are discussed for all radio-collared bobcats, individuals, and all observations. The tools errors and efficiencies are also discussed.

The individuals were added not only because the results were part of the original deliverables, but served to test important functionalities of optional Group and Case Fields. In addition, the tools were tested with the complete bobcat observation (sightings) dataset. Results for radio-collared bobcats are detailed in section 6.1, bobcat sightings are detailed in section 6.2, zonal statistics are detailed in section 6.3, the urban interaction surface is detailed in section 6.4, and the chapter is concluded with the discussion of errors and efficiency in section 6.5 .

\subsection{Radio-Collared Bobcat Results}

This section details a testing scenario of two different tool aspects: (1) for all bobcats and (2) for individual considerations. Individuals were included to test the tool's capability of handling analytics with grouping attributes. Although only one attribute, animal ID, is considered for this project, it served as a working example for the use of other important attributes. Testing scenarios and results for sex and seasonal attributes were included in the geodatabase but were not discussed in this project.

\subsubsection{Linear Density Analysis}

The linear density analysis tool was run for the entire dataset considering the densities of roads, streams, and urban edges. The tool was executed six different times to achieve results, considering two different scenarios and three habitat features. The purpose was to summarize these features by measuring density; the number of features in the study area polygon divided by its total area, and linear density, the total length of features in the study area polygon divided by its total area. Considering roads, not only can this indicate the level of urbanization within a defined study area, but can also be used to identify individuals who may become victims of road kill.

Road count density can indicate the proportion of residential development, where high density values may be reflected by a large number of small streets. Linear road density may indicate the presence of major roadways, which may extend throughout an entire study area polygon. In addition, these results could be used to gain a better understanding of the level of road densities, count and linear, that an individual can tolerate. They may either adapt to the development increase or change their movement patterns, yielding a new home range boundary. The density of flow lines, particularly streams, is important throughout the bobcat's home range, especially when there are no 
other water sources nearby. The length of linear water features can lead to a better understanding of network feature drainage and the amount of water available. Urban edge density can lead to a better understanding of the level of fragmentation in an area. Variations in linear edge densities can be explained by the sizes of land cover polygons. Home ranges with large areas of natural land cover would produce higher linear edge densities. Areas with large amounts of fragmented landcover patches would produce larger count densities. The intersected study area features are illustrated in Figures 6-1 and 6-2.
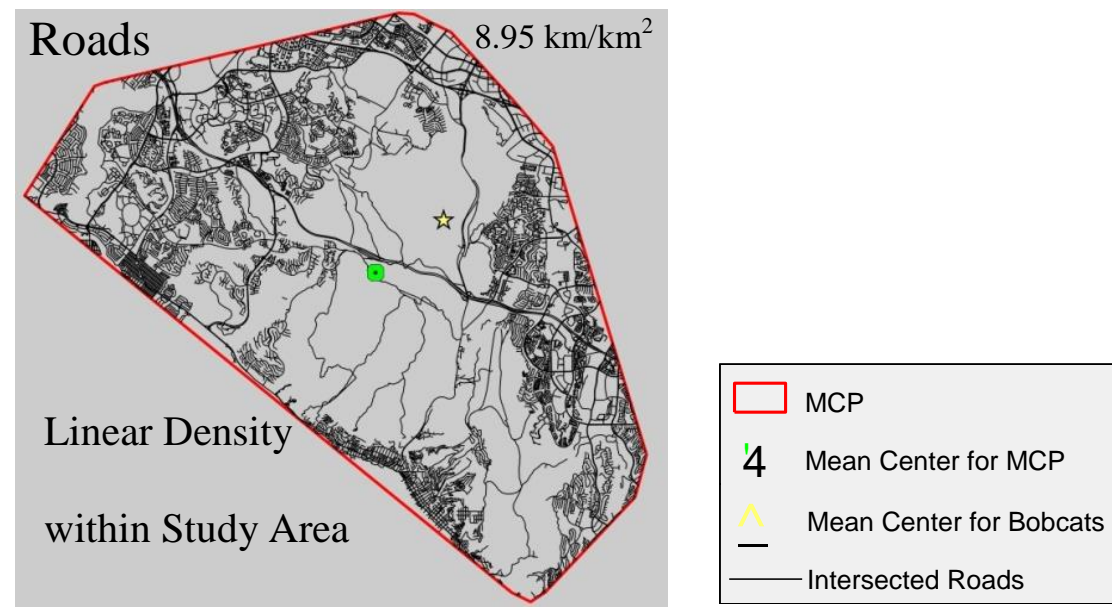

Figure 6-1: Intersected linear feature output (Roads).
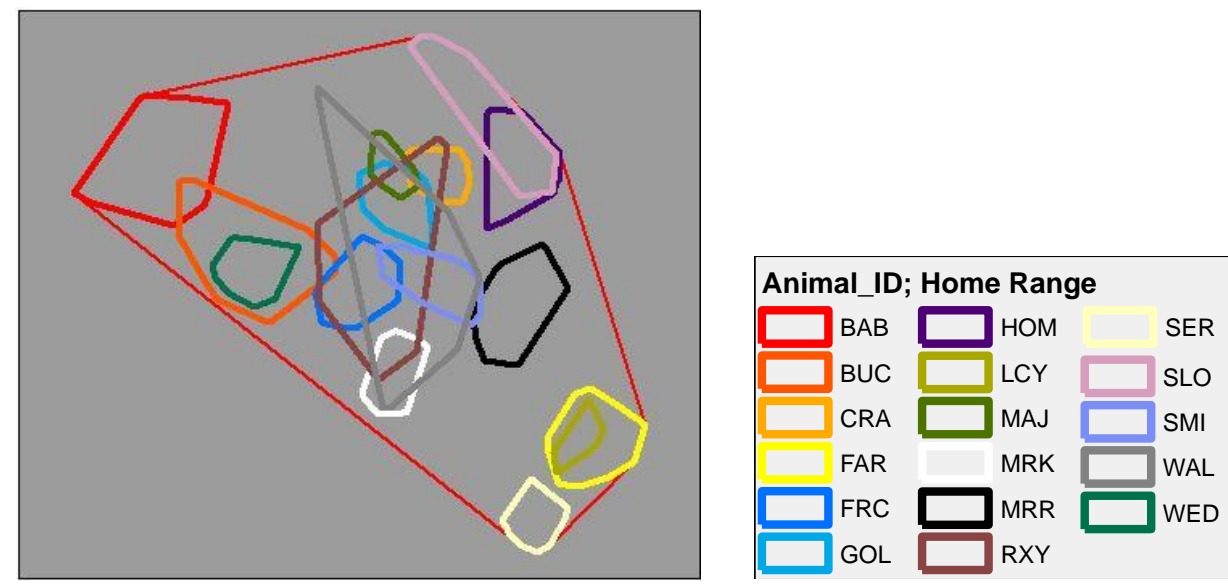

Figure 6-2: Home range polygons (MCP's) generated for 17 individual radiocollared bobcats.

Tabular results for linear features are outlined on the next page in Table 6-1 for all radio-collared bobcats. Linear density results are based on three habitat features: roads, flow lines, and urban edges. 


\section{Table 6-1: $\quad$ Linear density results for three habitat features.}

\begin{tabular}{|c|c|c|c|c|c|c|c|c|}
\hline Feature & Count & Mean & Min & Max & $\begin{array}{c}\text { Total } \\
\text { Linear } \\
\text { Length }\end{array}$ & $\begin{array}{c}\text { MCP } \\
\text { Area } \\
\left(\mathbf{K m}^{2}\right)\end{array}$ & $\begin{array}{c}\text { Linear } \\
\text { Feature } \\
\text { Density }\end{array}$ & $\begin{array}{c}\text { Length } \\
\text { Network } \\
\text { Density } \\
\left(\mathbf{K m} / \mathbf{K m}^{2}\right)\end{array}$ \\
\hline Roads & 6,819 & 0.27 & $1.11 * 10^{-3}$ & 18.15 & 1853.60 & 207.19 & 32.91 & 8.95 \\
\hline Flow lines & 414 & 0.88 & 0.01 & 207.19 & 336.73 & 207.19 & 2.00 & 1.63 \\
\hline $\begin{array}{c}\text { Urban } \\
\text { Edges }\end{array}$ & 32,592 & 0.03 & $2.17 * 10^{-3}$ & 0.03 & 975.10 & 207.19 & 157.31 & 4.71 \\
\hline
\end{tabular}

Using the animal ID field, results for individuals were calculated using the tool's grouping and case options. For land cover results, descriptive statistics and percent coverage were summarized by gridcode to provide the percent coverage for each land cover classification within each animal's home range. Two individuals with relatively similar habitat characteristics and two individuals with completely different habitat characteristics were analyzed in further detail. BAB and BUC are two individuals not only with similar linear feature densities, but have nearly the same size home ranges with a $6.5 \%$ overlap. FAR has a significantly smaller home range boundary and contains a significantly higher road density than the other three individuals, possibly indicating a higher interaction with urban features. MRR's home range boundary contains more major road types, such as highways and primary roads, which yields a higher linear density. The southern portion of MRR's home range is lacking of roads, although there are a few long country roads that contribute to a higher linear density. Two particular patterns can be observed for road density. One group, which has a similar home range boundaries and density values and the other group, which has a similar home range boundary, but higher road density values. One can speculate that the home ranges for these individuals contain areas of dense residential road networks and businesses that contain lots of small road segments, and fewer highways than the first group. Figures 6-3, 6-4, and 6-5 illustrate the geographies of the four individuals. Although BAB's home range has a lower density of stream networks, it contains a very high percentage of water bodies, mainly the Upper Newport Bay. 


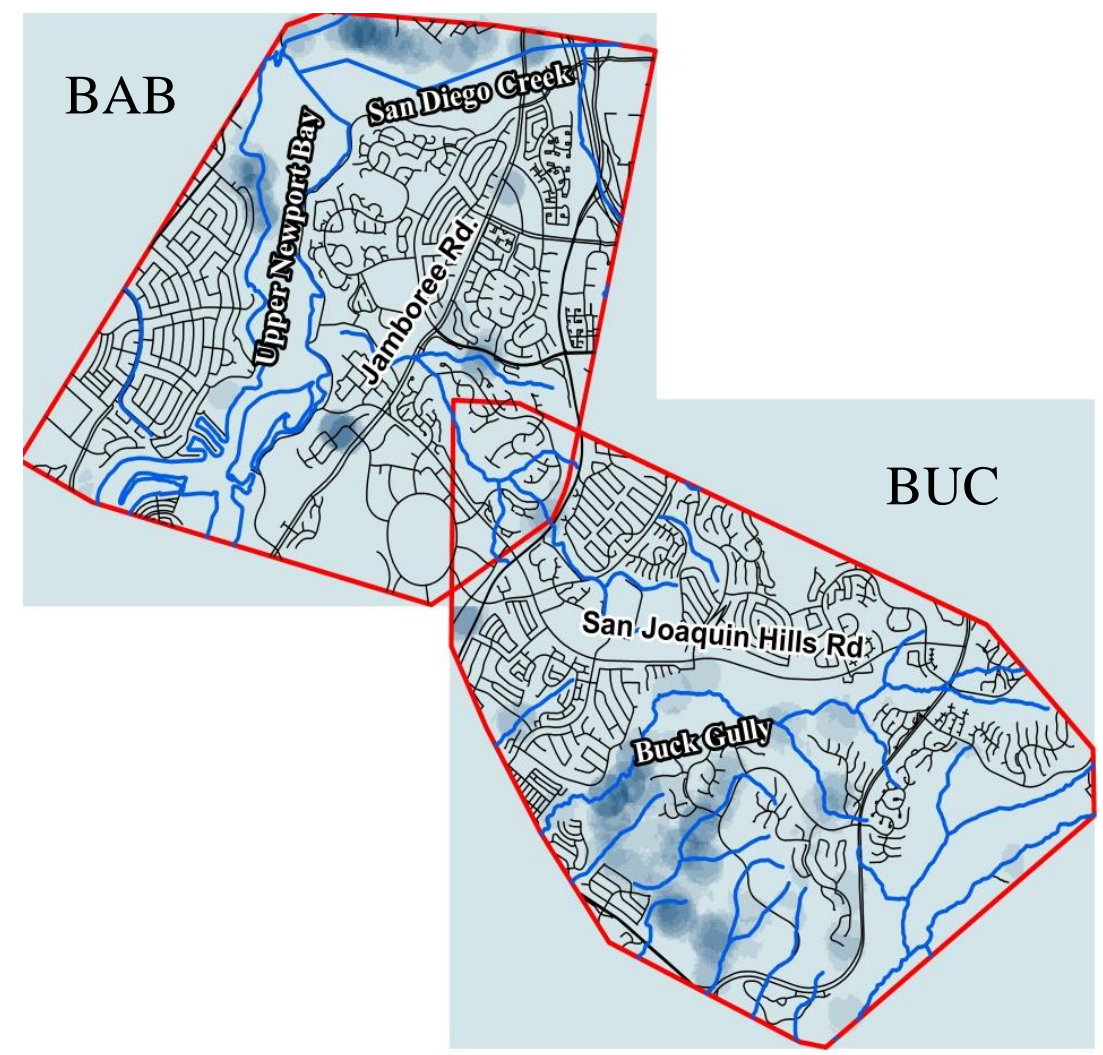

Figure 6-3: Home ranges for BAB (Top Left) and BUC (Bottom Right) with intersected roads and streams over a point density raster $(\mathrm{Km} 2)$. BUC has a $6.5 \%$ Home Range overlap with BAB.

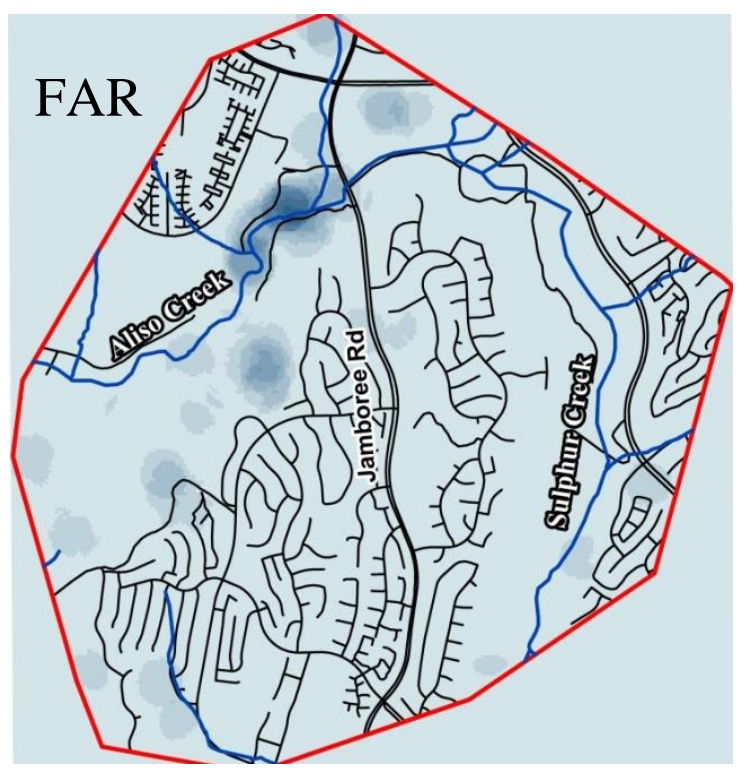

Figure 6-4: Home range for FAR with intersected roads and streams over a point density raster $(\mathrm{Km} 2)$. 


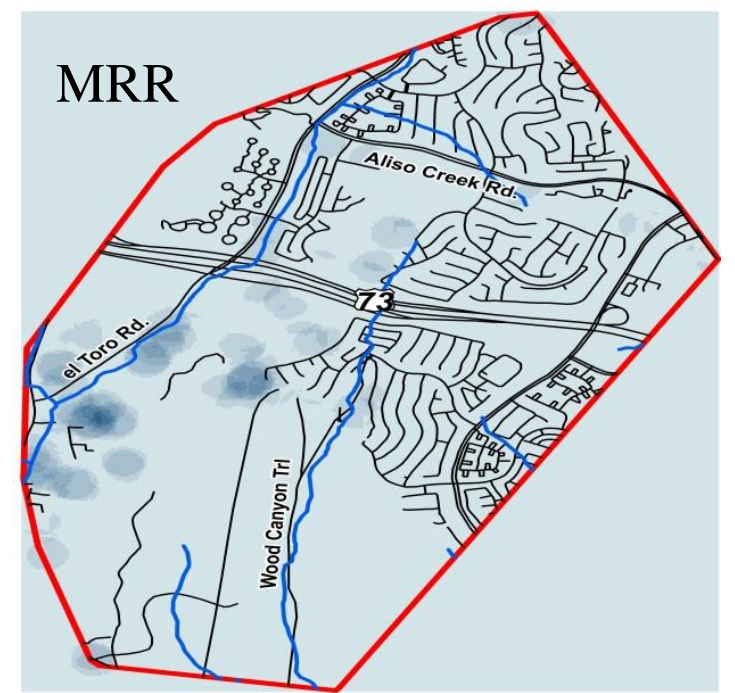

Figure 6-5: Home range for MRR with intersected roads and streams over a point density raster $(\mathrm{Km} 2)$.

Road, flow line, and urban edge density results are illustrated for their densities within each home range boundary, displayed on the next page in Figures 6-6, 6-7, and 6-8 respectively. As mentioned previously, the NHD database describes flow lines as being: Underground Conduit, StreamRiver, Pipeline, ArtificialPath, CanalDitch, Connector, and Coastline. Home range boundary sizes were added for comparative analysis and for determining which individuals may be more urban associated. 


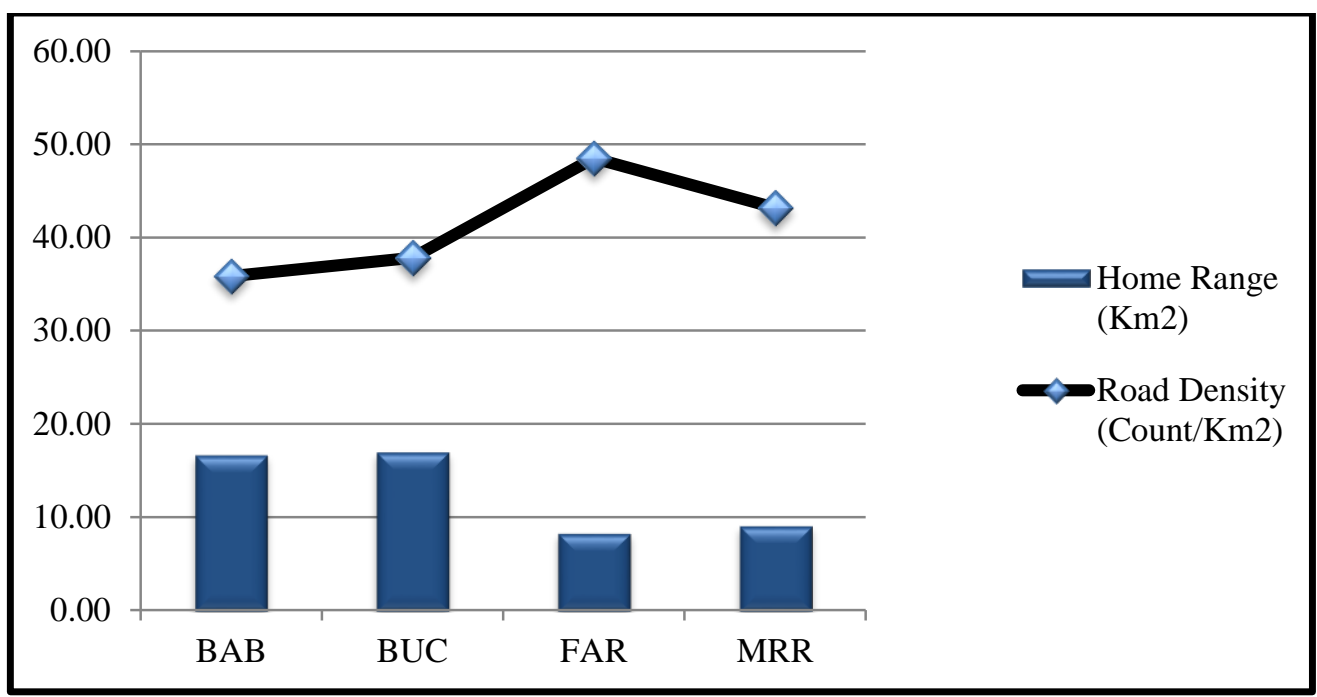

Figure 6-6: Road densities for individual home ranges calculated by the number of features/Km2.

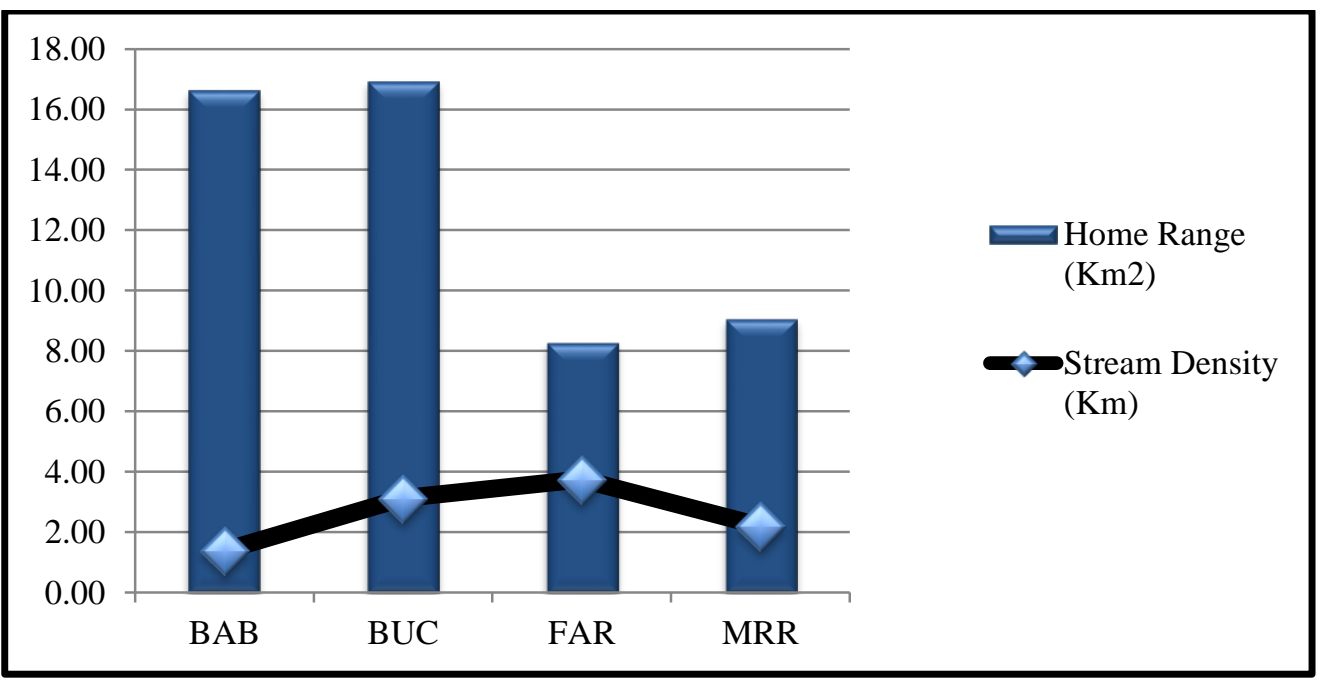

Figure 6-7: Flow line densities for individual home ranges calculated by the number of features/Km2. 


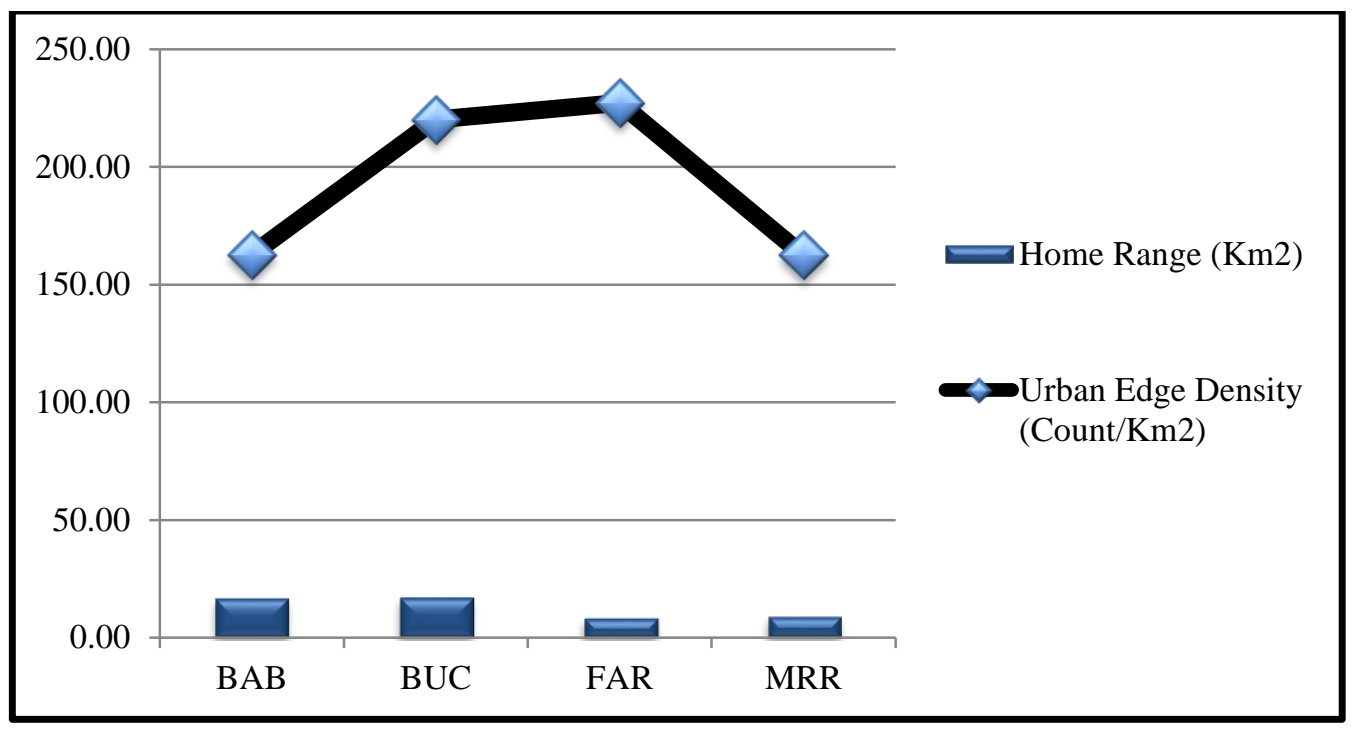

Figure 6-8: Urban edge densities for individual home ranges calculated by the number of features/Km2.

Length density, the features length per total home range boundary is illustrated in Figure 6-9.

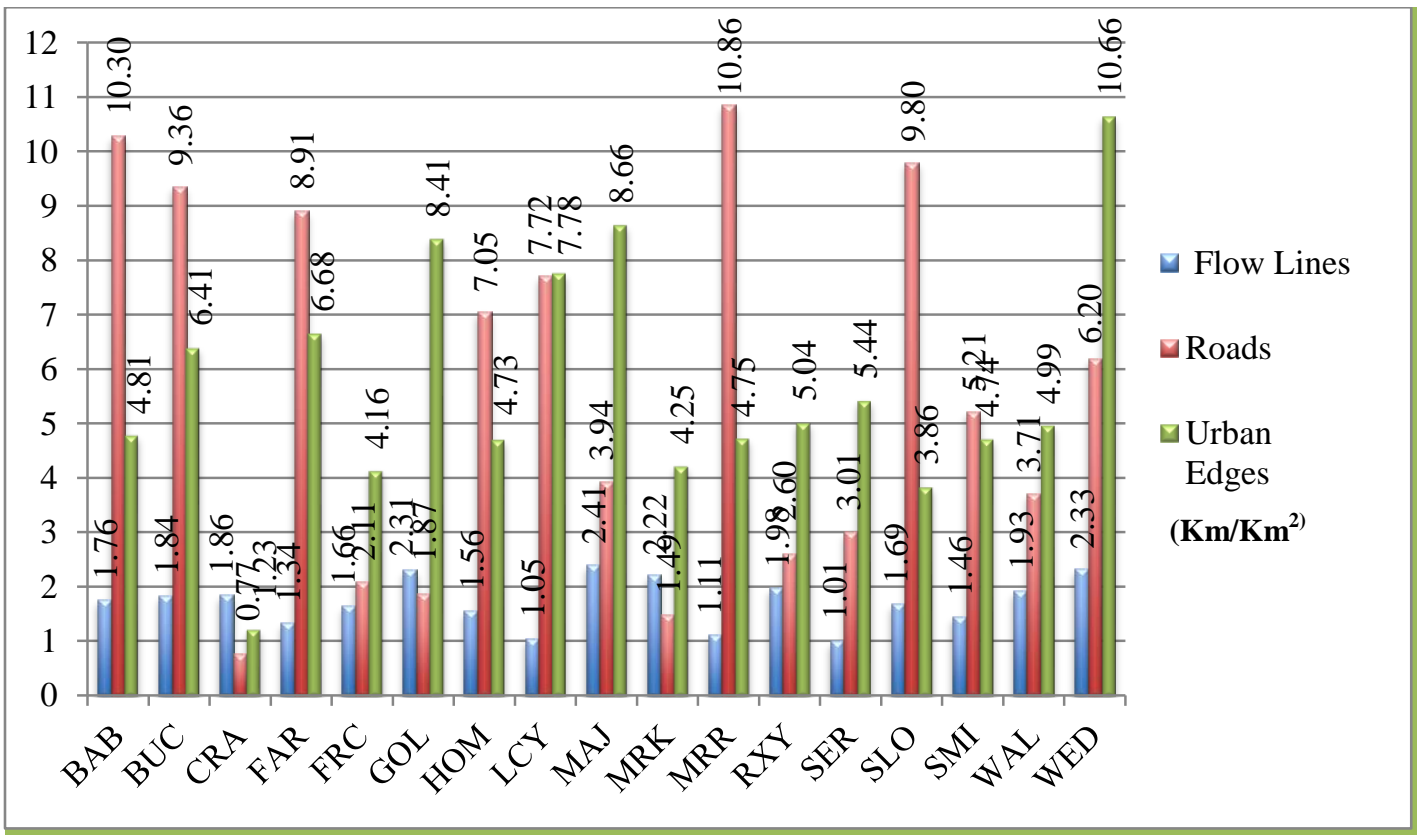

Figure 6-9: Linear (length) densities, $\mathrm{Km} / \mathrm{Km} 2$, for flow lines, roads, and urban edges within each individual's home range. 


\subsubsection{Polygon Density Analysis}

The percentage of a particular land cover type is an important aspect in the bobcat's home range selection. Land cover types must have a sufficient amount of food and water resources for the bobcat's survival. Land cover types that contain vital resources are especially important in a human altered landscape, where the critical habitat may be fragmented. Polygon density results are based on open/natural land cover and water bodies. The results for all radio-collared bobcats are represented in Table 6-2.

Table 6-2: $\quad$ Polygon density results for two habitat variables.

\begin{tabular}{|c|c|c|}
\hline Feature & $\begin{array}{c}\text { Total } \\
\text { Area } \\
\left(\mathbf{K m}^{2}\right)\end{array}$ & $\begin{array}{c}\text { \% Coverage } \\
\left.\left(\mathbf{K m}^{\mathbf{2}} / \mathbf{K m}^{\mathbf{2}}\right) * \mathbf{1 0 0}\right)\end{array}$ \\
\hline $\begin{array}{c}\text { Open/Natural } \\
\text { Land Cover }\end{array}$ & 166.61 & 80.41 \\
\hline Water Bodies & 2.08 & 1.00 \\
\hline
\end{tabular}

Land cover density and water body density results were not included with the linear density results because of the nature of how they were calculated within each home range boundary, by their percent coverage. Land cover was further separated because it was analyzed by its classifications (gridcode) instead of animal ID. Land cover was not analyzed by percent coverage per individual home range (animal ID and gridcode) because of erroneous results provided by the tool, where some percentages were over one hundred percent in the output table.

This issue is further discussed at the end of this chapter. However, land cover percentage was analyzed for the four the individuals: BAB, BUC, FAR, and MRR. Percent land cover for all radio-collared bobcats is illustrated on the next page in Figure 6-10. The percentage of water bodies is illustrated for each individual bobcat in Figure 611 on the next page. 


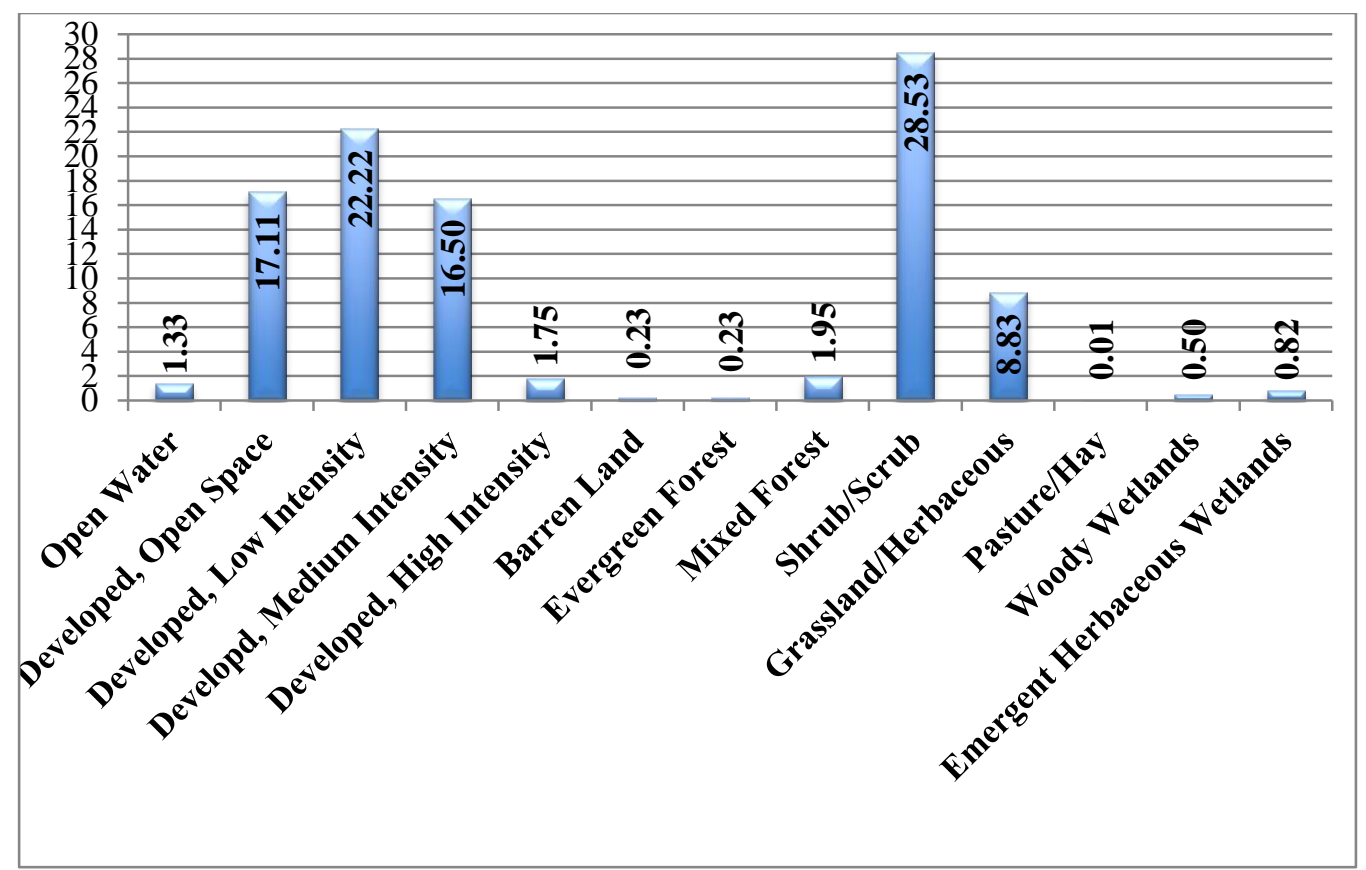

Figure 6-10: Percent Land Cover for all radio-collared bobcats. Note gridcode or the classification was used for the case field in Summary Statistics, instead of animal ID.

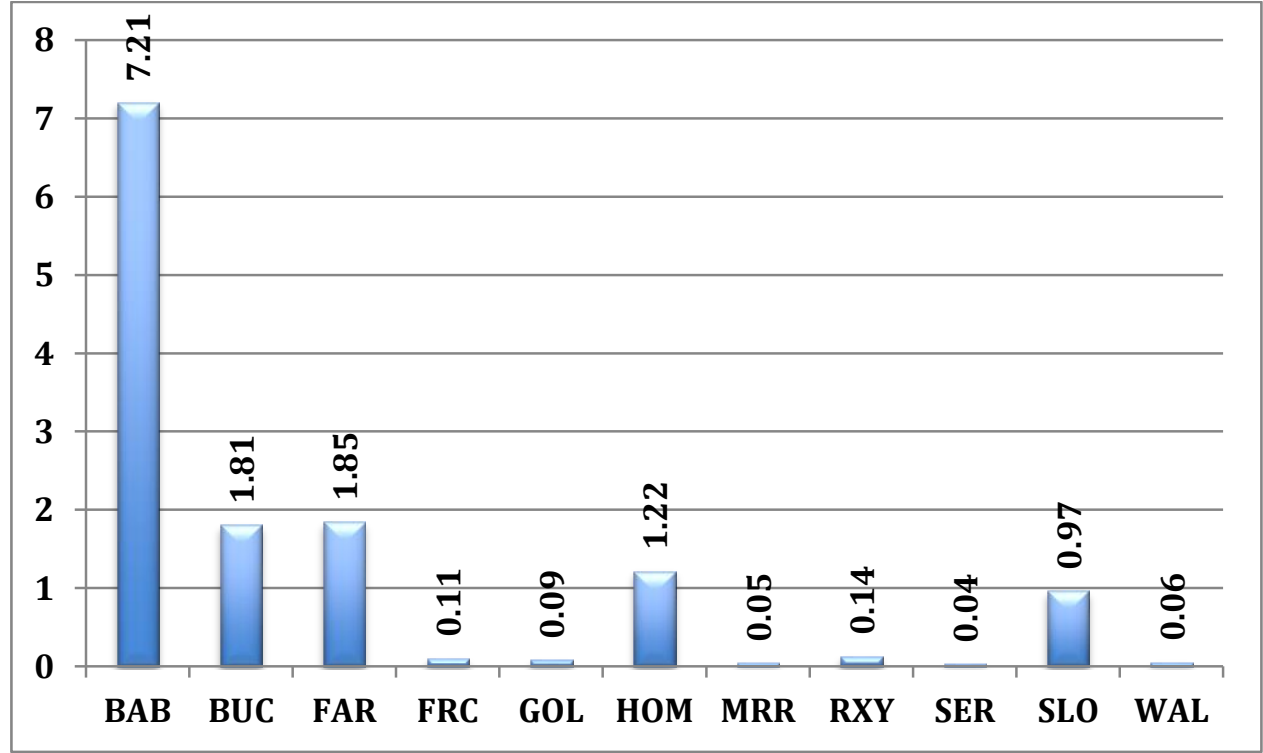

Figure 6-11: Percent water body coverage for individual home ranges. 
The four individuals were analyzed for the land cover types within their home range boundaries. All results were exported to Database Files or DBF's that were used in Microsoft Excel to create column charts for illustration purposes. The pie charts in Figures 6-12 - 6-14 illustrate the percent coverage of land cover types for the four individuals.

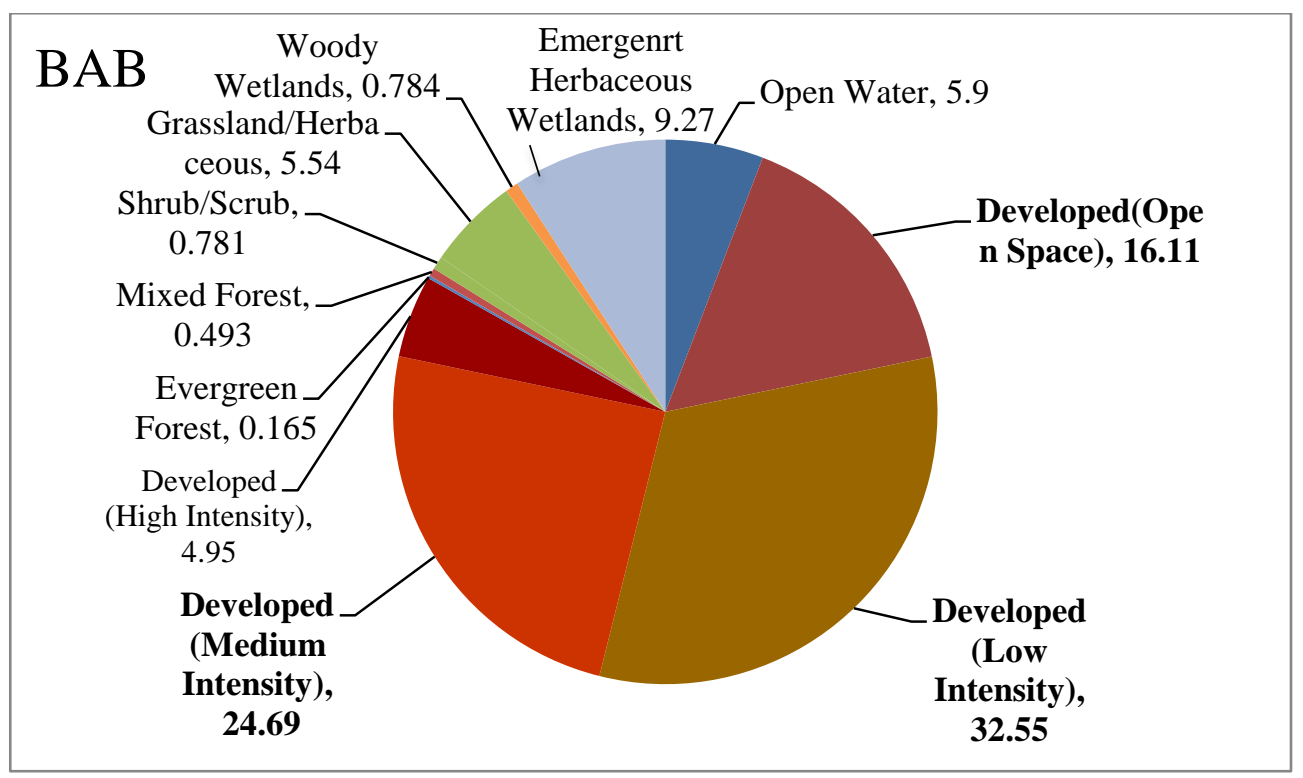

Figure 6-12: Land cover types and corresponding percentages for BAB's home range boundary. Pasture/Hay and Barren Land (Rock, Sand, Clay) were omitted because their complete lack of presence. Top three percentages are indicated in bold. 


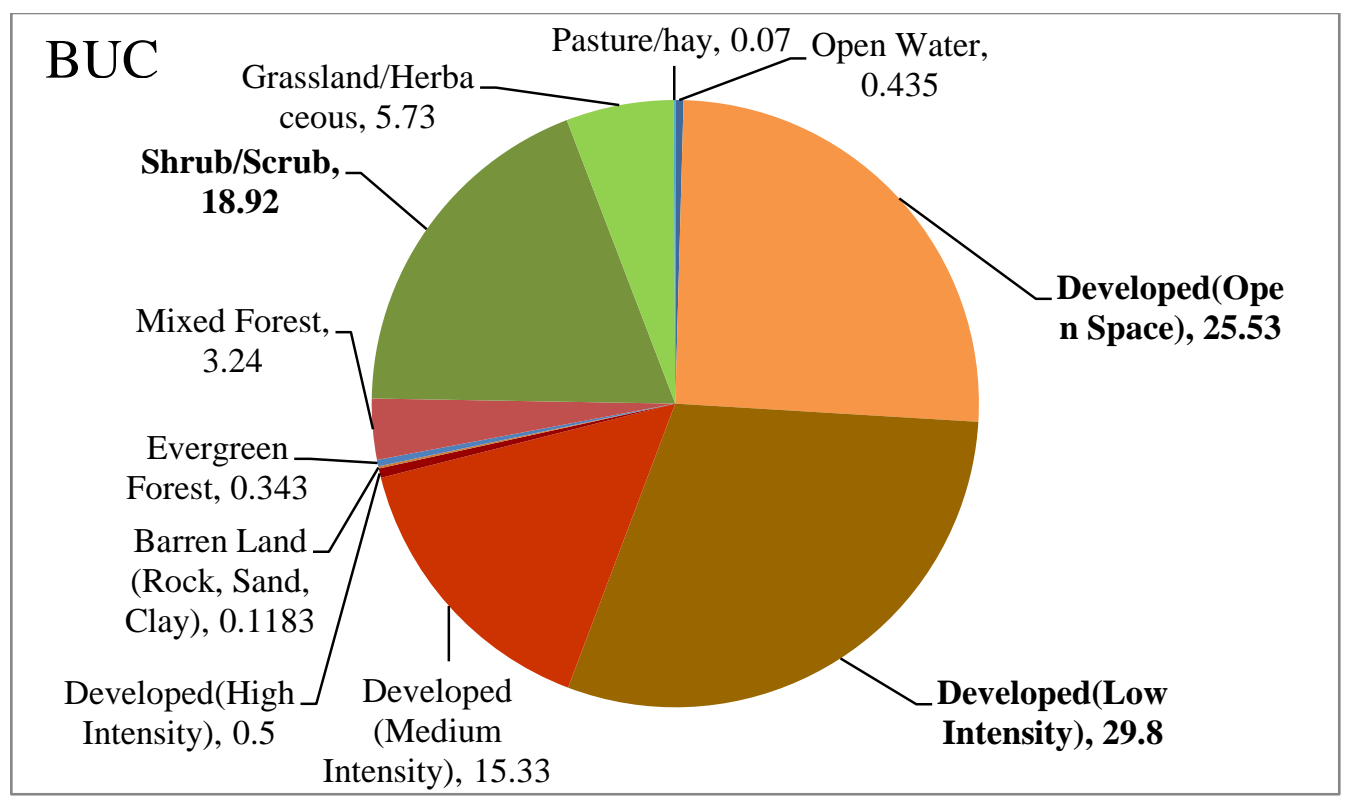

Figure 6-13: Land cover types and corresponding percentages for BUC's home range boundary. Woody Wetlands and Emergent Herbaceous Wetlands were omitted because their complete lack of presence. Top three percentages are indicated in bold.

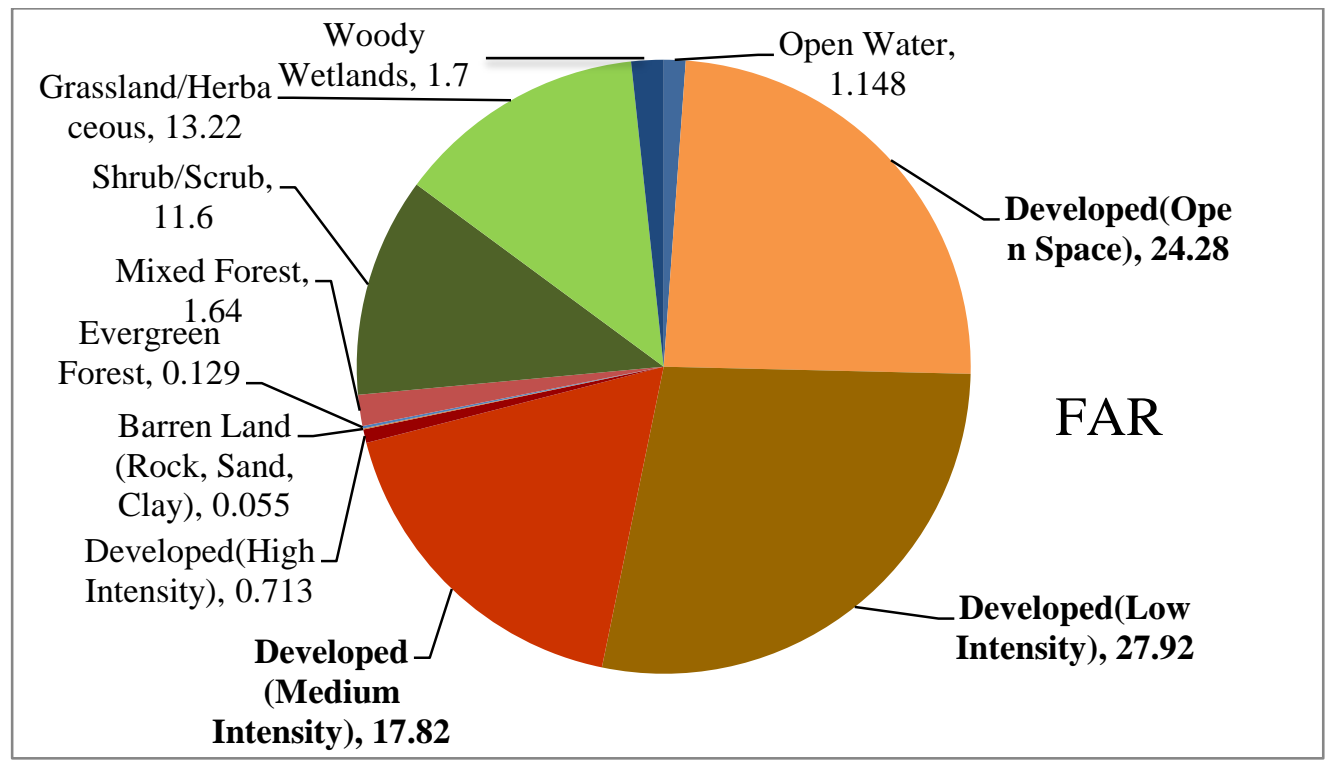

Figure 6-14: Land cover types and percentages for FAR's home range boundary. Emergent Herbaceous Wetlands and Pasture/Hay were omitted because their complete lack of presence. Top three percentages are indicated in bold. 


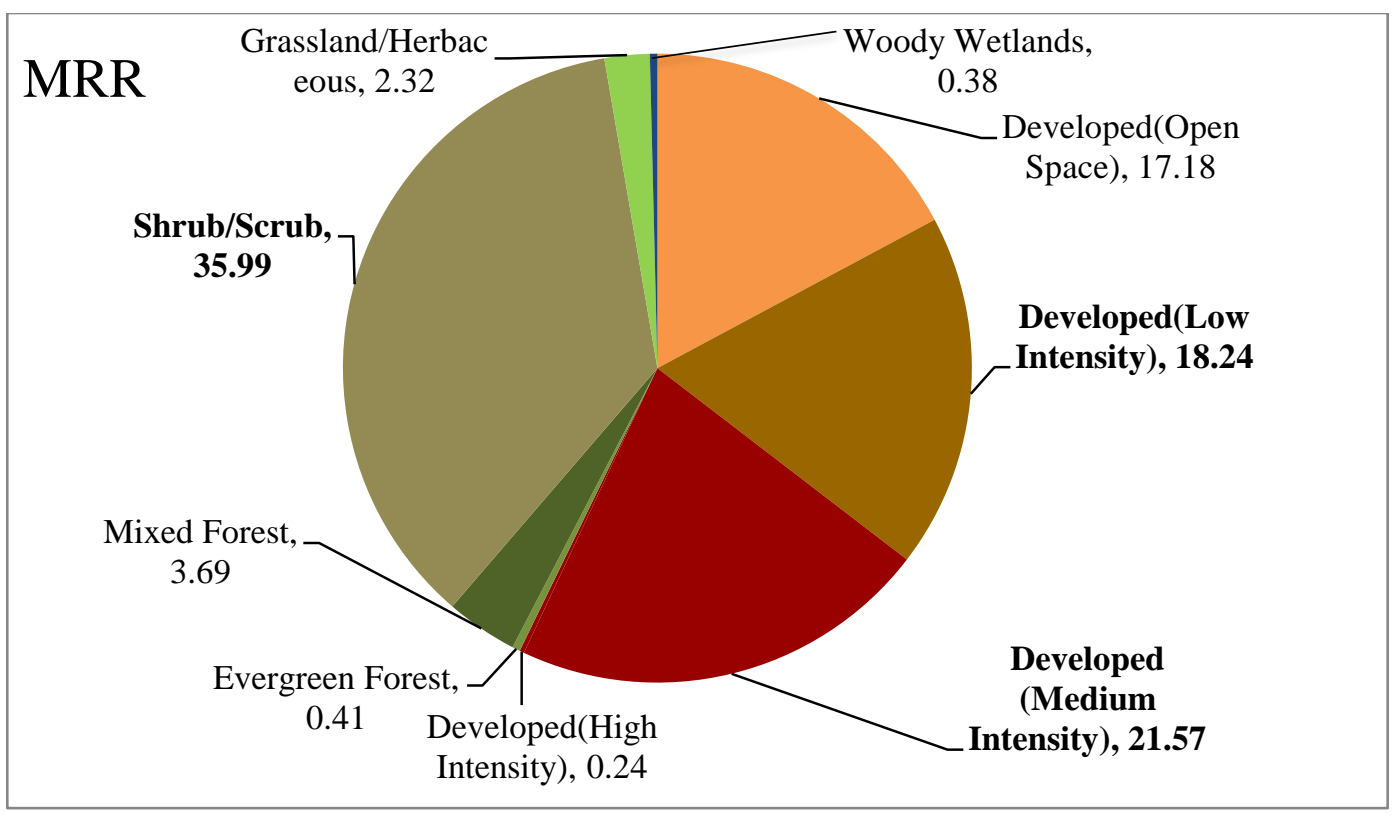

Figure 6-15: Land cover types and percentages for MRR's home range boundary. Barren Land (Rock, Sand, Clay), Emergent Herbaceous Wetlands, Open Water, and Pasture/Hay were omitted because their complete lack of presence. Top three percentages are indicated in bold.

Low intensity development made up the highest percentage of home ranges for all individual's, except for MRR. MRR's home range contained the highest percentage of Mixed Forest, a favorable environment for food resources. BAB's home range contained the largest percentage of developed land cover types, of medium and high intensities, with important resources such as open water and Emergent Herbaceous Wetlands. As mentioned earlier her home range is formed around the upper Newport Bay, a location that would supply critical resources such as water and vegetation for cover and food, refer to Figure 6-3. Another significant land cover type within her home range is grassland, a landcover type that could provide food resources. BUC's home range contained the largest amount of altered open space and a high percentage of shrub/scrub, native vegetation in Southern California known as Chaparral. In addition, most of the altered open space areas are locations where Chaparral vegetation is slightly disturbed by development, such as a park or recreation area. Other altered open areas include golf courses and high income residential housing, where the surrounding vegetation is usually chaparral. Chaparral is a very important resource for the bobcat providing food, cover, and water. Also, the bobcat has adapted to this vegetation type prior to human development, so it is a natural and familiar habitat. Mixed Forest and Grassland areas are other significant land cover types within BUC's home range, providing vital resources. Finally, FAR's home range was similar to BUC's in terms of developed land coverage, but contained the largest amount of grassland. In addition, Shrub/Scrub had approximately the same coverage within FAR's home range. Open water, Woody 
Wetlands, and Mixed Forest are other significant and critical land cover types within FAR's home range. Figures 6-16, 6-17, and 6-18 illustrate the land cover within each home range boundary.

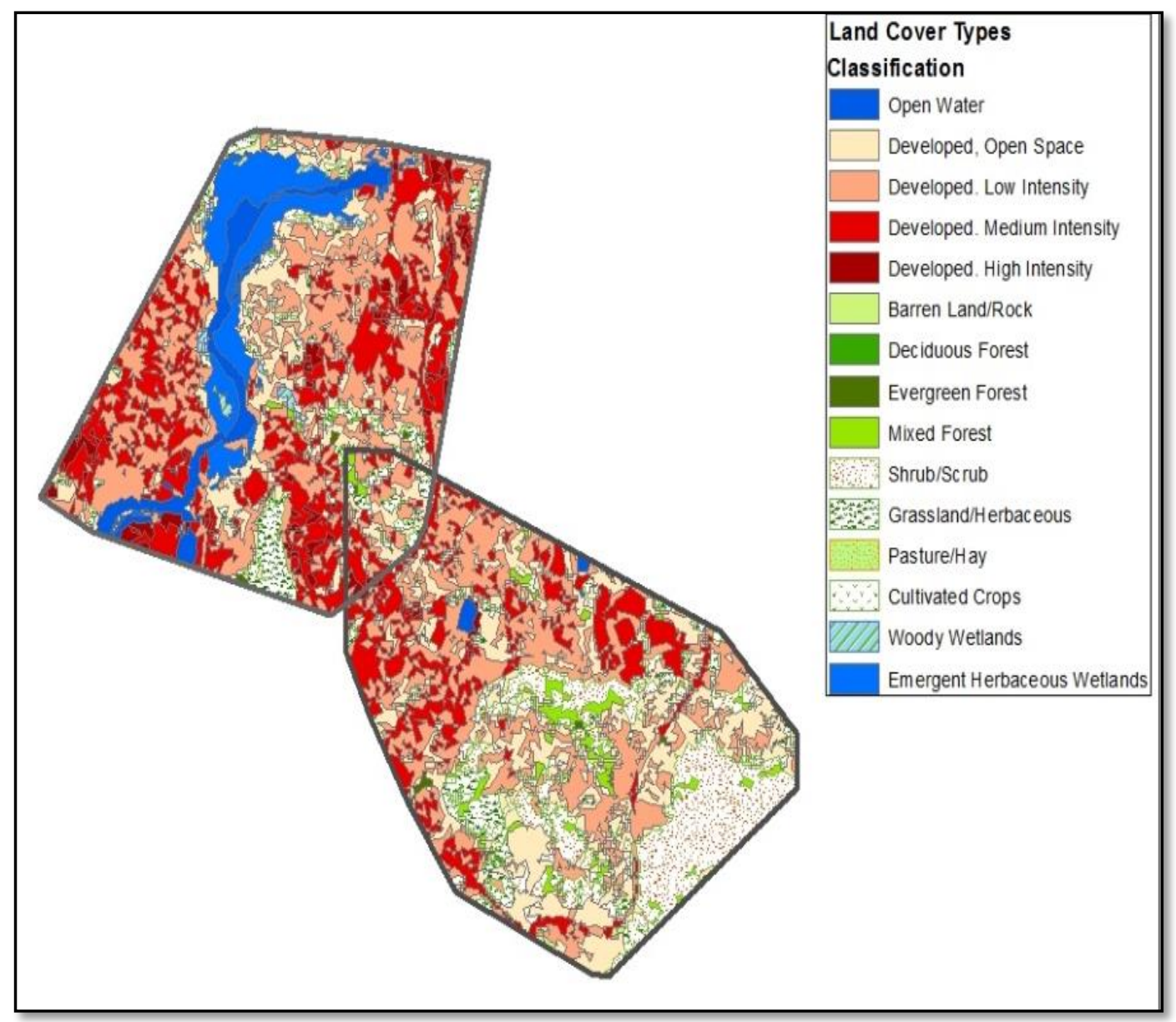

Figure 6-16: Land cover types for BAB and BUC. 


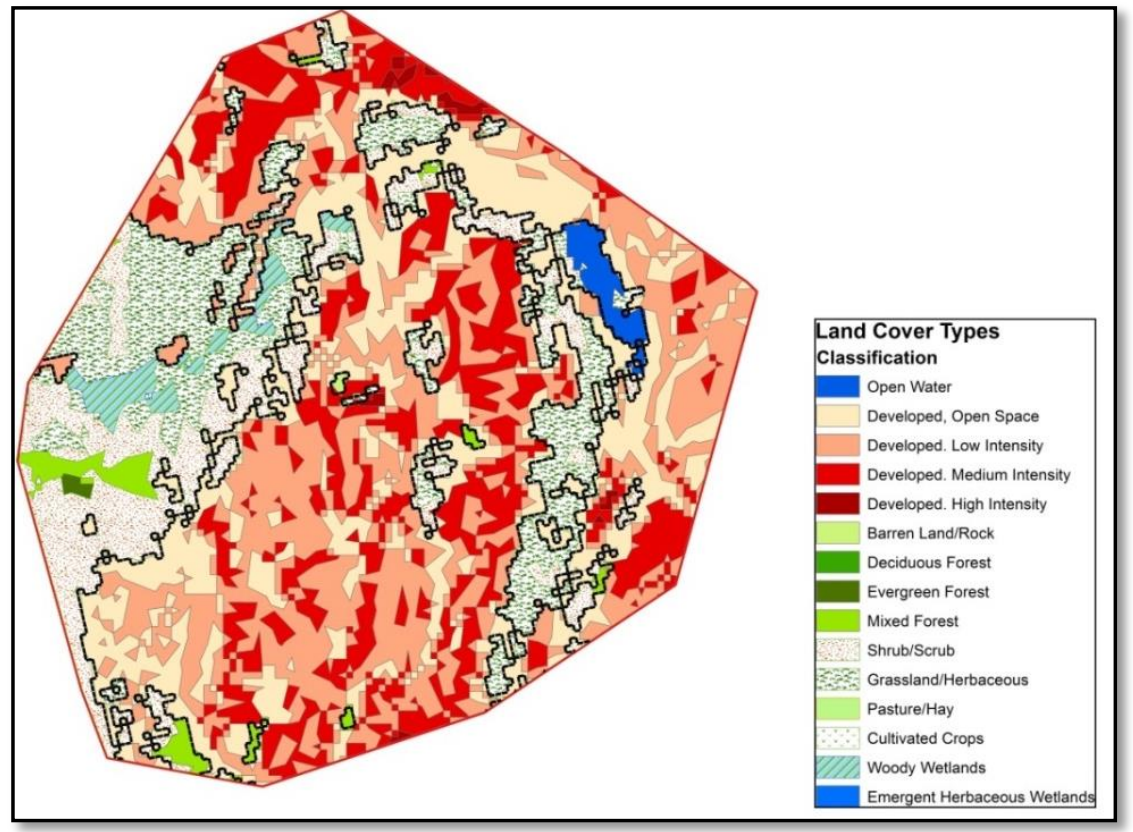

Figure 6-17: Land cover types for FAR.

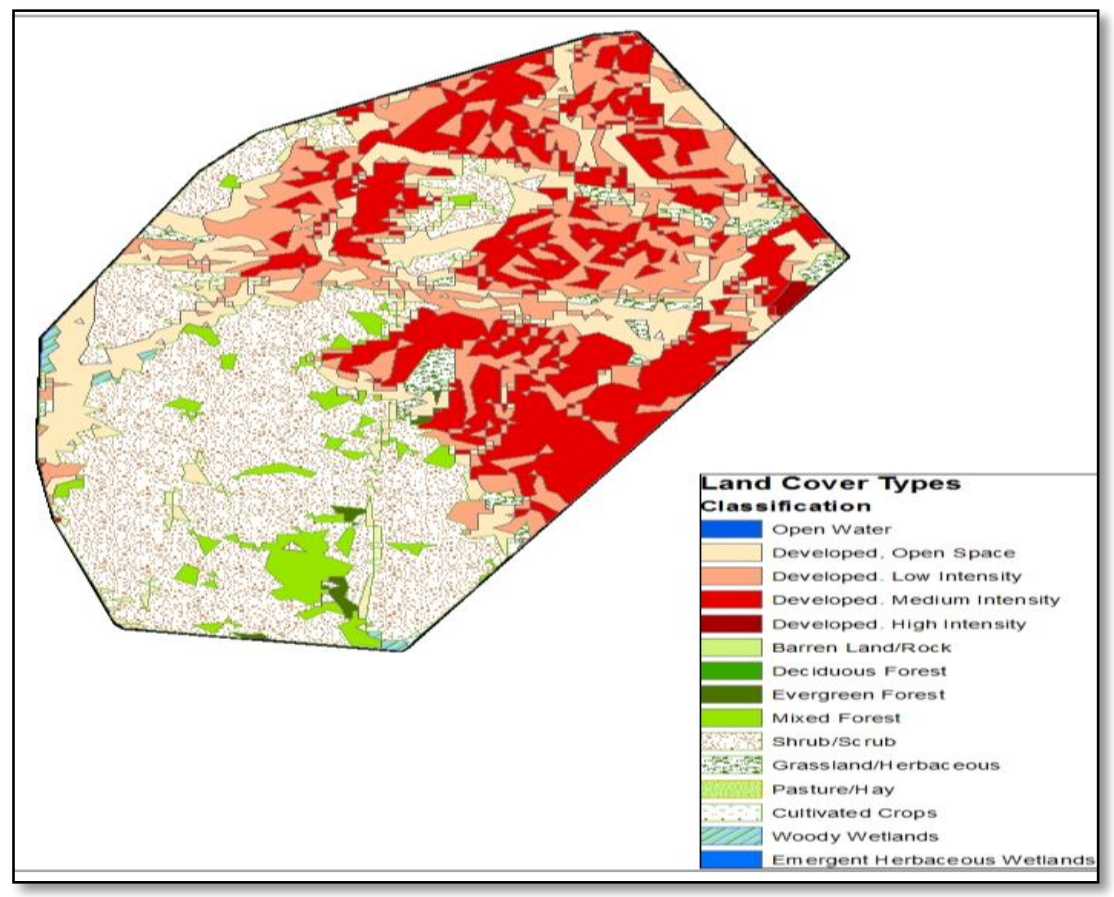

Figure 6-18: Land cover types for MRR. 
Understanding the quantity of a particular resource or land cover type that is available to the bobcat is important for research purposes. However, knowing what land cover types that are actually being used by the bobcat is even more useful. Developed (Low Intensity) was the most frequented land cover by MRR at 240 observations. Second and third most frequented was Developed (Open Space) at 196 observations and Developed (Medium Intensity) at 111 observations. Other important land cover types frequented by MRR were Mixed Forest, Shrub, and Grassland in decreasing order of frequency. These land cover types offer great resources for acquiring food. Developed (Open Space) was the most frequent land cover type that was visited by BAB at 120 observations. Second and third most frequented was Developed (Low Intensity) at 79 observations and grassland at 16 observations respectively. These land cover types immediately surround critical water resources. The four observations in Open Water land cover types are most likely areas where water levels were low. Other important land cover types frequented by BAB were Developed (Medium Intensity), Emergent Herbaceous Wetlands (Open Water areas), and Shrub/Scrub. Observations within the Shrub/Scrub land cover type illustrate the importance of this natural habitat because it has a very small coverage within her home range boundary.

BUC frequented Developed (Low Intensity) the most, at 199 observations. Shrub/Scrub was second with 115 observations and Developed (Low Intensity) was third, at 55 observations. Close to third was Grassland at 52 observations. Other important land cover interactions were with Evergreen Forest and Developed (Medium Intensity) land cover types. As expected, BUC had high interactions with natural land cover types due to their large coverage within his home range boundary. Finally, the land cover type most frequented by FAR was Developed (Open Space), at 189 observations. Shrub/Scrub was second at 84 observations, and Developed (Low Intensity) was third at 39 observations. Other important interactions were with Grassland, Woody Wetlands, Mixed Forest, and Developed (Medium Intensity) types. These are listed in order of decreasing observations. Woody Wetlands is an important one to note because of its high interaction and very low coverage within FAR's home range boundary. To a lesser extent, this was the case for the Shrub/Scrub land cover type. Not one individual interacted with the high intensity developed areas, although they all were observed within medium intensity developed areas, indicating the need for urban interaction.

Observations were high within low intensity developed areas with lots of open space, particularly for MRR. These are areas of very low human impact on natural habitat and can provide resources for the bobcat. MRR also had the highest observations for the Developed (Medium Intensity) land cover type, where critical patches of Chaparral and natural/altered water resources are located, in addition to recreational open spaces.. In all cases, the presence of natural habitat was critical to acquire food and water resources, as well as for cover. BAB is a female that was known to rear kittens within her home range. Areas with minimal human impact and access to water resources are vital for her and her kitten's survival. Also, natural habitat is also crucial for food resources and cover. High interactions with very low coverage of natural land cover types within her home range boundary emphasize their importance for her and her young. Furthermore, some natural resources are limited within her home range boundary due to the presence of a male (BUC) to the south. 
There is critical Chaparral (Shrub/Scrub) in the southern part of her home range boundary that she needs for survival, which is why there may be some home range overlap in that region, and possibly due to mating. The higher presence of BAB in heavier developed areas could be explained by her desperate need for any available resource to ensure the survival of her and her kittens. Observations with the land cover types for the three individuals are illustrated in Figure 6-19.

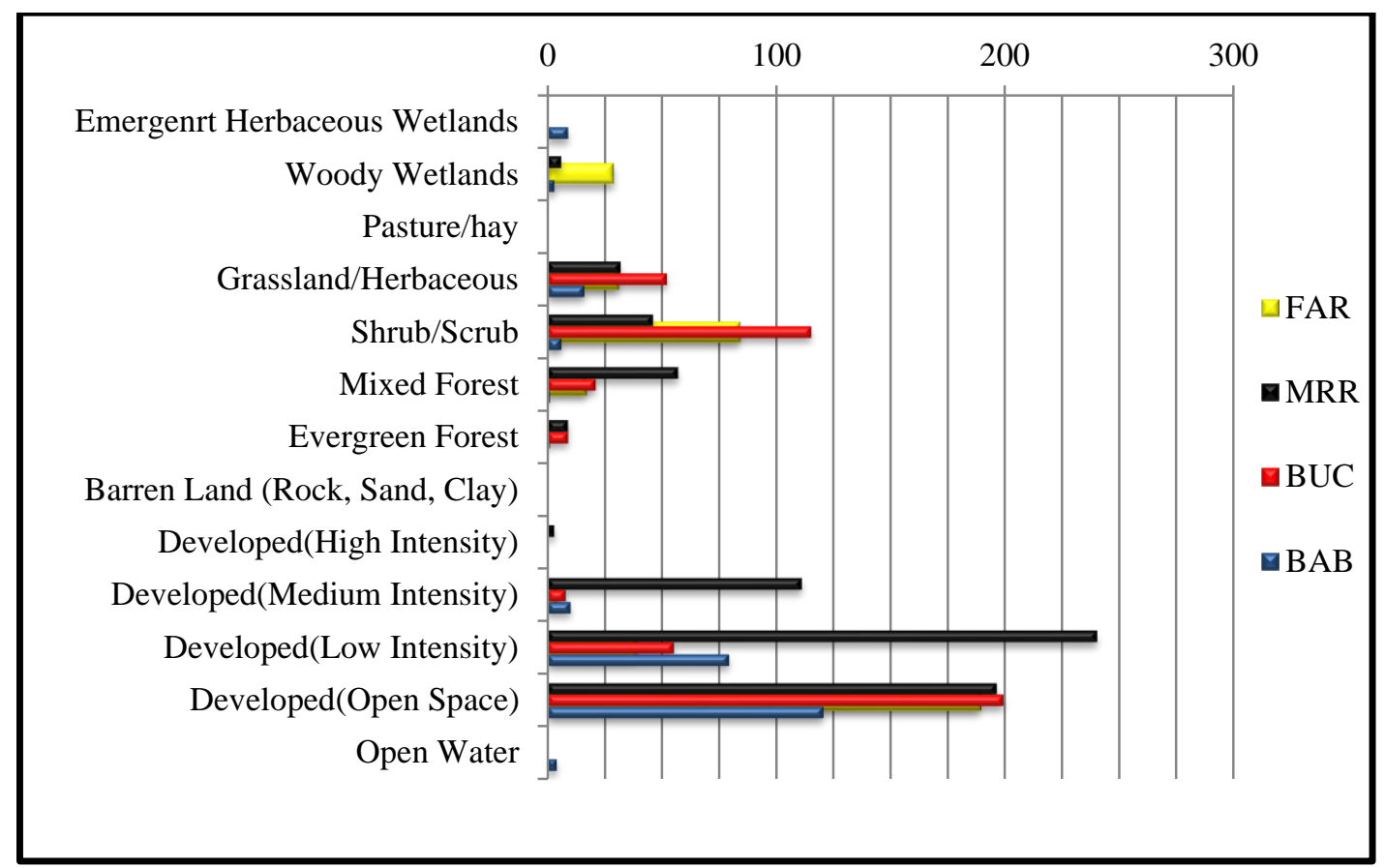

Figure 6-19: Number of observations within each land-cover type for BAB, BUC, FAR, and MRR.

\subsubsection{Proximity Analysis}

The same testing scenario for the density tools was applied for the proximity tool. The tool was executed ten times to measure distances to roads, streams, urban edges, water bodies, and land cover for all radio-collared bobcats and for individuals. Distances were measured without a study area for a complete proximity analysis, where a confined study area would eliminate proximity to features just outside of the polygon boundary. Individual illustrations were created in Microsoft Excel as described in section 6-1. Proximity results for all radio-collared bobcats are outlined in Table 6-3. 
Table 6-3: Proximity results for all radio-collared bobcats considering five habitat variables and their proximity to observed bobcats. Distances are in meters.

\begin{tabular}{|c|c|c|c|}
\hline Feature & $\begin{array}{c}\text { Mean } \\
\text { Distance }\end{array}$ & $\begin{array}{c}\text { Minimum } \\
\text { Distance }\end{array}$ & $\begin{array}{c}\text { Maximum } \\
\text { Distance }\end{array}$ \\
\hline Roads & 131.722 & 0.005 & 1460.21 \\
\hline Flow lines & 104.47 & 0 & 926.24 \\
\hline Urban Edges & 93.80 & $0-2$ & 1285.51 \\
\hline $\begin{array}{c}\text { Open/Natural } \\
\text { Land Cover }\end{array}$ & 0.78 & 0 & 142.02 \\
\hline Water Bodies & 955.14 & 0 & 3158.15 \\
\hline Observed & 1794.312 & 7.155 & 3721.507 \\
Bobcats & & & \\
\hline
\end{tabular}

These illustrations are displayed for all habitat variables, linear and polygon features, because they were all measured the same way for distance. Distance was measured in meters, but the user has the option to change the search radius units if one is applied. If a search radius is not applied to the near features, a search will be performed on all input features in the linear unit of its inherent coordinate system, in this case meters. It is important to note that near statistics for all land cover was not included because this would yield zero distances for all bobcats and individuals, because bobcats are found over each land cover type. This would be different if the tool was designed to pick up gridcode classifications from the land cover dataset. In that case, animal id and gridcode would be used for analysis, and output results would be generated for each classification for each individual bobcat. A land cover intersection with the study area would have to be included for complete attribute carry over and recognition within the case field. This was not included because near features exist outside of the study areas as well, and therefore the tool would provide erroneous results.

Although proximity statistics for individual radio-collared bobcats were defaulted for four different descriptive types; a majority of the illustrations below only deal with the maximum and mean for each individual for a better visualization and a more appropriate 
analysis result. Only the proximity statistics of certain habitat variables that contained high enough minimum values for visualization purposes were included, otherwise they did not even display in the column charts. Furthermore, the mean and maximum proximity results to open/natural land cover types had to be split into two charts because of the large range between the datasets. Individual results are illustrated in figures 6-20 6-25.

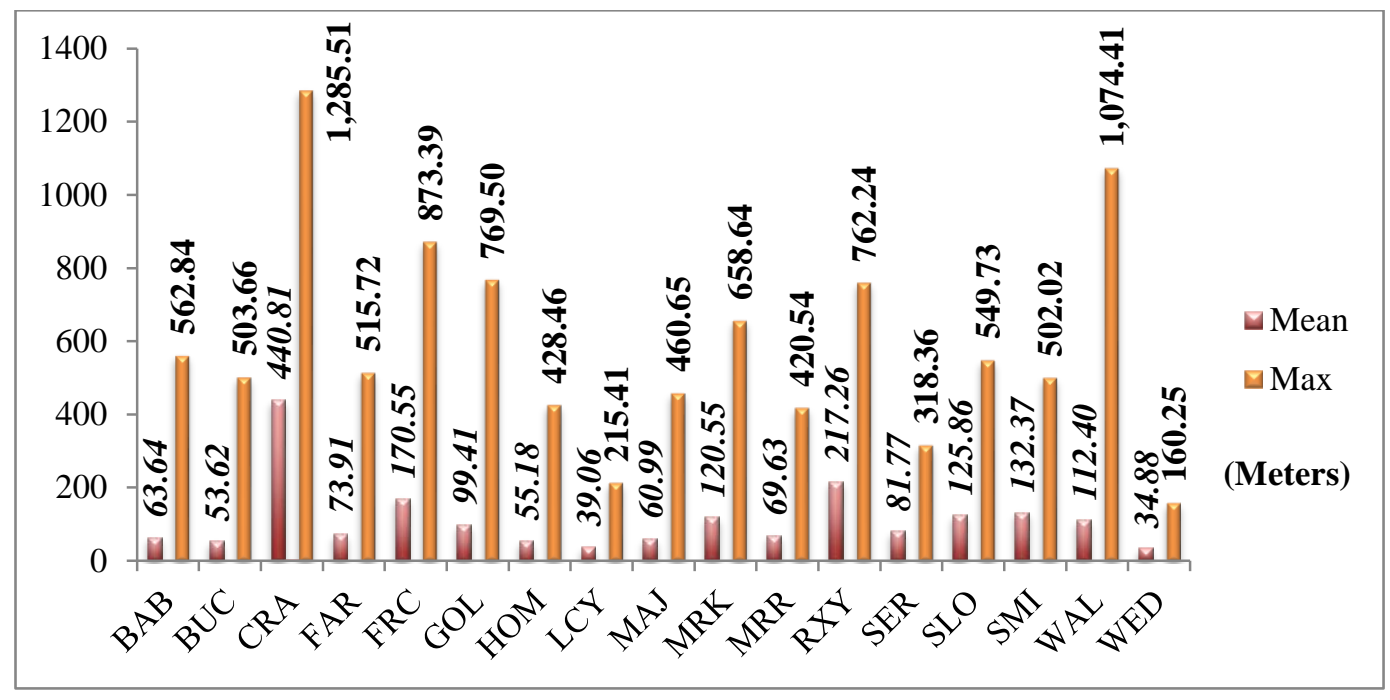

Figure 6-20: Bobcat proximity to urban edges summarized by mean and maximum distance values.

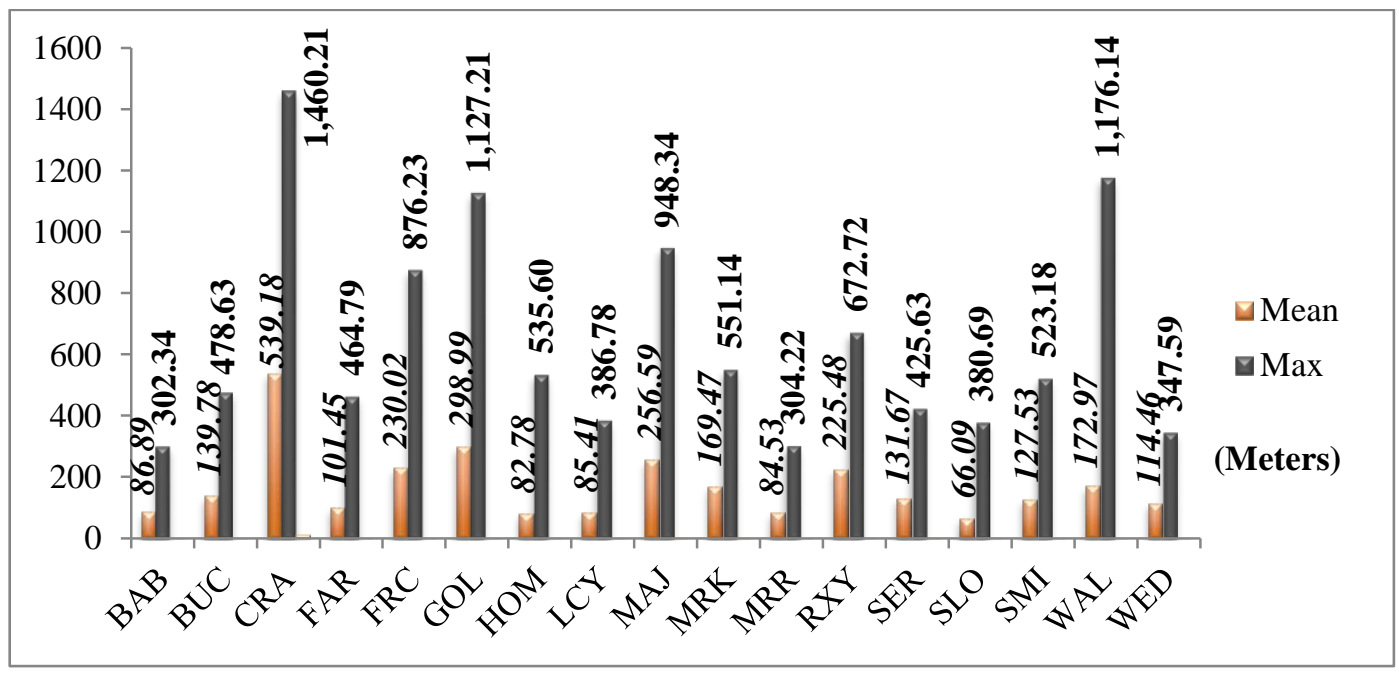

Figure 6-21: Bobcat proximity to roads summarized by mean and maximum distance values. 
A smaller distance to roads for $\mathrm{BAB}$ can be explained by a higher percentage of developed land cover types within her home range boundary, including a higher road linear density. Proximity results for BUC and FAR appears to be relatively similar, possibly due to a higher percentage of natural habitats within their home range boundaries, as well as their male gender with zero kittens to rear.

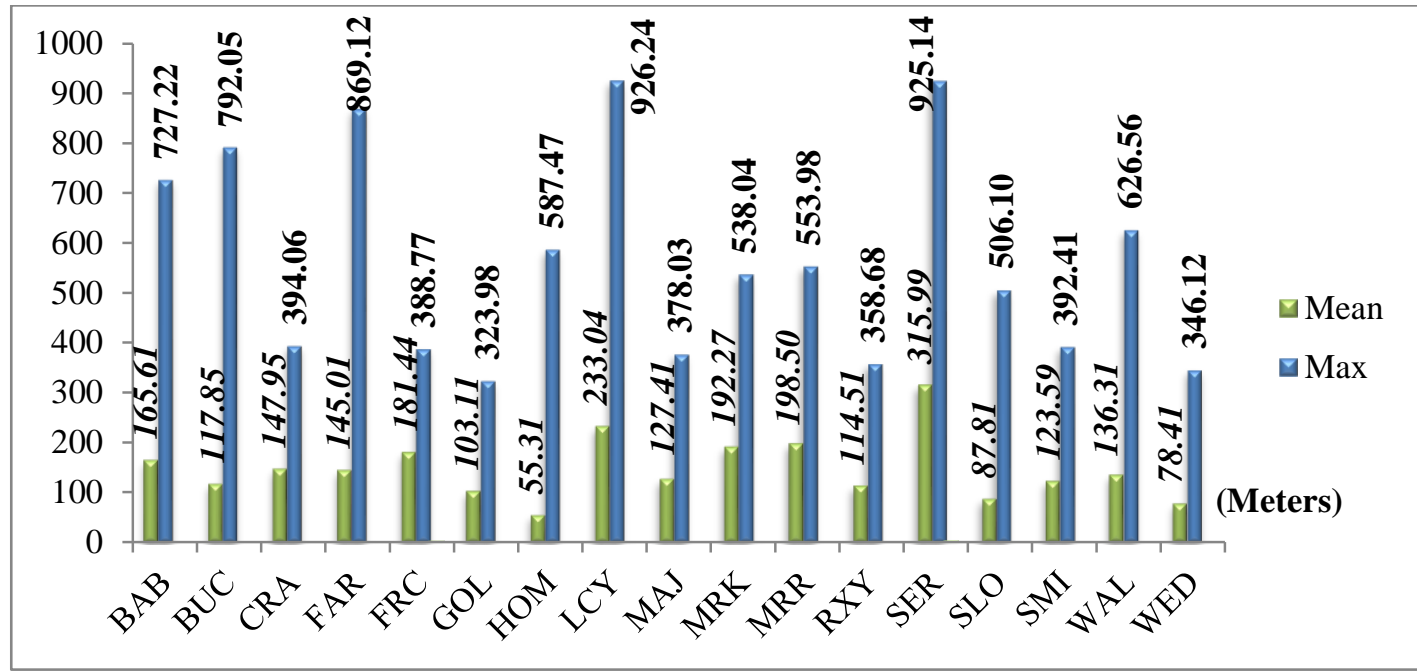

Figure 6-22: Bobcat proximity to flow lines summarized by mean and maximum distance values in meters. Minimum values were excluded because the value was zero for a majority of individuals, and nearly zero for the rest.

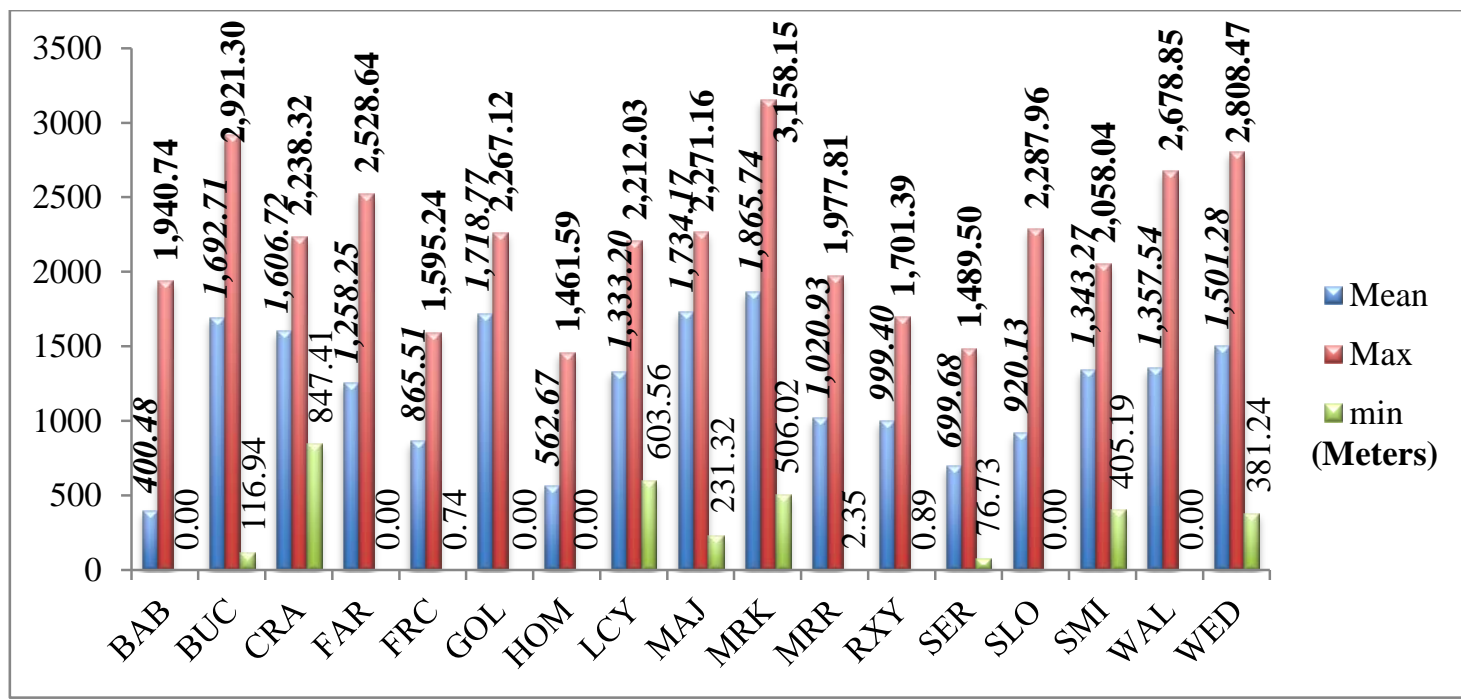

Figure 6-23: Bobcat proximity to water bodies summarized by mean, minimum, and maximum distance values. 
For $\mathrm{BAB}$, a mother that is raising kittens, a shorter distance to water resources is optimal for survival. A maximum distance from these resources is observed possibly due to the fact that she needs to travel elsewhere for other critical resources, such as food. Also, a higher mean distance from streams may be due to a higher presence of water bodies within her home range. Native vegetation patches exist in copious amounts on the opposite side of her prime locations within her home range boundary, making observations to these places extreme deviations to regular denning locations, primarily to water resources. BUC and FAR, whose home ranges contain higher amounts of external natural habitat types may rely less on water resources for survival, yielding a higher proximity to this resource.

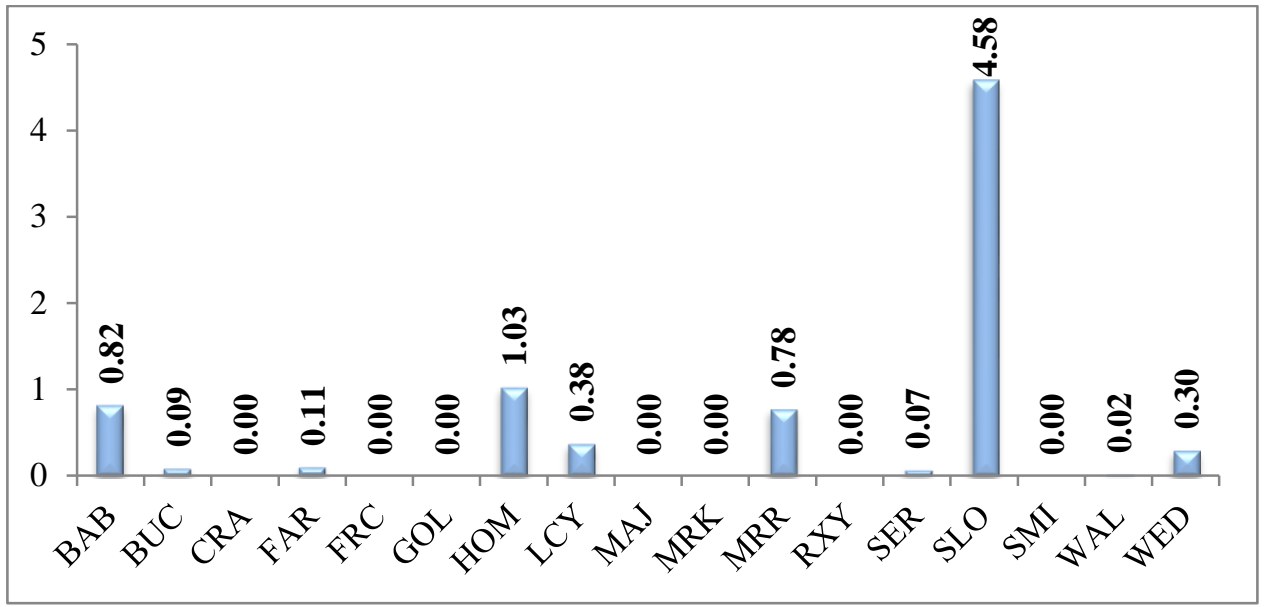

Figure 6-24: Bobcat proximity to "open/natural" land cover types summarized by the mean value.

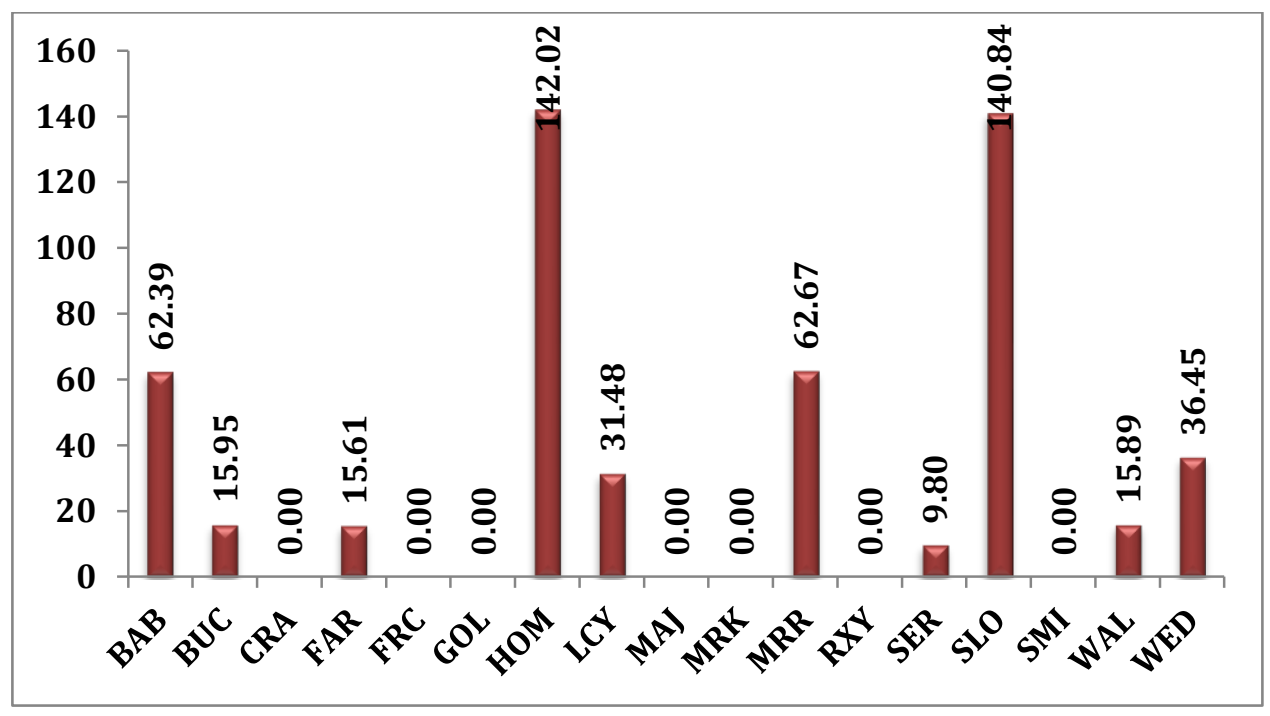

Figure 6-25: Bobcat proximity to "open/natural" land cover types summarized by the maximum value. 
Considering that BAB's habitat contains significantly less open/natural habitat coverage, the higher mean and maximum distance is expected, especially to acquire resources elsewhere. This distance is furthered by the fact that she has kittens to feed and will search elsewhere for resources that are necessary for their survival. BUC and FAR have significantly higher percentages of Developed (Open Space) and natural land cover types within their home ranges. This higher opportunity for acquiring critical resources would explain having a shorter distance to these land cover types, being relatively the same distance for both mean and maximum distances.

\subsection{Observation Results}

All observations (bobcat sightings) were analyzed for density and proximity against all habitat variables. This data set does not contain an attribute for individual bobcats due to the nature of how it was collected, although some sighting story attribute fields do contain information on particular radio-collared individuals. Other grouping attributes will be included in the final geodatabase; but they were not included in this project. These other attributes include season, dens/possible dens, and time comments. However, dens/possible dens and the time comments were only recorded for a few bobcat sightings. This dataset is an important part of the testing scenario because it is inherently different from the radio-collared dataset in terms of how the data was collected and recorded. Observation results are outlined in Table 6-4 and 6-5. Proximity results are outlined in Table 6-6.

Table 6-4: $\quad$ Linear density results for all observed bobcats, considering three habitat variables: roads, flow lines, and urban edges.

\begin{tabular}{|c|c|c|c|c|c|c|c|c|}
\hline Feature & Count & $\begin{array}{c}\text { Mean } \\
\mathbf{( K m )}\end{array}$ & $\begin{array}{c}\text { Min } \\
\mathbf{( K m )}\end{array}$ & $\begin{array}{c}\text { Max } \\
\mathbf{( K m})\end{array}$ & $\begin{array}{c}\text { Sum } \\
\mathbf{( K m )}\end{array}$ & $\begin{array}{c}\text { MCP } \\
\text { Area } \\
\left(\mathbf{K m}^{2}\right)\end{array}$ & $\begin{array}{c}\text { Line } \\
\text { Density } \\
\mathbf{( K m})\end{array}$ & $\begin{array}{c}\text { Length } \\
\text { Density } \\
\left(\mathbf{K m} / \mathbf{K m}^{2}\right)\end{array}$ \\
\hline $\begin{array}{c}\text { Roads } \\
\text { lines }\end{array}$ & 1,534 & 0.86 & $2.4 * 10^{-3}$ & 1072.76 & 1322.08 & 1072.76 & 1.43 & 1.23 \\
\hline $\begin{array}{c}\text { Urban } \\
\text { Edges }\end{array}$ & 141,174 & 0.03 & $2.4 * 10^{-3}$ & 1072.76 & 4230.70 & 1072.76 & 131.59 & 3.94 \\
\hline
\end{tabular}


Table 6-5: Polygon density results for all observed bobcats considering two habitat variables.

\begin{tabular}{|c|c|c|c|c|}
\hline Feature & Count & $\begin{array}{c}\text { Sum } \\
\left(\mathbf{K m}^{2}\right)\end{array}$ & $\begin{array}{c}\text { Area } \\
\left(\mathbf{K m}^{2}\right)\end{array}$ & $\begin{array}{c}\text { \% Coverage } \\
\left(\mathbf{K m}^{2} \mathbf{\mathbf { K m } ^ { 2 } )} * \mathbf{1 0 0}\right)\end{array}$ \\
\hline $\begin{array}{c}\text { Open/Natural } \\
\text { Land Cover }\end{array}$ & 49,358 & 166.61 & 1072.76 & 70.10 \\
\hline Water Bodies & 315 & 8.12 & 1072.76 & 0.76 \\
\hline
\end{tabular}

Table 6-6: $\quad$ Proximity results for all observed bobcats considering five habitat variables and their distance to radio-collared bobcats.

\begin{tabular}{|c|c|c|c|}
\hline Feature & Mean & Min & Max \\
\hline Roads & 89.484 & 0.130 & 1041.502 \\
\hline Flow lines & 227.155 & 0.312 & 1165.760 \\
\hline Urban Edges & 83.517 & 0.065 & 978.545 \\
\hline $\begin{array}{c}\text { Open/Natural } \\
\text { Land Cover }\end{array}$ & 20.625 & 0 & 9400.367 \\
\hline $\begin{array}{c}\text { Water Bodies } \\
\text { Radio- }\end{array}$ & 869.590 & 0 & 2854.871 \\
\hline $\begin{array}{c}\text { Collared } \\
\text { Bobcats }\end{array}$ & 1078.030 & 7.156 & 26707.791 \\
\hline
\end{tabular}




\subsection{Zonal Statistics}

This tool was used to report raster values within a defined zone. Although it is not part of the analytical tools internal design, it was externally used to summarize coincident land cover, elevation, and slope values for input bobcat locations. Table 6.7 outlines zonal statistics for all observed and radio-collared bobcats, and Table 6.7 outlines the majority landcover for individuals.

Table 6-7: Majority statistic results for radio-collared and observed bobcats. The top four most frequented values are reported.

\begin{tabular}{|c|c|c|}
\hline Rank & Collared & Observed \\
\hline \# 1 Land Cover & Shrub/Scrub & $\begin{array}{c}\text { Developed/ } \\
\text { Open Space }\end{array}$ \\
\hline \# 2 Land Cover & $\begin{array}{c}\text { Developed/ } \\
\text { Open Space }\end{array}$ & $\begin{array}{c}\text { Grassland/ } \\
\text { Herbaceous }\end{array}$ \\
\hline \# 3 Land Cover & $\begin{array}{c}\text { Grassland/ } \\
\text { Herbaceous }\end{array}$ & $\begin{array}{c}\text { Developed/ } \\
\text { Low Intensity }\end{array}$ \\
\hline \# 4 Land Cover & $\begin{array}{c}\text { Developed/ } \\
\text { Low Intensity }\end{array}$ & $\begin{array}{c}\text { Developed/ } \\
\text { Intensity }\end{array}$ \\
\hline
\end{tabular}

\subsection{Urban Interaction}

Proximity results used to create a prediction surface for urban bobcat interaction considering the five habitat features, with the addition of slope. Empty spaces refer to areas of no data values. These areas did not meet one or more criteria specified by reclassification methods. Although bobcats most likely exist in unaltered natural areas, particularly in the South Eastern part of the county, the lack of "urban" influences create the data gaps. In addition, the lack of natural influences contributes to the data gap as well, most likely in developed areas classified as high intensity. The purpose of this raster is to identify where bobcats may be located based on the results of the radio-collared proximity analysis. Refer to section 5.3 for more information about the development of this raster. Results were applied to the entire area of Orange County to create a bobcat urban interaction raster, illustrated in Figure 6-22 on the next page. 

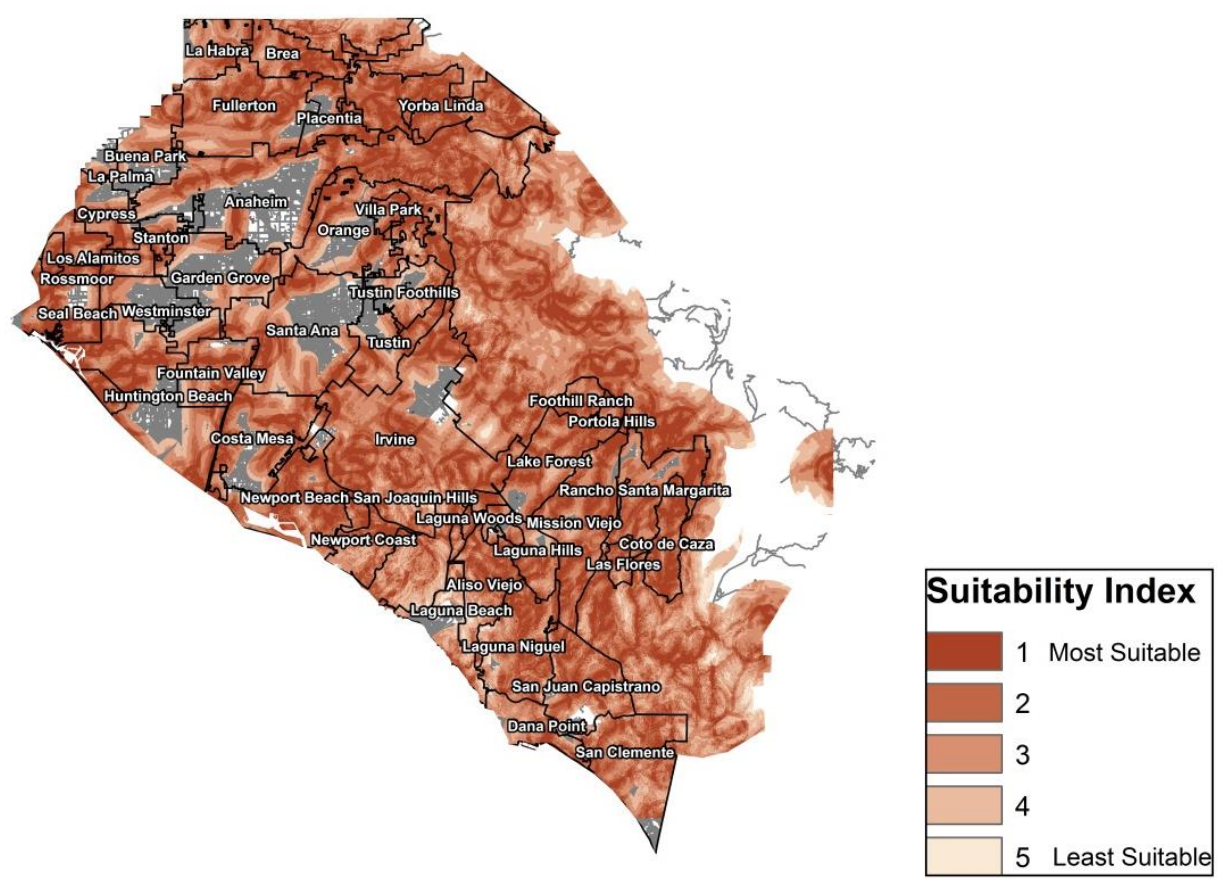

Figure 6-26: An urban interaction surface for bobcats in Orange County, California. The raster was created from radio-collared bobcat proximity analysis results.

\subsection{Errors and Quality Control}

In the beginning stages of modeling, tools and processes were run from within the editing environment for designing and testing. Adding tools, creating variables, setting parameters, and creating preconditions had to be done within this environment. Once this was accomplished, other aspects of the model were manipulated outside of the editing environment. The tool's property window can be accessed from the catalog window and offers options for model name, parameter order, environments, and iterations. All tools were designed and initially executed from within this environment. The linear density tool required substantial debugging to achieve final functionality. There is no "Calculate Geometry" option when populating a field in the model builder environment. In addition, the study area (MCP) created by the Minimum Bounding Geometry (MBG) tool did not carry over its area field, an addition that was automatically created in the output polygon. Therefore the Calculate Areas script was used to hold the area value of the study area polygon. This was an issue with both density tools that required the MBG tool for habitat characterization. When the tools were executed outside of the model builder "editing" environment, the tools would not recognize certain fields because the data was not processed in successive steps. This problem was solved when proper preconditions were set. 
In the first stages of prototyping, the linear density calculation would not work consistently. The unique identifier for the unit prepared linear intersect output feature would not stay consistent. It would change from FID to OBJECTID and the model would constantly have to be changed accordingly in its calculations. The current model however runs successfully with all urban variables using the OBJECTID field. This may be because the final linear intersect output was chosen as a parameter rather than the initial linear intersect within the model. There was also an issue with shape length geometry field recognition within the Summary Statistics. And when the field was carried over, the statistical results were sometimes way off. These inconsistencies were corrected by using a python expression within the calculate field, refer to Formula 5-2.

For the polygon density tool, input polygon features required the Calculate Areas script, not for area carry over, but for a reliable area field to use for calculations. A new feature of ArcMap is the ability to create shape geometries after intersections regardless if they were inherent in the input dataset. Without the Calculate Areas tool, populated area fields would either take area values from the intersected study area or would have the same area unit for all records. All polygons, land cover and water bodies, are not exactly the same size. Furthermore, the land cover tool would generate percent coverage values greater than 100 percent. Calculations were double checked and the tool still continued to generate these erroneous results. A further test was using intersected land cover output feature and adding a field within its attribute table and using the Calculate Geometries option under the field heading. The proper units were selected and the two fields were compared. The majority of records contained the same values but some records in the model generated area field were larger than the newly created field values. Some records were significantly larger while some were very small. These issues were even more frequent when the tools case field considered animal ID and gridcode, for percent coverage within each individual home range. This phenomenon did not occur with the other polygon (water body) density tool. This may be because it contains significantly fewer polygons. Areas calculated were also exaggerated due to an algorithm in the raster to polyline conversion tool, which produced triangular polygon features. Smaller areas were particularly sensitive to this algorithm fallacy, and ultimately affected the overall results.

Proximity tools worked almost flawlessly. Design issues attributed to the majority time spent. The tool runs a lot faster with the observation dataset because there are fewer bobcat locations. The radio-collared dataset contains 12,543 records, whereas the observation dataset contains 618 records. The tools were executed in the same manner as with the radio-collared dataset in terms of a full analysis considering all bobcat locations. Grouping and case fields were tested with different attributes and functioned properly as with the animal id field in the radio-collared bobcat analysis. Linear results were checked manually by checking the intersected features attribute tables, calculating statistics, and performing hand calculations. In addition, feature lengths and polygons were selected at random to double check their geometries. Proximity results were checked for accuracy by checking minimum, maximum, and random distance values; selecting them in arc map, and manually using the measure tool. Another accuracy check was made by conducting manual calculations of the intersected data, and comparing the descriptive statistical results. This was done by right clicking the field of interest and selecting the statistics option. 
There were other issues with using some tools within the models. The land cover to polygon tool was originally inherent in the polygon density tool. However, when the tool was run from the user interface, the gridcode was not recognized in the selection and Summary Statistics fields. This was because the land cover polygon has not been created, and down the line the attribute is not recognized. The Zonal Statistics as Table tool was also originally inherent in the density tools but the tool did not allow for the selection of certain statistics, primarily the majority statistic. These tools were taken out and the land cover to polygon model was packaged as a separate tool, and zonal statistics were provided externally. 


\section{Chapter 7 - Conclusions and Future Work}

The bobcat is a very adaptable animal and is found throughout many different environments. In recent years, there has been a significant increase in bobcat presence near or within the urban environment. Habitat fragmentation from human development is the primary cause for this increase in urban bobcat interaction. There are many problems associated with urban bobcat behavior including: road collisions, toxin accumulations, and intra - inter species competitions for resources. Utilizing GIS technologies can help provide a better understanding and help identify and mitigate potential problem areas. The purpose of this project was to provide the client with a set of analytical tools that would generate useful results for her current and future bobcat research.

The tools were designed to analyze urban variables in terms of densities within a defined study area in addition to analyzing their interactions with these features by measuring their respective proximities. The developed tools can be used over time to monitor these habitat characterizations and urban interactions to acquire a better understanding of future the impacts of development on bobcat populations. Results may lead to a better understanding of behavioral changes regarding bobcat habitat preference and urban interactions. Using results from the proximity measures, an urban interaction surface was generated to help the client visualize where potential bobcats may intervene with the urban environment, and where to identify areas of potential road collisions.

The tools were executed multiple times and the corresponding results were subjected to quality control methods for accuracy. In addition they were subjected to two very different datasets and different grouping fields. This dynamic aspect was an important part of the functionality because it allows the user to analyze bobcat data considering specific attributes of interest. Furthermore, the tools can be used for other point data, particularly other wildlife data. They were designed for a novice GIS user who does not have experience with the newer GIS software. Packaging these tools and processes into functional models with a friendly user interface should be very beneficial to the client, especially as her data expands in the future. In addition, the client could use the tools to analyze many different combinations of grouping fields. For example, the road and flow line type attributes could be added in the grouping option of the tool, leading to a more detailed analysis. Inherent calculations were set as optional parameters to allow the user to change conversion expressions to desired units of measure. Another important aspect was the ability to analyze data by field groups, or attributes, to provide measures other than for every single record in the dataset.

For future work, automating the breakdown of MBG generated polygons with grouping options (attributes) would be a useful addition to the tools, allowing the user to store the polygons separately rather than selecting and exporting them manually. Also, generating 95 percent MCP's would better represent the study area, particularly for individual home range boundaries. This involves taking out the top 5 percent of the outliers, yielding a tighter bounding polygon. Adding image analyses, such as NDVI, to better capture open, green areas around houses would provide for a more detailed land cover analysis and better vegetation index than available land cover datasets. Food and cover indexes would be another beneficial aspect to this analysis, especially generated from image analysis methods. Corridor analysis would provide a better understanding of how bobcats move across vast expanses of urban territory, or between habitat fragments. 
This is also important for better management strategies to conserve these corridors and ultimately reduce urban interactions and facilitate the movement between natural resources. Choosing fewer classes of landcover types may also contribute to a better analysis. Merging landcover types such as Developed into two classes is not only more reflective of the land cover results, but yields a smoother raster surface. Developed (open and low intensity) and developed (medium and high intensity) classifications may be a better classification scheme for future research, refer to Figure 6-19. Further data scrubbing of the observation dataset would be an added benefit. There are instances where bobcat individuals overlap in both datasets, where careful examination would be needed to weed them out, making the observation dataset even more beneficial to results.

Adding additional data would also yield a more profound analysis. Although residential parcels were not available for this project due to certain legalities, they would enhance urban characterization. Also, using different datasets with the tools would help build a richer analysis. Data such as road kill and denning sites would offer a different dynamic of urban behavior. Analyzing bobcat behavior in illumination conditions (day, night, and twilight) would even increase the urban behavior dynamic. There are a number of programs that were created for landscape analysis. GME was built to handle rigorous geospatial analysis and contains numerous tools to carry out the process. It uses the statistical program R and ArcGIS to power its functionality. Tools from GME can be used in python to create useful tools and scripts. FRAGSTATS is another spatial ecology tool designed to analyze landscapes, patterns, and metrics. Unfortunately, FRAGSTATS is only compatible up to ArcGIS 10.0 and could not be used in this project. 


\section{Works Cited}

Clark, W. R., Gosselink, T. E., Linde, S. A., \& Roberts, S. D. (2012). Habitat Modeling used to predict relative abundance of bobcats in Iowa. The Journal of Wildlife Management, 76(3), 534-543.

Esther S. Rubin, S. C., Boyce, W. M., \& Torres, S. G. (2009, August). Assessment of Predicive Habitat Models for Bighorn Sheep in California's peninsular Ranges. The Journal of Wildlife Management, 73(6), 859-869.

Ewers, R. M., \& Raphael K, D. (2006). Confounding factors in the detection of species responses to habitat fragmentation. Biological Reviews, 81(1), 117-142.

Ferguson, A. W., Currit, N. A., \& Weckerly, F. W. (2009). Isometric Scaling in homerange size of male and female bobcats (Lynx rufus). Canadian Journal of Zoology , 87, 1052-1060.

Fowles, G. \&. (2006). A predictive habitat model for bobcat (Lynx rufus) in northern New Jersey. New Jersey Department of Environmental Protection Division of Fish and Wildlife. New Jersey Department of Environmental Protection Division of Fish and Wildlife.

Gibbs-Kieninger, T. J., Nielsen, C. K., Weber, T., \& Woolf, A. (2002). Statewide modeling of bobcat, Lynx rufus, habitat in Illinois, USA. Biological Conservation, 104, 191-198.

Juanita M. Constible, C. M., \& Leopold, B. D. (2006). Relationships Between Landscape Pattern and Space Use of Three Mammilian Carnivores in Central Mississippi. American Midland Naturalist, 155(2), 352-362.

Mohr. (1947). Minimum Convex Polygons. Retrieved from http://mathworld.wolfram.com/ConvexPolygon.html

Ordenana, M. A., Crooks, K. R., Boydston, E. E., Fisher, R. N., Lyren, L. M., Siudyla, S., et al. (2010, December). Effects of urbanization on carnivore species distribution and richness. Journal of Mammalogy, 91(6), 1322-1331.

Quinn, T. (1997). Coyote (Canis latrans) Habitat Selection in Urban Areas of Western Washington via Analysis of Routine Movements. College of Forest Resources, 289-297.

Riley, S. P., Boydston, E. E., Crooks, K. R., \& Lyren, L. M. (2010). Urban Carnivores: Ecology, Conflict, and Conservation. (S. D. Gehrt, S. P. Riley, \& B. L. Cypher, Eds.) The Johns Hopkins University Press, 121-138.

Roberts, S. B., Jordan, J. D., Bettinger, P., \& Warren, R. J. (2010, April). Using Bobcat Habitat Suitability to Prioritize Habitat Preservation on a Suburbanizing Barrier Island. Journal of Wildlife Management, 74(3), 386-394.

Rubin, E. S., Stermer, C. J., Boyce, W. M., \& Torres, S. G. (2009, August). Assessment of Predicive Habitat Models for Bighorn Sheep in California. Journal of Wildlife Management, 73, 859-869. 

Appendix A: Attributes for the observed bobcat dataset.

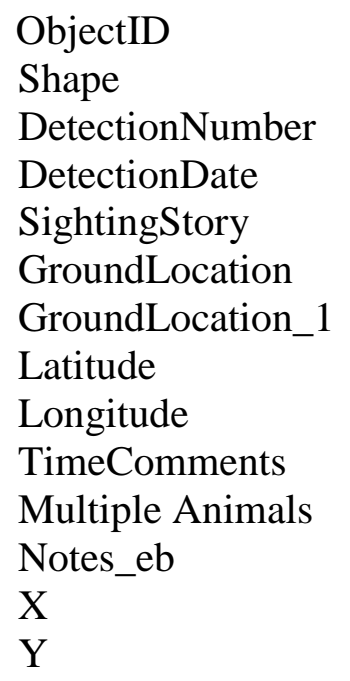

Appendix B: Attributes for the radio-collared bobcat dataset

OBJECTID

Shape

Project

Species

Sex

Pt_ID

Animal_ID

DateTimePS

DateTime 1

Latitude

Longitude

FixType

Easting

Northing 